NBER WORKING PAPER SERIES

\title{
THE PRISON BOOM AND THE LACK OF BLACK PROGRESS AFTER SMITH AND WELCH
}

\author{
Derek Neal \\ Armin Rick \\ Working Paper 20283 \\ http://www.nber.org/papers/w20283
NATIONAL BUREAU OF ECONOMIC RESEARCH
1050 Massachusetts Avenue
Cambridge, MA 02138
July 2014

We thank Joseph Altonji, Elizabeth Carson, Steven Levitt, Jens Ludwig, Justin McCrary, Thomas Miles, Bruce Western, Max Schanzenbach, workshop participants at the IRP Summer Research Workshop, the NBER Summer Institute, Duke, and the Becker Friedman Institute Conference honoring Finis Welch for helpful comments. We are especially grateful to Janet Currie, Steven Raphael, and an anonymous referee for comments on a related project that led to this work. This work grew out of discussions during the October 2008 meeting of the Chicago Workshop on Black-White Inequality, which was funded by the Searle Freedom Trust. We thank the George J. Stigler Center for Study of the Economy and the State for research support. We thank Andrew Jordan, Ian Fillmore, Ezra Karger, Sarah Komisarow, and Joshua Shea for excellent research assistance. The views expressed herein are those of the authors and do not necessarily reflect the views of the National Bureau of Economic Research.

NBER working papers are circulated for discussion and comment purposes. They have not been peerreviewed or been subject to the review by the NBER Board of Directors that accompanies official NBER publications.

(C) 2014 by Derek Neal and Armin Rick. All rights reserved. Short sections of text, not to exceed two paragraphs, may be quoted without explicit permission provided that full credit, including $\odot$ notice, is given to the source. 
The Prison Boom and the Lack of Black Progress after Smith and Welch

Derek Neal and Armin Rick

NBER Working Paper No. 20283

July 2014

JEL No. J01,J31,K14

\begin{abstract}
$\underline{\text { ABSTRACT }}$
More than two decades ago, Smith and Welch (1989) used the 1940 through 1980 census files to document important relative black progress. However, recent data indicate that this progress did not continue, at least among men. The growth of incarceration rates among black men in recent decades combined with the sharp drop in black employment rates during the Great Recession have left most black men in a position relative to white men that is really no better than the position they occupied only a few years after the Civil Rights Act of 1965. A move toward more punitive treatment of arrested offenders drove prison growth in recent decades, and this trend is evident among arrested offenders in every major crime category. Changes in the severity of corrections policies have had a much larger impact on black communities than white communities because arrest rates have historically been much greater for blacks than whites.
\end{abstract}

\author{
Derek Neal \\ Department of Economics \\ University of Chicago \\ 1126 East 59th Street \\ Chicago, IL 60637 \\ and The Committee on Education \\ and also NBER \\ d-neal@uchicago.edu \\ Armin Rick \\ Johnson Graduate School of Management \\ Cornell University \\ 114 East Ave \\ Sage Hall \\ Ithaca, NY 14853 \\ ar964@cornell.edu
}

An online appendix is available at:

http://www.nber.org/data-appendix/w20283 


\section{INTRODUCTION}

More than two decades ago, Smith and Welch (1989) published their seminal work on the evolution of black-white inequality during the 20th century. They were among the first researchers to gain access to electronic versions of census long form data, and using census data from 1940 through 1980 as well as Current Population Survey (CPS) data from the 1980s, they traced the evolution of black-white differences in education, employment, and earnings for cohorts born from the late 19th century into the latter half of the 20th century. They titled their paper "Black Economic Progress After Myrdal," and they argued that, although the 1940 Census data supported Myrdal's (1944) bleak assessment of economic life among American blacks during the first four decades of the 20th century, subsequent census data recorded noteworthy gains for blacks relative to whites in not only education levels and measures of occupational prestige but also in levels of earnings and family income.

For example, Smith and Welch (1989) report that the black-white gap in completed years of schooling among males ages 26-35 fell from 3.9 years of schooling in 1940 to 1.4 years in 1980. This decline in the black-white schooling gap reflects an enormous increase in black educational attainment. Over the 1940-1980 period, average schooling levels among black men increased from just below 6 years of schooling to more than 12 years, while schooling levels among white men increased from just under 10 years to 13.5 years. Given the strength of the statistical relationship between earnings and education, it is not surprising that they also documented enormous gains in the earnings of black men relative to white men.

Most labor economists remember that Smith and Welch (1989) documented the dramatic economic and social progress of blacks during much of the 20th century, but in the final paragraphs of their paper, they offered this cautionary note, "..., there are also reasons for concern about the future, especially for the still large black underclass." ${ }^{1}$ Smith and Welch (1989) argued that problems with the quality of schools that serve black children, especially in Northern cities, were a barrier to further progress.

Wilson (1987) also drew attention to the struggles of black youth in the inner-city, and Neal (2006) used data from the National Assessment of Educational Progress (NAEP) to show that reading and math scores for black students in urban areas did fall during the 1980s relative to scores for other youth. ${ }^{2}$ Further, although aggregate black-white gaps in achievement and attainment continued to shrink for much of the 1980s, there is considerable evidence that overall black-white skill convergence had already stopped by the time Smith and Welch (1989) published their findings. Today, black-white gaps in math and reading scores among youth and black-white gaps in overall educational attainment among young

\footnotetext{
${ }^{1}$ Smith and Welch (1989), pp. 561

${ }^{2}$ Flanagan and Grissmer (2002) show that by the mid 1990s, test scores for black children in Northern cities were lower than test scores for black children in the rural Southeast. This pattern is striking because migration to Northern cities was an important engine of black progress for much of the 20th century.
} 
adults are quite similar to the corresponding gaps observed around $1990 .^{3}$ Further, our results below suggest that, relative to whites, labor market outcomes among black men are no better now and possibly worse than they were in 1970 .

Below, we explore several different methods for measuring recent trends in black-white inequality in labor market outcomes. Given several different estimators and imputation procedures, three facts shape these calculations. First, employment rates for men have fallen in recent decades. Second, this decline in male employment rates has been coincident with an unprecedented increase in incarceration rates. Third, since 1980, these declines in employment and increases in incarceration have been much more dramatic among black men than white men.

Tables 1 through 4 present employment rates and institutionalization rates for adult men in the United States. The data come from the Integrated Public Use Microdata Series (IPUMS) and cover six census years, 1960-2010. ${ }^{4}$ Each diagonal row in these tables presents data from one census year. Each column presents data for one age group over different census years. Each horizontal row presents data from different census years for a five-year birth cohort. Appendix Tables A1-A4 present parallel results for women. ${ }^{5}$ Given the numerous data sets we employ in this paper and the numerous different coding schemes that we encounter regarding Hispanic origin, we were not able to come up with a clean strategy for identifying Hispanic populations consistently over time. Therefore, we typically divide our samples into whites, blacks, and others. ${ }^{6}$

Institutionalization involves more than incarceration. Recent census files also include residents of mental hospitals and nursing homes in the institutionalized population. However, few persons under age 50 are in nursing homes, and the populations housed in mental hospitals have declined greatly over the past three decades. So, the institutionalization rates presented in these tables likely understate the magnitude of recent trends in incarceration rates, and the most recent institutionalization rates are reasonable proxies for the corresponding incarceration rates. ${ }^{7}$

\footnotetext{
${ }^{3}$ The National Assessment of Education Progress: Long Term Trend Studies track math and reading performance for students ages 9, 13, and 17 using exams that are designed to be comparable over time. Among nine-year olds in 2012, the black-white gap in reading scores was smaller than the corresponding gap in 1990. However, the other five 2012 measures of black-white gaps in reading and math for 2012 were comparable to or greater in absolute value than the corresponding gaps in 1990. See http://nationsreportcard.gov/ltt_2012/. While Murnane (2013) reports a recent increase in high school graduation rates among blacks both absolutely and relative to whites, this change does not appear to have generated a significant reduction in the overall black-white attainment gap. See Neal (2006) for an extensive treatment of trends in black-white achievement gaps.

${ }^{4}$ The 1960-2000 data come from the Census Long Form. The 2010 data come from the American Community Survey.

${ }^{5}$ See https://sites.google.com/site/dereknealresearch/ for all Appendix materials.

${ }^{6}$ Appendix A explains the complications that force us to use these categories.

${ }^{7}$ Before 1980, the Census Bureau produced more detailed codes that allow researchers to identify persons living in correctional institutions, but starting in 1990, the codes used in the census and American Community Survey (ACS) files simply identify persons as living in some type of institutional quarters. This broader
} 
Tables 1 and 2 present employment rates and rates of institutionalization for black and white men respectively. The employment rates presented in these tables are based on respondent activities during the survey weeks in question. Note that, for both black and white men, employment rates are lower now than in 1970 within each age group. While the declines in the ages 20-24 group may, in part, reflect higher levels of college and graduate school attendance, the declines among men at older ages strongly suggest weaker attachment to market work. In contrast, the Appendix tables indicate that both black and white women became more involved in market work over the same time period.

While Tables 1 and 2 document employment declines among both black and white men, the declines are much more pronounced for blacks, e.g. the decline in employment rates among white men ages 25-29 was roughly 11 percentage points between 1970 and 2010 while the comparable change among black males was over twice as large. By 2010, more than one third of black males ages 25-49 were either unemployed or out of the labor force.

The employment patterns in these tables have received less attention than they deserve in the economics literature on race and inequality. Many analyses of trends in employment and income rely on data from the CPS, ${ }^{8}$ but the CPS sampling frame does not include institutionalized persons, and the institutionalization rates in these tables show noteworthy increases among both black and white men at all ages. Further, current levels of institutionalization are particularly noteworthy among black men. On any given day in 2010, almost one in ten black men ages 20-39 were institutionalized, and rates of institutionalization were actually slightly higher among black men in 2000. Further, because turnover among prison populations is quite high, these results suggest that far more than ten percent of prime age black men will serve some time in prison or jail during a given calendar year. ${ }^{9}$

Table 3 demonstrates that, while black men experience high rates of institutionalization overall, rates among less-educated black men have reached levels that were unthinkable prior to 1980. By 2010, the institutionalization rate among black, male high school dropouts ages 25-29 was almost one third and the employment rate for this group was less than one fourth. Institutionalization rates among black dropouts ages 39 or less actually fell slightly between

definition of the institutionalized population includes those who reside in correctional institutions, facilities for the mentally ill, or facilities for the elderly and handicapped. For the sake of consistency, we use the post-1980 classification for all years. This means that the institutionalization rates in Tables 1 and 2 are larger than the corresponding incarceration rates for every year and demographic cell. Nonetheless, among prime age men, the fraction of institutionalized persons living in penal institutions has always been high and has increased since 1980 because rates of institutionalization in mental health facilities have fallen. See Figure 1 in Harcourt (2006). In 1980, roughly one fourth of the persons who were either in prison or mental hospitals were mental patients. This figure was less than $10 \%$ by 2000 .

${ }^{8}$ In a recent Handbook chapter, Acemoglu and Autor (2011) assess the literature on links between trends in technology and trends in earnings inequality. They discuss the rates of growth of employment in jobs classified by skill-type, but in keeping with much of the related literature, they devote scant attention to the stunning growth in the numbers of low-skilled persons who have no formal sector job or how many of these non-employed persons are in prison. Neal (2006), Western (2006), and Pettit (2012) discuss how the growing prison population affects the sampling frames used to create official labor market statistics.

${ }^{9}$ See Bonczar and Beck (1997). 
2000 and 2010, but rates among those over 39 continued to rise. Thus, among black men in 2010, more than 1 in 6 high school dropouts in their forties were institutionalized on any given day. These numbers do not simply reflect a significant number of men who are serving extremely long sentences. Admission rates for new court commitments are now also noteworthy for this age group. ${ }^{10}$

Table 4 presents results for white men with less than a high school education. Employment rates have fallen steadily among these men since 1970 across all age groups. Overall, rates of institutionalization among these men remained roughly constant during the 1970s but have risen steadily since 1980. As in Table 3, overall institutionalization rates increased only slightly during the 2000-2010 period.

In sum, among less educated men, rates of institutionalization have increased for both blacks and whites at all ages. Further, among both black and white dropouts, we see employment levels among men over 40 that are strikingly low by historical standards. Nonetheless, because the black samples contain proportionally more dropouts and even worse trends in outcomes among dropouts, these trends contribute to growing inequality between black and white men.

Since 1980, incarceration rates among both black and white men in most age groups have increased by factors of two to three, but these changes have had a much larger impact on black communities. Because black male incarceration rates were much higher than corresponding white rates before the prison boom ever began, the impact on blacks communities of a more than two-fold increase in incarceration rates has been dramatic.

It is logically possible that a common set of economic forces simultaneously drove recent trends in incarceration, black-white inequality, and overall income inequality. However, the existing literature contains noteworthy evidence consistent with the view that policy changes created the prison boom. Thus, we seek more precise answers to two sets of questions

(1) How important are changes in criminal justice policies as determinants of the dramatic rise in U.S. incarceration rates during the past three decades and have these changes had differential impacts on black men as opposed to white men?

(2) How does properly accounting for growth in incarcerated populations affect our assessment of recent trends in economic inequality among men in the US, both overall and between blacks and whites?

Below, we present new results derived from seven states that report reliable data to the National Corrections Reporting Program (NCRP) over the period 1985-2005. These results indicate that, in recent decades, a broad menu of changes in sentencing rules and parole policies created a much more punitive criminal justice system. In the 2000s, arrested offenders

\footnotetext{
${ }^{10}$ The NCRP files indicate that the prison admission rate for new court commitments among men ages $40-50$ was roughly 3 in 1,000 in 2005. This rate is about three time higher than the comparable rate in 1985.
} 
received much more severe punishment than their counterparts in the 1980s, and this is true for both black and white offenders regardless of the offenses that led to their arrests.

There is some evidence that the increased use of long sentences as punishment for violent crimes may have been even more pronounced among blacks, and as others have noted, the federal War on Drugs was not conducted in a color-blind manner. However, these factors are minor parts of our story. The key point is that, since black arrest rates are now and have always been much higher than white arrest rates, the move to much more punitive treatment for all arrested offenders has had much larger effects on black communities than white ones.

The existing literature does not provide definitive results concerning how punishing offenders with prison terms rather than probation or other forms of supervision impacts the future labor market outcomes of offenders. However, incarceration does prevent offenders from participating in market work during their prison terms, and we demonstrate that researchers must account for prisoners if they wish to accurately describe recent trends in labor market inequality among groups of men defined by race or education groups.

Because CPS data do not contain information about persons who live in prisons or other institutions, the prison boom has affected the degree to which persons who have low earnings prospects are counted in many official measures of employment and earnings, and this is especially true among black men. In section 8, we explore several imputation strategies that allow us to measure trends in income inequality between blacks and whites while accounting for race-specific trends in non-employment and institutionalization. Although black-white gaps in potential earnings appear to have shrunk during the 1990s, these gaps grew during both the 1980s and the 2000s. The Great Recession period of 2008-2010 was quite bleak for black men, and recent levels of labor market inequality between black and white prime-age men are likely not materially different than those observed in 1970.

In the following sections, we review the legal history of changes in criminal justice practice over the past three decades or more, and we also review the empirical literature on links between changes in criminal justice policies and prison growth. Then, we present original work with data from the (NCRP) that clarifies the role of policy changes as engines of growth in state prison populations and examines the extent to which certain changes may have disproportionately affected blacks. After briefly reviewing the literature on how incarceration affects future life outcomes, we analyze recent trends in black-white labor market inequality while paying special attention to how changes in incarceration rates impact different measures of trends in black-white inequality.

\section{Recent History of Trends in Criminal Justice Policy}

For most of the twentieth century, policies that governed justice and corrections in the United States reflected a paradigm known as indeterminate sentencing. Judges enjoyed great discretion when deciding whether to sentence convicted offenders to probation or prison, and they enjoyed similar discretion when deciding the sentences for those who entered prison. 
Further, holding constant the sentences that judges imposed, parole boards enjoyed considerable control over the time that specific inmates actually served.

The indeterminate sentencing model offered judges and parole boards the freedom to customize punishments to specific offenders rather than simply match specific punishments to specific offenses. Judges and parole officials were free to consider prospects for rehabilitation, the provision of incentives for good behavior and self-improvement, as well as expected impacts on public safety when making decisions that determined the punishments received by various offenders.

However, during the 1970s, indeterminacy came under attack from activists of many different political persuasions. Some on the left charged that indeterminacy gave judges and parole officials too much freedom to indulge their own racial prejudices when determining sanctions. Others on the right charged that indeterminacy allowed lenient judges and parole boards to undermine public safety by putting dangerous criminals back on the streets far sooner than legislators intended. ${ }^{11}$

Thus, in the late 1970s, legal changes began to move justice and corrections policies toward a determinate sentencing model. Table 5 summarizes some of the changes that different states made as they moved to more determinate sentencing practices. ${ }^{12}$ Before 1980, California, Colorado, Illinois, Indiana, Maine, and New Mexico eliminated or severely curtailed discretionary releases by parole boards, and since that time, 16 other states have either eliminated or curtailed the discretionary powers of parole boards. Further, a number of these states eliminated discretionary parole as one component of a large set of reforms that also involved establishing independent sentencing commissions. These commissions developed sentencing guidelines that constrain the sentencing decisions of judges. Minnesota, in 1980, was the first state to establish an independent sentencing commission. Since then, 24 other states have adopted commissions that vary greatly in terms of their missions and their powers.

In 1994, the federal government passed the Violent Crime Control and Law Enforcement Act. This law established the Truth-in-Sentencing (TIS) Incentive Grants Program which provided grants for prison construction and expansion to states that adopted policies requiring sentenced offenders to serve large portions of their sentences. The rules determining whether or not specific states qualified for these grants were complex, but the nominal goal of the program was to induce states to adopt policies that require most prisoners, especially violent offenders, to serve $85 \%$ of their sentences. Delaware, Minnesota, Tennessee, Utah,

\footnotetext{
${ }^{11}$ See Raphael and Stoll (2013) as well as Stemen and Rengifo (2011) for discussions of this literature. See Dansky (2008) for references specific to the debate in California.

${ }^{12}$ There are many factors that contribute to determinacy. Sentencing guidelines, narrow presumptive sentencing ranges, mandatory minimum laws and other policies restrict the discretion that judges may exercise at sentencing, while restrictions of discretionary parole release limit the ability of parole boards to affect actual time-served. We do not attempt to code some states as determinate and others as indeterminate at any point in time. Instead, we address a number of factors that influence both determinacy and punitiveness in many states.
} 
and Washington adopted TIS laws prior to 1994, and by 1998, 22 additional states adopted policies that secured their eligibility for TIS grant money. In addition, Table 5 shows that the vast majority of states now have some TIS law on the books that limits discretionary release by parole boards. ${ }^{13}$

It is easy to see how each one of the policies described in Table 5 could be employed not only to make criminal justice systems more determinate but also to make them more punitive. Nonetheless, empirical work on the effects of these policies has not produced a consistent set of results that link prison growth to the adoption of specific policies, and this is not surprising given that different states often implement nominally similar laws in quite different ways.

Frase (2005) points out that some states use sentencing commissions as devices for matching corrections populations and corrections budgets. ${ }^{14}$ In these states, restrictions on judicial latitude in sentencing and parole board discretion over release appear to function as vehicles for keeping prison populations within ranges that are in line with budgets allocated for corrections. However, some other states have used similar determinate sentencing practices as vehicles for making criminal justice policy more punitive. Nicholson-Crotty (2004) conclude, based on a panel data model of state commitment and incarceration rates between 1975 and 1988, that mandatory sentencing guidelines are negatively associated with state-level growth in commitment rates when such guidelines are linked to corrections budgets. However, the opposite pattern holds in states that develop sentencing guidelines and correction budgets separately.

Moreover, many states that never established sentencing commissions have created more determinate systems by simply legislating presumptive sentences. Stemen, Rengifo, and Wilson (2006) report that "between 1975 and 2002, every state adopted some form of mandatory sentencing," "15 but the number of crimes covered by such statutes and the harshness of these minimum sentences vary greatly among states and over time within states. California began legislating presumptive sentences in 1976 when they abolished discretionary parole, and the initial determinate sentencing law passed by the legislature would have likely had little impact on prison growth. However, the state legislature approved 43 amendments to the legislation during only the first year under determinate sentencing, and each of these 43 amendments plus many amendments in subsequent years increased the severity of sanctions. ${ }^{16}$

\footnotetext{
${ }^{13}$ See Ditton and Wilson (1999) for a Bureau of Justice Statistics report on the implementation of Truth in Sentencing laws during the 1990s.

${ }^{14}$ See Reitz (2006) for more evidence that the existence of sentencing commissions and restrictions on parole are not necessarily drivers of prison growth. MI is the only state that we analyze using NCRP data that Frase (2005) also identifies among the states that combine the work of sentencing commissions with the task of forming budget projections for state prison systems. Further, according to Frase, the MI resource impact assessments were not a permanent feature, and MI only employed a permanent sentencing commission during the period 1995-2002.

${ }^{15}$ See p. 118.

${ }^{16}$ See BJA (1996), p. 16.
} 
During the past two decades, the vast majority of states have also added laws that impose enhanced sentences for habitual offenders, but once again, the details of these habitual violator laws differ greatly among states. Although California was not the first state to pass a law mandating enhanced penalties for repeat offenders, the California statute commonly know as "Three Strikes and You're Out" has received considerable attention from scholars and journalists. The law was passed by both the legislature and voter initiative in 1994 following two well-publicized murders that were committed by offenders who had recently been released from prison. Many states have followed California's lead since 1994, but few states have adopted laws that are as severe as the California "Three Strikes" policy. Auerhahn (2002) claims that the California law stands out because it mandates a doubling of the presumptive sentence following only the second conviction for a covered offense, i.e. "strike," and because the "strike zone" that defines covered offenses is more inclusive than it is in other states.

In sum, states have pursued determinacy using many different approaches over the past three decades or more. However, the complexity of criminal justice systems at the state level creates almost insurmountable problems for scholars who conduct empirical investigations that seek to establish concrete links between prison growth and specific features of statelevel criminal justice systems that promote determinacy. The presence of a specific "type" of law in a given state tells researchers little about the extent of legislative efforts to make corrections policies more punitive in that state. Groups of states often adopt new corrections laws that are nominally similar but still differ in important ways. Further, state legislators who wish to adopt more punitive policies have many different policy levers at their disposal. Thus, it is not obvious how one could construct a comprehensive index of punitiveness at the state level for even a single point in time, much less a set of indices that track the evolution of punitiveness within each state over time, and we have found no studies that even attempted these quixotic measurement tasks. ${ }^{17}$

Nonetheless, we argue below that researchers can build a strong case that changes in criminal justice policy must be the key reason that prison populations are so large now relative to those observed in the 1970s. During the late 1990s and the 2000s, crime rates and arrest rates for most serious crimes remained flat or fell, but prison populations continued to grow until at least 2008 and have fallen only slightly since. The reforms that began in the 1970 s as attempts to enhance determinacy created corrections policies that were not only more determinate but also much more punitive, and although some states have moved in recent years to moderate their corrections policies, arrested offenders in all crime categories likely face harsher expected punishments than their counterparts did in 1980.

\footnotetext{
${ }^{17}$ Note that in order to create such an index, researchers would have to understand how a specific set of policies translated into a set of distributions of time-served that condition on conviction for specific offenses. Then, researchers would need to conduct simulations that generated sample distributions of simulated timeserved for various populations of convicted offenders, and then collapse the information contained in these simulated distributions into an index of punitiveness.
} 
1.1. Recent Leveling. Before moving on to the empirical literature on the links between criminal justice policy and prison growth, it is important to note that overall prison populations have fallen slightly since 2009, and this development may also reflect recent policy changes.

In 2004 and 2005, two United States Supreme Court decisions made it more difficult for states and the federal government to build enhancements into determinate sentencing systems. In Blakely v. Washington (2004), the court held that any factors that judges rely upon to determine the sentence for a specific defendant must be proven beyond a reasonable doubt to a jury. Thus, if guidelines developed by a sentencing commission or provisions contained in statutes passed by a legislature dictate enhancements to base level sentences based on specific aggravating circumstances, e.g. "deliberate cruelty," judges may not apply these enhancements unless the aggravating circumstances have been submitted and proved to a jury. In United States v. Booker (2005), the court held that the same principle applies to federal judges, and the enhancements built into federal sentencing guidelines became advisory provisions.

These decisions may have weakened the importance of guidelines developed by sentencing commissions or rules contained in statutes that attempt to spell out more punitive sentences for various crimes when certain aggravating circumstances are present. Unless prosecutors prove the existence of these circumstances while proving guilt of the crime in question, such enhancements impose no constraints on judges. Judges can ignore the aggravating circumstance when imposing sentences, and their decisions are not subject to review.

Further, a more recent Supreme Court decision may have important implications for the costs of incarcerating large state prison populations. In Brown v. Plata (2011), the United States Supreme Court upheld the decision of a three-judge court that had been appointed by the Chief Judge of the United States Court of Appeals for the Ninth Circuit to deal with a class action lawsuit that alleged California had violated the constitutional rights of prisoners by operating prisons that were so overcrowded as to deny them adequate health care. This three-judge court had ruled in favor of the plaintiffs and mandated that the California prison population be no more than 137.5 percent of the design capacity for the system. This ruling implied that California needed to reduce its total state prison population by more than 35,000 prisoners. $^{18}$

California has long been an outlier in terms of prison over-crowding, so the recent reduction in California prison populations that followed this decision has been noteworthy. However, it is not clear what the immediate impact of this decision will be on prison populations in other

\footnotetext{
${ }^{18}$ Yet, from the end of 2011 through April of 2013, the total stock of incarcerated persons in California only fell by about 20,000. The state prison system has not fully complied with the 137.5 percent rule, and the state also increased jail populations by around 8,000 inmates as part of its efforts to reduce prison populations. See Lofstrum and Raphael (2013). The Brown v. Plata decision also settled an earlier class action suit, Brown v. Coleman. Here, the plaintiffs argued that overcrowding compromised the capacity of the prison system to provide adequate mental health care services.
} 
states since it is not clear how many states are currently beyond the 137.5 percent threshold or whether these states have found some different but satisfactory way to address prisoner health and safety in prisons with populations that exceed the 137.5 percent threshold. Still, for many states, this Supreme Court decision clearly raises the expected costs of policies that impose punitive sentences on offenders, and it is reasonable to expect these additional costs to influence future policies.

The final Brown v. Plata decision came after almost a decade of trials and hearings in lower courts, so the outcome did not come as a complete shock to officials in California or other states. Further, the budget problems that have plagued many states since 2008 have raised public awareness of the costs associated with running large prison systems. Thus, some states are exploring ways to punish non-violent offenders that do not involve prison. ${ }^{19}$

Still, in 2009, not only incarceration rates but also admission rates into prison remained more than twice as high as they were in the 1970s, even though both crime rates and arrest rates had been constant or falling for well over a decade. Our goal in the next two sections is to shed some light on why prison populations grew so rapidly from before 1980 well into the 2000s. Data limitations force us to restrict our most detailed analyses to the period 1985 to 2005, so we are not able to carefully examine the entire prison boom. However, we have much to say about both the mechanics of prison growth over this twenty year period and why prison populations remained at such high levels after 2005.

\section{Empirical Literature on the Effects of Specific Laws}

The literature contains a number of papers that attempt to isolate the effects of specific types of legal reforms on the growth of prison populations by applying panel regression methods to data sets that track variation in outcomes and policies among states and over time. Zhang, Maxwell, and Vaughn (2009) is a recent and prototypical contribution to this literature. The authors attempt to explain variation in measures of admission rates, incarceration rates, and expected time served among states and over time by regressing these outcomes on six different measures of policy plus a set of additional control variables that often include state and year fixed effects. They employ data from 1973 through 1998. Their policy variables are a set of indicators for the presence of the following policies: (1) voluntary sentencing guidelines (2) presumptive sentencing guidelines (3) habitual offender laws (4) abolition of discretionary release by parole boards (5) requirements that sentencing guidelines consider prison capacity (6) truth-in-sentencing laws.

On the whole, the results imply few statistically significant effects for these policy variables and even fewer that are of the expected sign. The authors conclude that sentencing policies associated with determinacy did not contribute much to prison growth over the period 1973

\footnotetext{
${ }^{19}$ The Pew Center on the States recently released reports, Pew (2010) and Pew (2012), that, among other things, describe steps that several states are taking to reduce the punitiveness of their criminal justice systems and thereby reduce the size and cost of their state prison systems.
} 
to 1998. Stemen, Rengifo, and Wilson (2006) and Stemen and Rengifo (2011) follow a similar research strategy, but they focus only on incarceration rates as outcomes. Taken as a whole, the results in these papers are similar to those in Zhang, Maxwell, and Vaughn (2009). Indicator variables for adoption of these specific policies are not strong predictors of future prison growth within states. Still, it is worth noting that all three of these studies found that states that abolished discretionary parole release experienced slower than average growth in prison populations. ${ }^{20}$

This literature is limited in at least two important ways. To begin, these regressions do not directly address a precise counterfactual that informs policy. In the language of the program evaluation literature, these regressions are trying to identify treatment effects associated with specific policies, but the indicator variables for treatment do not capture the implementation of homogeneous policies, and therefore, the treatments are not precisely defined.

For example, Zhang, Maxwell, and Vaughn (2009) note in their conclusion that the details of habitual offender laws, which are often known as "three-strikes" laws, vary greatly among states. While California, Georgia, and Florida handed down numerous enhanced sentences to many offenders under these laws, a significant number of states defined their "strike zones" so narrowly that the statutes are rarely used. ${ }^{21}$ Thus, if a particular study reports an average treatment effect associated with the adoption of a state-level statute that legal analysts classify as a habitual offender law, researchers cannot correctly interpret this result without learning a great deal about how each habitual offender law was written and implemented in each state.

Further, because other policies with similar effects but different names are often implemented in non-treated states, the implied control groups in these regressions are not valid control groups. We have already noted that, since 1975, all states have adopted more mandatory minimum statutes, and it seems reasonable to conjecture that many also tightened standards for parole revocation, applied more public scrutiny to parole board decisions, etc. in ways that may not be reflected in coding schemes that seek to capture the adoption of a specific type of statute. The results from these panel regression studies tell us little about whether or not changes in the punitiveness of criminal justice policies are responsible for the dramatic growth in prison populations that we have witnessed over the past three decades or more. These results simply tell us that states associated with a specific set of readily identifiable policies do not typically stand out as having above average rates of prison growth.

\footnotetext{
${ }^{20}$ We noted above that both Frase (2005) and Nicholson-Crotty (2004) conclude that mandatory sentencing guidelines reduce prison populations in states where the guidelines are used as a tool to manage corrections expenditures. Marvell (1995) reached a similar conclusion using earlier data.

${ }^{21}$ Auerhahn (2002) uses a simulation model to demonstrate the large effect that these polices had on prison growth in California in the late 1990s and also to predict the continued growth in the population during much of the 2000s.
} 
Stemen, Rengifo, and Wilson (2006) performed additional analyses in which they tried to construct variables that captured some of the variation over time and among states in mandatory sentencing practices. Given the enormous variation in mandatory sentencing rules among states at a point in time and within specific states over time, it is hard to imagine how researchers could create an accurate index that captured both geographic and temporal variation in mandatory minimum punitiveness, and the authors did not attempt to create such an index. Rather, they created counts of the different types of mandatory minimum statutes in several different categories: (i) weapons use (ii) serious harm to victims (iii) crimes committed under supervision or in custody and (iv) hate crimes.

With the exception of (ii), increases in the numbers of each of these statutes on the books are significantly correlated with growth in prison populations, and on average, when states add 10 new mandatory minimum statutes, the expected incarceration rate increases by 23 (out of 100,000). However, the authors write, "we do not believe that the mandatory sentencing laws considered here are necessarily directly contributing to increases in incarceration rates; rather, they are used here as proxies for states' general approaches to mandatory sentencing laws and, in this sense, indicate the states' general use of mandatory sentencing policies."

The use of the term "proxies" in the quote above is important. The authors are conjecturing that in times and places where legislatures are devoting considerable energy to passing these types of statutes, state officials are engaged in other unmeasured activities that also enhance the punitiveness of criminal justice policies.

This is a reasonable conjecture, but it also highlights the limits of panel regression methods as tools for discovering whether or not specific policy changes drove prison growth. When scholars code different policies as the same policy or omit controls for relevant but unmeasured policies that are changing contemporaneously with measured policies, they should not expect panel regressions to produce useful or even interpretable results.

In addition, it is not obvious what we should expect from such models even if the measures of sentencing policy were more precise. Imagine a homogeneous change in sentencing policy adopted in a number of different states at varying times and assume that this new policy took a simple form. Assume that it simply added three years to every sentence of at least two years that would have been given under previous law. This change would have no direct effect on admissions rates in any period because it would only apply to prisoners who were going to serve at least two years anyway. However, it would have important effects on steady-state incarceration rates and expected time-served among admitted prisoners.

Yet, it is not clear that regression models like those in Zhang, Maxwell, and Vaughn (2009) would accurately measure these effects on incarceration rates and time-served. Recall that these regressions project admission rates, incarcerations rates, and proxies for time-served on contemporaneous measures of policy, and such a policy change would not have any effect on incarceration rates for at least two years. Further, it would take many years for the full effects 
of such a change to unfold. Finally, because the authors are using ratios of prison populations to admissions flows to estimate expected time-served, the measures of expected time-served in states affected by such a law would be biased down for years following adoption, and this bias would create a correlation between any indicator variable for the existence of such a law in a given state in a given year and the residual associated with the observation for that state-year combination.

\section{Decomposition Methods}

Given the limitations of these regression methods, many scholars have adopted an indirect approach. A large literature employs statistical decompositions derived from the observation that, in a steady-state, the fraction of the population incarcerated, $i$, can be expressed as:

$$
i=(c-i) * \alpha * \gamma * \delta * \bar{s}
$$

where

$$
\begin{aligned}
& c=\text { the fraction of criminals in the population } \\
& \alpha=\text { the probability of arrest given engagement in crime } \\
& \gamma=\text { the probability of conviction given arrest } \\
& \delta=\text { the probability of admission given conviction } \\
& \bar{s}=\text { the expected time served given admission }
\end{aligned}
$$

This equation ignores parole and parole revocations. So, in this thought experiment, new entrants to prison are always newly convicted offenders, and all prisoners serve their entire sentence. This simple framework facilitates our exposition, but our key points remain in a more cumbersome version that models transitions in and out of parole. See Raphael and Stoll (2013) for a steady-state analysis that includes parole and parole revocations.

One can derive this equation from many different models of criminal, police, and court behaviors, but the most straightforward approach is to assume that a fixed fraction of an infinitely-lived population exhibits complete persistence in crime, i.e. those who choose crime as a career engage in crime whenever they are not incarcerated. This framework also rests on the assumption that no innocent persons are ever arrested, convicted, or imprisoned. Further, we are implicitly assuming that the composition of crimes does not vary over time, so that it is meaningful to talk about single rates for crimes, arrests, convictions, and admissions. ${ }^{22}$

The first two terms in the decomposition above remind us that even if prosecutors and judges do not change their behavior, changes in the prevalence of criminality or the effectiveness of policing may generate changes in prison populations, and it is worth considering

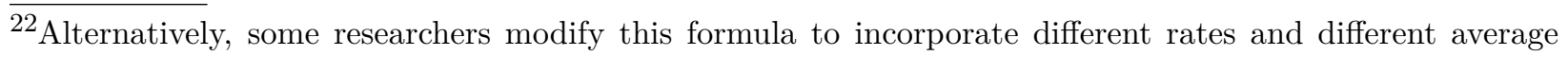
sentences for different types of crime. 
these two forces before moving on to the role of criminal justice policy as a driver of prison growth.

A large literature argues that technical change and globalization have harmed the labor market opportunities of unskilled men, and a smaller literature suggests that less skilled men are more likely to choose crime as an occupation when their prospects for legal employment are diminished. ${ }^{23}$ The fact that employment rates have fallen most rapidly over the past 30 years for the groups of men who have experienced the most rapid rise in incarceration rates suggests that we should entertain the hypothesis that prison populations grew because opportunities for legal employment among the less-skilled shrank.

The first six columns of Table 6 describe trends in crimes and arrests nationally over the period 1970-2011. The remaining columns describe trends in state and federal prison admissions as well as population trends for jails, state prisons, and federal prisons. Consistent data for the prison stocks and admissions numbers are not available for all years, but we have pieced together available series where possible. The blank entries represent instances where we were not able to calculate a reliable estimate of a given stock or flow for a given year.

We conjecture that property crimes and drug crimes should be the categories most affected by trends in labor market opportunities because dealing in stolen goods and drugs are alternatives to legal employment. We see increases in property crime during the 1970s and the 1980s that cannot be accounted for by population growth. However, since 1991, reported property crimes have fallen in almost every year. In contrast, state prison populations grew steadily from 1973 to 2008 before leveling off and then declining slightly in 2010 and 2011. In addition, prison admissions grow, almost every year, from the beginning of our admissions series in 1978 to $2007 .^{24}$

Arrests for drug crimes do increase through 2006, and we cannot rule out the possibility that, over time, declining (legal) labor market opportunities for less skilled men increased the number of men who tried to make a living by producing, transporting, or selling illegal drugs. On the other hand, these arrest trends alone can account for only a small portion of the prison growth we observe over this period. ${ }^{25}$ In addition, trends in drug arrests are more difficult to evaluate because there are no series of reported drug crimes. It is possible that the increases in drug arrests we observe do not reflect changes in levels of criminal activity but changes in police behavior. This possibility is noteworthy because available evidence

\footnotetext{
${ }^{23}$ See Grogger (1998) and Gould, Weinberg, and Mustard (2002).

${ }^{24}$ We see no evidence that changes in police behavior generated important trends in the number of persons arrested for property crime holding crime levels constant. Although there are year to year fluctuations in the ratios of arrests to reported crimes, these ratios remain in roughly the interval [.17 \pm .016$]$ for the entire four decades. Thus, arrests for property crime follow the same basic trends as reported property crime.

${ }^{25}$ The simulation model we build below suggests that less than three percent of the growth in state prison populations between 1985 and 2005 can be attributed to trends in drug arrests. Growth in drug arrests played a more important role as a driver of federal prison growth, but the federal system is a small part of the overall prison system.
} 
on drug use suggests that rates of illegal drug use have likely remained constant or declined during the past two decades even though drug-related arrest rates continued to rise. ${ }^{26}$ Taken as a whole, data on the time-series patterns of arrests for different crimes suggest that prison growth during the past twenty years cannot be the result of a simple shift by low-skilled persons from legal to illegal work.

Table 6 does document dramatic increases in arrests for violent crimes during the late 1970 s and 1980s. However, prison admissions grew even faster over the same period. So, unless there were important changes in the composition of violent crime arrests during the late 1970s and 1980s, the growth in prison admissions during this period is suggestive of a move toward more punitive corrections.

We cannot provide more than suggestive evidence about the nature of changes in corrections policies before 1985. However, the NCRP data do allow us to examine the period 1985 to 2005 in much greater detail, at least for a small sample of states that provide consistent information about arrests, prison admissions, and prison releases. Our results from this sample suggest that the $190 \%$ growth of total state prison populations $(462,000$ to $1,338,000)$ over this twenty-year period cannot be explained by changes in flows of arrested offenders or changes in the compositions of these flows. In our sample, inmate populations grew much faster than arrests within every major crime category. Thus, recent prison growth in the US almost surely reflects changes in policies and procedures that determine the punishments offenders receive after being arrested, and our simulation results suggest that these changes in corrections policies account for the vast majority of prison growth from 1985 to 2005 .

Because data on the probability of conviction given arrest, $\gamma$, are so scarce, ${ }^{27}$ scholars often implicitly assume that $\gamma$ does not vary over time and focus on admission rates given conviction $(\delta)$ and expected time served given admission $(\bar{s})$ as empirical proxies for the punitiveness of criminal justice systems. When movements in these two variables account for most of the movements in $i$, scholars typically conclude that changes in the criminal justice system rather than changes in criminal behavior are the key drivers of changes in prison populations.

Further, most scholars that employ this method distinguish between movements in $\delta$ and movements in $\bar{s}$ when discussing the potential importance of changes in broad features of criminal justice systems. The following paragraph from Blumstein and Beck summarizes the prevailing paradigm concerning the interpretation of the results from these decompositions:

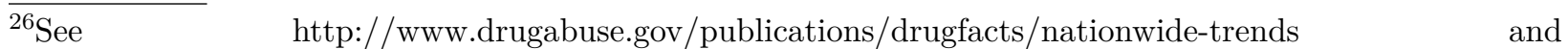
http://www.drugabuse.gov/publications/drugfacts/high-school-youth-trends.

${ }^{27}$ Better data on convictions may be available in the future through the National Judicial Reporting Program, but the Bureau of Justice Statistics does not provide any data that allow researchers to trace offenders from the dates of their arrests to the dates of the dispositions of their cases, e.g. charges dropped, acquittal, conviction, etc.
} 
"Growth in incarceration is typically a consequence of growth in one or more of the sequence of stages leading to an increased prison population. Those stages begin with commission of crime, which can then be followed by arrest, conviction, commitment, and time served in prison, including time served as a result of a parole violation. Changes in any or all of these stages can contribute to growth in the prison population. By examining each stage of the criminal justice process separately, the contribution of each to the total growth in incarceration can be isolated. Such a partition can also provide insights into the degree to which the growth is associated with greater criminality; greater police effectiveness in arresting offenders; some combination of increased effectiveness by prosecutors and punitiveness by judges in convicting arrested offenders and sending them to prison; increases in time served once sent to prison because of longer sentences (including mandatory minimum sentences), because the parole boards or other release policies are slower in offering release or because of more aggressive policies in recommitting parolees, either for a new offense or for a technical violation. ${ }^{128}$

Note how Blumstein and Beck (1999) discuss the last two terms, $\delta$ and $\bar{s}$. Given that a person is convicted of a crime, the literature divides the punitiveness of criminal justice systems into two components: (i) how likely are judges to sentence convicted offenders to prison, and (ii) among those who receive a prison sentence, how long will they expect to stay in prison. Further, Blumstein and Beck (1999) implicitly assert that, if there are changes in sentencing or parole policies that lead to more long prison spells, e.g. mandatory minimum sentence provisions, restrictions on release to parole, etc., then researchers can detect the effects of these changes in policy by measuring changes in time-served among those admitted to prison. ${ }^{29}$ This assertion is wrong, and it has created much confusion in this literature. However, before addressing this issue in detail, we review the empirical findings in the existing literature, and describe what appears to be an unresolved debate concerning the role of mandatory minimums and other sentencing enhancements as drivers of prison growth. We then show how a different framework for analyzing the data resolves this debate while also confirming some key conclusions from the existing literature.

3.1. Existing Literature. Blumstein and Beck (1999) examine national data from 1980 through 1996 on offense rates, arrest rates per offense, prison admissions per arrest, expected time served given admission, and incarceration rates. They examine linear trends in each of these statistics for six different crime categories, and ask how much trends in the first four statistics contribute to trends in incarceration rates by offense. They conclude that

\footnotetext{
${ }^{28}$ Blumstein and Beck (1999), pp. 26.

${ }^{29}$ Zhang, Maxwell, and Vaughn (2009) adopt the same approach. When reporting that changes in admission rates contribute more to prison growth than changes in expected time-served, they write, "Accordingly, sentencing reforms that resulted in increased prison admissions increased prison populations more than sentencing reforms that lengthened prison terms." See p.197.
} 
88 percent of the 1980-1996 growth in total incarceration rates for state prisons was due to trends toward more punitive sanctions, and they break this contribution down in the following way "the decision to incarcerate (51 percent) and ... (increases) in time served by those incarcerated (37 percent)." 30

Raphael and Stoll (2013) develop a steady-state model of prison populations that is richer than the simple steady-state equation above because it includes parole. The model has six states: (1) not incarcerated or on parole (2) incarcerated for a violent felony (3) incarcerated for a property felony (4) incarcerated for a drug felony (5) incarcerated for a parole violation and (6) on parole. They employ data from the National Corrections Reporting Program in a few years around 2004 and a few more years around 1984 as well as data from the 1986 Survey of Inmates in State Correctional Facilities. They also use data from the 2004 Survey of Inmates in State and Federal Correctional Facilities and the FBI Uniform Crime Reports. They calculate the transition probabilities between these six states and then solve for the steady-state incarceration rates implied by these transition matrices under the assumption that crime rates in different categories determine the population at risk for entering the prison system.

Raphael and Stoll (2013) perform these steady-state calculations for the 1984 and 2004 parameter values, and then calculate a counterfactual 2004 steady-state assuming 2004 crime levels and 1984 policy parameters. They also repeat the counterfactual calculation making adjustments for the fact that 2004 crimes rates would have been higher if incarceration rates had been lower. However, even with these adjustments, Raphael and Stoll (2013) conclude that more than 90\% of the difference between the 1984 and 2004 steady-states reflects differences in corrections policy. When discussing the relative contribution of different components of policy to prison growth, they echo the conclusions of Blumstein and Beck, "our enhanced tendency to sentence convicted felons to prison is particularly responsible for incarceration growth, though longer sentences are also a contributing factor. ${ }^{\text {"31 }}$

Both Raphael and Stoll (2013) and Blumstein and Beck (1999) conclude that expected time served given admission to prison rose sharply for violent criminals over time, and they identify this change as a noteworthy driver of prison growth. In contrast, a recent paper by Pfaff (2011) concludes that changes in expected time served for admitted prisoners played no role in prison growth over a similar time period. The analyses in Pfaff (2011) differ from much of the related literature in three ways. First, Pfaff does not rely on steady-state methods but follows cohorts in and out of prison over time. Second, while Blumstein and Beck (1999) relied on national aggregates and Raphael and Stoll (2013) employed data from all states that filed reports with the NCRP, Pfaff (2011) relied on NCRP reports from 11

\footnotetext{
$\overline{30}$ See page 43 .

${ }^{31}$ See page 80 and Figure 3.1. The authors also demonstrate that their 1984 and 2004 steady-state calculations are reasonable approximations for the 1984 and 2004 prison populations and do a good job of approximating the change in prison populations between the two years.
} 
states that he identified as providers of reliable data. Third, Pfaff (2011) did not calculate admission rates and time-served distributions that are specific to particular crime categories. He dealt with aggregate flows.

Pfaff (2011) concludes that distributions of time-served prior to release remained roughly constant over the 1980s and 1990s. He examines different percentiles in state-specific timeto-release distributions for prisoners admitted in particular years and finds rather mixed results and no evidence of a clear trend toward longer prison spells conditional on admission. He then concludes that "attention to sentencing matters is misplaced," and he argues that growth in mandatory minimum sentence provisions and other policies that enhance sentences played little or no role in the growth of prisons. ${ }^{32}$

Pfaff (2011) does acknowledge that, if states made sentencing more harsh by dictating positive sentences for some offenders who previously received probation as well as longer sentences for offenders convicted of more serious crimes, average time-served among admitted prisoners could remain constant as prison populations grow. However, he then proceeds to wrongly argue that, if various percentiles of the time-served distribution, e.g. 10th, 25th, 50th, 75th, and 90, do not change over time, then policies that increase the use of long prison spells as punishments cannot be important drivers of prison growth. This argument is logically wrong, as we illustrate below.

Below, we perform our own analyses using data similar to the data Pfaff (2011) employs. Like Pfaff (2011), we do not employ steady-state methods but track successive cohorts of offenders as they move in and out of prisons over time. However, we do analyze all transitions separately by offense category and admission type.

Similar to the results reported by Raphael and Stoll (2013), our results show that distributions of time-served prior to first release shifted modestly to the right for persons entering prison following new convictions, and consistent with much of the previous literature, we find that this shift was quite noteworthy for those convicted of violent crimes, e.g. murder, rape, assault, and robbery. The length of prison spells that began due to parole revocations shrank over this period as the number of such prison admissions grew both in levels and as a fraction of all admissions. Overall, the expected length of prison spells appears to be slightly shorter in recent years than in the 1980s.

However, we also find that, given arrest, both the expected time-served and the probability of serving at least five years in prison increased dramatically for offenders in all major crime categories. Compared to their counterparts in 1985, arrested offenders in 2005 faced both longer sentences on average and greater likelihoods of serving lengthy prison terms. These

\footnotetext{
${ }^{32}$ In fact, Pfaff (2011) concludes that the wide-spread view that the increased use of long prison spells has been an important driver of prison growth is a "myth" and argues that changes in "admissions policies" drove prison growth. He argues that prisons grew because offenders were more likely to enter prison not because courts were more likely to hand down sentences that resulted in long prison spells.
} 
results strongly suggest that changes in sentencing policies were an important driver of prison growth over the 1985-2005 period.

The contrast between our findings and those of Pfaff (2011) highlights the importance of examining data on admissions and time-served separately by offense category and admission type. Because Pfaff did not makes these distinctions, he did not realize that the relatively stability of the distribution of time-served among admitted prisoners during the 1980s and 1990s resulted from off-setting increases in various types of admissions. The number of persons serving short terms increased as the number of admissions associated with parole revocations and convictions for minor crimes increased, but the number serving long terms also increased as long prison spells became more common among arrested offenders in almost all crime categories and as many more violent criminals received long prison terms.

In addition, our approach demonstrates that changes in expected time served given admission are not, per se, germane to scholarly assessments of the impacts of changes in sentencing and parole practices on rates of prison growth. Although the existing literature contains the repeated contention that changes in $\bar{s}$ provide direct evidence concerning whether or not harsher sentencing and parole policies, e.g. elevated mandatory minimums, enhanced penalties for habitual violator, Truth in Sentencing laws, etc, are important drivers of prison growth, this is simply not true. ${ }^{33}$

3.2. The Wrong Denominator. If researchers want to know the extent to which policies that result in longer time-served, given the severity of crimes committed, contribute to growth in prison populations, they do not want to measure changes in the fraction of admitted prisoners who serve long sentences. Instead, they want to measure changes in the fraction of convicted offenders who serve long sentences. Further, because prosecutors have some discretion over which charges to file and how to bargain terms of plea agreements, one can argue that researchers should take another step back and focus on the fraction of arrested alleged offenders who serve long sentences. ${ }^{34}$

3.3. A Different Decomposition. Instead of characterizing corrections policy as a choice of an admissions probability and an expected sentence length, one could characterize policy as a set of probability weights, $\rho_{s}$, where $s=0,1,2, \ldots, S$ are the potential times that a convicted offender may serve, and $\rho_{s}$ is the probability of serving a sentence of $s$ given conviction. Here, $s=0$ denotes being fined, sentenced to probation, or some other punishment that does not

\footnotetext{
${ }^{33}$ Langan (1991) makes a similar mistake when analyzing data from an earlier period. He argues that mandatory sentencing laws did not drive prison growth, and cites as evidence that "Prison sentence lengths have not gotten longer since 1973, although mandatory sentencing laws commonly authorized or required longer sentences." Changes in the average lengths of sentences among admitted prisoners provide no information about the impacts of changes in sentencing policy.

${ }^{34}$ Below, we discuss Rehavi and Starr (2013) who demonstrate that, among those arrested for the same offenses, federal prosecutors have considerable discretion over how to charge offenders, and these charge decisions constrain the discretion of judges in sentencing.
} 
involve prison time. At the other extreme, $s=S$ denotes serving the maximum possible sentence.

Again, we deal with the simplest case and ignore parole. Given our new notation, it is straightforward to re-write our steady-state equation as

$$
i=(c-i) * \alpha * \gamma * \sum_{s=1}^{S} s \rho_{s}
$$

Now, consider a change in policy that involves uniformly harsher sentencing policies, i.e. let $\boldsymbol{\rho}^{\prime}=\left[\rho_{0}^{\prime}, \rho_{1}^{\prime}, \ldots, \rho_{S}^{\prime}\right]$ describe the new sentencing regime, and let $\rho_{s}^{\prime}=k \rho_{s} \forall s>0$ with $k>1$. Further, let $\rho_{0}^{\prime}=1-\sum_{s=1}^{S} \rho_{s}^{\prime}$. If we assume that criminal behavior, arrest rates, and conviction rates do not change in response to this change in sentencing policy, the new steady-state prison population ${ }^{35}$ is monotonically increasing in $k$. However, $\bar{s}$, the average time served among convicted offenders who enter prison does not change since

$$
\bar{s}=\frac{\sum_{s=1}^{S} s \rho_{s}^{\prime}}{\sum_{s=1}^{S} \rho_{s}^{\prime}}=\frac{\sum_{s=1}^{S} s \rho_{s}}{\sum_{s=1}^{S} \rho_{s}}
$$

Moreover, the entire distribution of time-served among admitted prisoners is the same under $\boldsymbol{\rho}^{\prime}$ as it is under $\boldsymbol{\rho}$.

Changes in sentencing policy can create enormous growth in prison populations while having little or no effect on the distribution of time-served among admitted prisoners. Further, it is easy to construct scenarios in which a move to more punitive sentencing increases prison populations while lowering the average time-served among admitted prisoners.

The framework we describe can easily be extended to include crime-specific sentencing weights. Let $j=1,2, . ., J$ denote an exhaustive and mutually exclusive list of crime categories. We can define $\rho_{s j}$ as the baseline probability of serving a sentence of $s$ years given conviction for crime $j$, and then define $\rho_{s j}^{\prime}=k \rho_{s j} \forall j$. It is straightforward to show that, $\forall k>0$, the distribution of time-served among admitted prisoners under the corrections policy summarized by the $S \times J$ matrices $\boldsymbol{\rho}^{\prime}$ and $\boldsymbol{\rho}$ are identical. Further, we can create infinitely many new matrices of sentencing weights with elements, $\rho_{s j}^{\prime}=k_{s j} \rho_{s j}$, such that the implied changes in corrections policies imply higher admission rates and larger steadystate prison populations but no changes in the distribution of time-served among admitted prisoners.

In the next section, we show that, compared to arrested offenders in 1985, those arrested in recent years faced much higher likelihoods of serving short, medium, and long prison spells, and this result holds for almost all offense categories. In terms of the notation above, the

$\overline{35 i^{\prime}=\left(c-i^{\prime}\right)} * \alpha * \gamma * \sum_{s=1}^{S} s k \rho_{s}$ 
best way to describe how policy has changed since 1985 is to state that $k_{s j}>1$ for almost every combination $(s, j) \cdot{ }^{36}$

We do not document dramatic changes over time in distributions of time-served among admitted prisoners prior to first release. However, this fact should cause no one to conclude that more punitive sentencing rules and less lenient parole policies are not the key drivers of prison growth in recent decades. The relative stability of the time-served distribution simply reflects that fact that, given arrest, prisons spells of all lengths became more likely over time. ${ }^{37}$

\section{NeW ApproACH}

In this section, we present results from our own analyses of data on arrests, admissions, releases, and prison populations. We use the National Corrections Reporting Program (NCRP) to construct measures of admissions, releases, and time served for different states and timeperiods. We follow Pfaff's (2011) approach of auditing the NCRP data in order to select a set of states that provide reliable data over a long period of time. However, our audits are more extensive than those performed by Pfaff (2011), and we take the additional step of using micro-data on arrests to create offense-specific measures of arrests for each state-year-race cell in our NCRP data.

We also use agency level data from the Uniform Crime Reports to construct state level data on arrests by offense for different years, and we demonstrate that our ability to track co-movements in arrests and admissions over time by offense is key to developing a more complete understanding of how prison populations grew over time. In particular, we show how ratios of admissions to arrests evolved for various offense categories. These ratios do not tell us everything we want to know about how the likelihood of imprisonment changed over time for persons arrested for specific offenses because some offenders are convicted of crimes that differ from the charges associated with their arrests and because there are lags between arrest and conviction. However, we gain useful insights by tracking these ratios over time, and in some analyses below, we treat these ratios as proxies for the likelihoods of entering prison given arrest for various offenses.

We also create offense-specific survivor functions for prisoners who enter prison in each year from 1985 to 2005. For each major offense category, we trace not only how the likelihood of imprisonment given arrest changes over time but also how the likelihoods of serving sentences of various lengths change over time. Our key tables describe how likely the persons arrested for a specific crime in a given year were to serve prison spells of various lengths. These

\footnotetext{
${ }^{36}$ The one exception is that the likelihood of serving short prison terms fell among those arrested for some violent crimes. However, the likelihoods that these same arrested offenders serve medium or long terms increased by even more.

${ }^{37}$ Note that, in our framework above, the admissions rate for a given convicted offender is simply the sum of the likelihood of receiving each of $S$ possible positive sentences.
} 
results establish that sentencing and parole policies became much more severe over the past several decades.

Finally, we attempt to quantify the importance of these changes using simulations that describe how prison populations would have evolved under different assumptions about sentencing and parole policies. Here, we are careful to distinguish between admissions that result from new court commitments and admissions that result from parole revocations. Because the majority of prison spells that result from new court commitments are less than two years in length, any policies that increase the number of prison admissions will soon increase the number of persons on parole. Further, this rise in the stock of parolees increases the number of parole revocations that generate new prison admissions, even if the standards for parole revocation remain fixed.

Our simulation results indicate that the vast majority of prison growth we observe from 1985 to 2005 resulted from changes in policies that govern the sentencing and time-served of arrested offenders. Trends in arrests account for only a small portion of the prison growth we observe, and changes in policies that govern standards for revoking parole appear to have had small impacts on the overall growth of prison populations.

4.1. Reliable Data. Many social scientists are aware that available data on crimes, arrests, admissions to prison, releases from prison and stocks of prisoners in the United States are usually of lower quality than well known data series that track employment or education levels. Data on crimes and outcomes in the criminal justice system are not usually gathered through the types of field operations that government agencies often use to collect information about labor market outcomes or education. Instead, these data sets are typically compilations of self-reports made by government agencies within the criminal justice system concerning their own activities. This data collection process generates many missing reports as well as data that are often internally inconsistent or transparently wrong.

Social scientists have typically responded to these data quality problems by either avoiding certain data series altogether or by hoping that at least the estimates of national aggregates derived from various series are somewhat reliable. We take a different approach. We analyze NCRP data from each state separately and then restrict our attention to a set of states where NCRP data pass a number of reliability tests. We then clean the Uniform Crime Reports (UCR) data on arrests for these states to make sure that we have reliable information on the evolution of arrests over time in these states.

4.1.1. Cleaning the NCRP Data. Appendix A provides details concerning our data cleaning and construction procedures. Here, we provide an overview. We began by auditing the NCRP data. Pfaff (2011) performed similar audits on the NCRP admission and release files, but his sample ended in 2002, and our cleaning and checking procedures are more involved.

The NCRP data provide detailed records of admissions and releases for many states in many years from 1983 to 2009 as well as stocks of prisoners in custody for the years 2005 
through 2009. We begin our audit process by restricting our attention to states that filed NCRP reports on a fairly consistent basis, especially during the 1990s when prison populations were rising quite rapidly. This requirement eliminates 16 states and the District of Columbia.

For the 34 states that remain, we conduct several checks for internal and external consistency. In our first check on NCRP data quality, we examined the dates in the release and admission data in the NCRP to check for internal consistency in the following sense: for any given year $t$, the total number of prisoners in the release files with recorded admission dates in year $t$ should not be greater than the number of prisoners recorded in the admissions files for year $t$.

In our second check on NCRP data, we used the admission and release flows from 1987 through the period 2005-2009 to determine whether or not the age-specific stocks in the post2005 NCRP files are consistent with the flow data on admissions and releases prior to 2005. For example, if we assume that teenagers 15 and under are not entering regular prisons, the difference between total admissions and total releases after 1987 among the cohorts who were 15 or younger in 1987 will tell us what the stocks of prisoners under age 35 should be in 2007 .

Our third and fourth checks involved comparisons between the NCRP data on admissions and releases of prisoners and the National Prisoner Statistics (NPS) data on flows and stocks. These NCRP and NPS data series should not match exactly because they do not define the prisoner populations of interest in exactly the same way. However, large deviations in reported flows or large deviations between the reported changes in NPS stocks and the implied NCRP stock changes are cause for concern. ${ }^{38}$

These four checks allow us to identify eight states that provide continuous reports that appear to be of acceptable quality. They are CA, CO, MI, NJ, NY, SC, WA, and WI. ${ }^{39}$ However, we do not use NY because NY release records contain no information on the type of admission or year of admission to prison in several years. Without these variables, we cannot determine how distributions of time-served for different types of offenders evolved over time.

Figure 1 uses data from the NPS to display percentage growth in prison populations for three samples: (i) state prisons in the seven states in our main sample, (ii) all state prisons and (iii) all state and federal prisons. The overall growth pattern for our seven states is similar to the pattern observed for all states. However, growth is more rapid early and levels off earlier in our sample. The data for CA account for most of these discrepancies. CA is

\footnotetext{
${ }^{38}$ For years before 1999, the stock data for the NCRP and NPS are comparable. Both contain counts for all prisoners in custody. However, later stock data and all flow data are not comparable. See Appendix A for details.

${ }^{39} \mathrm{IL}$ also provides reliable data but stops reporting in 2003.
} 
a large state that experienced rapid prison growth early, and in part because of capacity constraints, CA prison populations stopped growing while many others continued to grow.

4.1.2. Reliable Data on Crime and Arrests. The FBI Uniform Crime Reporting (UCR) system collects data on crimes and arrests through reports from local law enforcement agencies. However, these data are filled with missing reports as well as reports that appear transparently wrong. Further, while the FBI uses these data to produce national estimates of annual crime and arrest rates by offense, we are not aware of any FBI efforts to produce comparable estimates at the state level. Justin McCrary has produced edited versions of the UCR crime files and made them publicly available. We employ these data in our analyses below. We also employ our own edited versions of the UCR arrest files for the seven states in our NCRP sub-sample. ${ }^{40}$

As a first step, we examine the monthly reports to identify incidences of "backlog filing." Some agencies periodically place the crimes and arrests for a several month period in one monthly report, and it is necessary to identify these reports before making any determination about the monthly frequency of crimes or arrests in any given agency over any specific period. Based on monthly averages of valid reports of arrests within agencies within specific calendar years, we make imputations for missing monthly reports that do not result from "backlog filing." In cases where agencies do not report for entire years, we use interpolation procedures described in Appendix B to fill in the missing data.

4.2. NCRP Results. Table 6 above demonstrates that national trends in prison admissions and total prison populations do not track national trends in crimes or arrests after the early 1990s. Before turning to NCRP results on prison admissions and time-served in our sevenstate sample, we first document that, in broad terms, trends in crimes and arrests follow the same patterns in our subsample of states that we see in the national totals. Here, we do not display crime rates or arrest rates but simple counts of crimes and arrests. Counts of this type are the key inputs in our simulation procedures. When we discuss the results of our simulations and their interpretation, we then discuss alternative ways to account for demographic changes over time.

Figure 2a shows trends in UCR data on violent crimes for the nation and our seven-state sample. Each dot is an index number with the 1985 level normalized to 100. The basic patterns are the same in the two samples. Violent crime became more common during the late 1980s and early 1990s, but violent crime has been roughly at or below the 1985 level since 1999. Figure $2 \mathrm{~b}$ shows the same basic trends in arrests for violent crime, but here the increases during the late 1980s and early 1990s are even more dramatic. Further, the curve for our NCRP states diverges slightly from the national curve because arrests rise to

\footnotetext{
${ }^{40}$ The crime files are here, http://emlab.berkeley.edu/ jmccrary/UCR/index.html. We describe the construction of our arrest files in Appendix B. When we apply our cleaning procedures to the UCR Crime files, we are able to create edited versions of the crime data that closely match McCrary's files.
} 
a higher peak in our NCRP states. Nonetheless, since 1995, arrests for violent crime have been falling, almost steadily, both nationally in our NCRP sample.

Figures 2c and 2d present parallel results for property crimes and arrests. The trends are similar in the two samples. Property crimes and arrests rise initially and then fall. However, property crimes and arrests fall below 1985 levels several years earlier in our NCRP states.

Figure 2e shows that drug arrests follow qualitatively similar patterns in our NCRP sample and the nation as a whole, although some noteworthy quantitative differences emerge after 1995. Drug arrests in our NCRP states remain more than 50 percent above 1985 levels throughout the 2000s, but for the nation as a whole, drug arrests were at least double their 1985 levels for most of the 2000s. Most of this gap reflects the fact that drug arrests in California remained roughly flat from 1994 to 2002, and California accounts for a significant fraction of the arrests in our seven-state sample.

Figures 2a-2e show that the patterns in crime and arrest data for our sample of NCRP states follow the same broad trajectories that we observe for the nation as a whole, just as Figure 1 demonstrated that prison growth in our NCRP states followed national trends. We have already argued based on the results in Table 6 that the national growth in prison populations since the 1980s cannot be readily explained by trends in arrest data. Below, we show, in detail, that the growth in prison admissions and prison populations in our NCRP states since 1985 is far greater than one would have expected based on sentencing and parole policies in 1985 and observed trends in arrest data since 1985.

The three panels of Table 7 present the key patterns in the NCRP and FBI-UCR data. The first three columns of each section give arrests, admissions, and admissions per arrest for a given crime. The remaining three columns give the number of prisoners (per 1000 admitted prisoners) who remain in prison two, five, or ten years after admission. When discussing our results on time-served among admitted prisoners, we often restrict attention to cohorts that entered prison in 2000 or before. We do not have data on all of our seven states in each year past 2005. Thus, we do not have complete information on release dates after 2005 . The survivor function entries in Table 7a-7c that describe release patterns in 2006 through 2009 are based on the assumption that cohort hazard rates for any subsample of our states match the corresponding cohort hazard rates for these years in our full seven-state sample.

The first thing to note about the patterns in Tables $7 \mathrm{a}-7 \mathrm{c}$ is that the admissions to arrests ratios increase for every offense category. For all offenses, the likelihood of entering prison given arrest increased between 1985 and 2000, and, in some cases, by factors of two or three.

We see particularly dramatic increases in admissions to arrests ratios for two crimes that have not historically been associated with high admissions to arrests ratios. The 2005 admissions to arrests ratios for both non-aggravated assault and motor vehicle theft are more than three times the corresponding ratios for 1985. The distributions of time-served among prisoners admitted for these offenses exhibit mixed changes over time, but given such large increases in the likelihood of admission given arrest, those arrested for these offenses in the 
early 2000s faced higher probabilities of serving short, medium, and long prison sentences than those arrested for the same offenses in 1985.

The patterns for drug offenders in Table 7c are also striking. The ratio of admissions to arrests for drug trafficking more than doubled between 1985 and the early 2000s, and over the same period, the corresponding ratio for drug possession more than tripled. Among those entering prison for drug-trafficking and drug possession, the probability of serving at least two years in prison is higher now than in the 1980s. For those who enter prison following a conviction for possession, the probability of serving five years is lower in the 2000s than in the 1980s, but the opposite is true among those convicted for trafficking.

When we multiply the admissions to arrests ratios by the entries for various survivor function levels, it becomes clear that Table 7c implies a trend toward harsher treatment for those arrested on drug charges. For example, in 1985, we see 74 admissions to prison for every 1,000 arrests for drug trafficking, and 190 of every 1,000 prisoners who entered prison for drug trafficking served at least two years prior to release. Thus, for every 1,000 persons arrested for drug trafficking in 1985, roughly 14 served at least two years in prison, but the comparable figure for 2005 is 51. If we repeat these calculations for the outcome of serving at least five years in prison, the resulting numbers are 3.5 for 1985 and 13 for 2005 .

Although we do not see the same dramatic increases in admissions to arrests ratios among those arrested for violent crimes, the results in Table 7a still imply a trend toward harsher punishment of violent offenders. For every 1,000 persons arrested for homicide in 1985, roughly 168 persons remained in prison ten years later. For those arrested for homicide in 2000, the comparable figure is 377 . The exact numbers differ, but the same patterns hold for Rape, Robbery, and Aggravated Assault. Compared to comparable alleged offenders in 1985, persons arrested for violent crime in the 2000s faced not only greater risks of entering prison but much greater risks of serving long prison terms prior to first release.

The panels of Table 7 demonstrate that arrested offenders in the early 2000s faced much higher probabilities of serving significant prison time than their counterparts in 1985. Further, this apparent change in the severity of policies that govern sentencing and time-served is evident within all major crime categories. Taken as a whole, the results in Tables 7a7c show that, over time, courts and corrections officials found ways to impose more short, medium, and long prison terms on those arrested for particular crimes.

Table 8 presents these results in a more compact manner that closely matches the statistical model of prison populations that we presented above. Recall that, for a person who is arrested and convicted of crime $j$, we defined $\rho_{s j}$ as the probability that the offender serves a prison spell of length $s$ given some baseline set of corrections policies. We then noted that one can define a new set of corrections policies, $\rho_{s j}^{\prime}$, using a matrix of constants $k_{s j}$ that scale these punishment probabilities up or down, i.e. $\rho_{s j}^{\prime}=k_{s j} \rho_{s j}$. Further, one can collect these probabilities in matrices $\boldsymbol{\rho}$ and $\boldsymbol{\rho}^{\prime}$ that fully characterize the two corrections policy regimes. 
Now, consider data on corrections outcomes for two cohorts of arrested offenders where the first cohort faces $\boldsymbol{\rho}$, and the second cohort faces $\boldsymbol{\rho}^{\prime}$. Further, make three assumptions about the charging and sentencing processes that govern both regimes. First, assume that each convicted defendant in both cohorts is convicted of the offense listed in the UCR arrest record that documents his arrest, i.e. the most serious charge against the defender at the time of arrest. Next, assume that the probabilities of conviction given arrest for specific crimes are identical for both cohorts. Finally, assume that prisoners enter prison in the same year they are arrested.

None of these assumptions are strictly valid. However, they allow us to link data on arrests and admissions in a useful way. We consider combinations of offense categories $j=1,2, . ., J$ and prison spell length $s=1,2, . . S$. Then, we calculate, within each cohort of arrested persons, the ratios of the number of persons convicted of offense $j$ who served $s$ periods in prison to the number of persons that were originally arrested for offense $j$. Given our assumptions, the ratio associated with any pair $(s, j)$ in our baseline cohort is a consistent estimator of the quantity $\left(\gamma_{j} * \rho_{s j}\right)$, where $\gamma_{j}$ is the probability of conviction given arrest for offense $j$. The corresponding ratio for the latter cohort is a consistent estimator for $\left(\gamma_{j} * \rho_{s j}^{\prime}\right)$.

Now, recall that $k_{s j}=\frac{\rho_{s j}^{\prime}}{\rho_{s j}}$ defines the severity of corrections policies for the latter cohort relative to the baseline cohort. Thus, for each pair $(s, j)$, we can form a consistent estimator of $k_{s j}$ by forming ratios of the ratios we describe above, i.e.

$$
\hat{k}_{s j}=\frac{\widehat{\left[\gamma_{j * \rho_{s j}^{\prime}}\right]}}{\widehat{\left[\gamma_{j * \rho_{s j}}\right]}}
$$

Since $k_{s j}$ is the proportional change in the likelihood of receiving a prison term of length $s$ given arrest or conviction for crime $j$, we can describe how corrections policies changed between the two cohorts using a $(S \times J)$ matrix $\widehat{K}$ with elements $\hat{k}_{s j}$.

Table 8 presents these results for $84(s, j)$ pairs that capture the intersections of $J=14$ offense categories and $S=6$ spell lengths. For example, consider the cell in Table 8 that corresponds to the row "Drug-Trafficking" and the column "2-3 years." The first entry tells us that for every 1,000 persons arrested for drug trafficking in 1985, there were just over seven persons who entered prison in 1985 and served between two and three years for drug trafficking. The second entry implies that the corresponding figure for 2000 is almost 27 persons. The final entry, 3.68, is the ratio of these two ratios, $\hat{k}_{s j}$. Given our assumptions above, this value indicates that the probability of serving between two and three years in prison, conditional on being arrested for drug trafficking, increased by 268 percent between 1985 and 2000.

Table 8 is a compact way to demonstrate that the data imply a shift to uniformly harsher punishments for offenders in all crime categories. Note that, for all non-violent crimes, each $k_{s j}$ entry is greater than one, and the majority are greater than two. In every category, 
arrested offenders in 2000 faced a higher likelihood of serving prison terms of 0-1 years, 1-2 years, 2-3 years, 3-4 years, 4-5 years, or more than five years. Since only tiny fractions of those arrested for non-violent offenses ever serve more than five years in prison, we lose little information by aggregating all prison spells longer than five years into one category, and these results clearly establish that those arrested for all non-violent offenses faced harsher expected punishments in 2000 than in 1985.

The results for violent crime may appear different at first glance, but they still imply a shift to harsher punishments. Several of the $\hat{k}_{s j}$ ratios that correspond to short prison spells for violent crimes are actually less than one, but this does not indicate that corrections policies became more moderate in some respects over time. Recall that Table 7a demonstrates that total admissions to arrests ratios increased over the 1985 to 2000 period within every violent crime category. Thus, within each category, any declines in the likelihood of short prison spells simply imply that the shift toward more frequent use of long prison spells was even greater than the increases in overall admissions rates given arrests. Note that the likelihood of serving at least five years given arrest increased by at least a factor of two in each violent offense category.

We note above that, beginning in 2006, we have less than full coverage of releases in our seven NCRP states. Thus, in order to get better information on changes in the likelihood of long prison spells for violent criminals over time, we made similar comparison between the 1985 and 1995 cohorts.

We compute $\hat{k}_{s j}$ values that describe changes in criminal justice policies between 1985 and 1995 governing sentence lengths of 0-1 years, 1-2 years, 2-3 years, 3-4 years, 4-5 years, 5-6 years, 6-7 years, 7-8 years, 8-9 years, 9-10 years, and more than 10 years given arrest for each violent crime. The results for spells less than five years resemble those in Table 8 and those that describe spells longer than five years indicate a clear shift to longer prison spells for violent offenders. All of these $\hat{k}_{s j}$ values are greater than one, and more than half of the values are greater than 2. Compared to those arrested in 1985, persons arrested for violent crime in 1995 were much more likely to enter prison and serve long prison terms. ${ }^{41}$

Table 8 not only demonstrates that the shift to harsher punishment for arrested offenders applied to all crime categories, it also shows that the sizes of some shifts are stunning. Conditional on being arrested for drug possession, the likelihood of serving between two and five years in prison increased by more than a factor of five, and the shift toward harsher punishment for drug traffickers is also dramatic. Finally, compared to their counterparts in 1985, persons arrested for simple assault in 2000 were five times more likely to serve at least five years in prison.

\footnotetext{
${ }^{41}$ We see qualitatively similar results for the 2000 cohort when we simply rely on the data that we have in each year after 2005.
} 
4.3. Simulation Results. The results in Tables 7a-7c and Table 8 clearly show that arrest offenders faced harsher expected punishments in the early 2000s than in 1985. However, these results do not provide precise information about the total contribution of these implied changes in sentencing and corrections policies to the growth of prison populations after 1985.

Thus, we next describe a simulation model that directly maps both changes in arrest rates and changes in policies that govern expected punishments for arrested offenders into changes in prison populations. The logic of our model is quite similar to other simulation models in the literature. The Raphael and Stoll (2013) steady-state approach ignores transition paths but follows the same basic logic. In addition, McCrary (2010) develops a mathematically similar model with a single offense and no parole, and McCrary and Sanga (2012) use a parameterized version of this model to illustrate how deterrence elasticities shape the paths of prison populations following exogenous shifts in the severity of sentencing. Appendix $\mathrm{C}$ provides details concerning our methods. Here, we provide an overview.

We assume, as before, that each convicted offender is convicted of the most serious charge listed in his arrest file, i.e. the charge recorded in UCR arrest files, and that the offender enters prison in the year of his arrest. Given these assumptions, we can use our arrest data, data from the 1985-2009 NCRP files, ${ }^{42}$ and NPS data from 1982 through 1985 to estimate the following probabilities:

(1) the probability that an offender arrested in 1985 enters prison as a new court commitment

(2) the probability that a person who was paroled from prison in year $(1985-p)$ enters prison in 1985 as the result of a parole revocation

(3) the probability that a person exits prison to parole in year $(1985+s)$ given that he entered prison in 1985 due to a new court commitment

(4) the probability that a person exits prison to parole in year $(1985+s)$ given that he entered prison in 1985 due to a parole revocation

(5) the probability that a person exits prison without parole supervision in year $(1985+s)$ given that he entered prison in 1985 due to a new court commitment

(6) the probability that a person exits prison without parole supervision in year $(1985+s)$ given that he entered prison in 1985 due to a parole revocation

In the NCRP data, only trivial numbers of parolees face parole revocation more than three years after their release to parole. Thus, we let $p=0,1,2,3$, and we treat all revocations after three years as if they happened in $p=3$. We do not need to keep track of releases

\footnotetext{
${ }^{42}$ We do not employ the actual admissions data from the NCRP. Rather, we use the most recent NCRP stock data for a given state and the NCRP release files from the previous years to construct admissions files that are completely consistent with the stock and release data for 1985 and subsequent years. Given our state selection rules, these constructed admissions series closely track the actual NCRP admission series. By using these constructed admissions data we ensure that all of the probabilities that we calculate for use in our simulation model are between zero and one.
} 
directly from parole to freedom because these releases do not change the stock of prison inmates.

We let $s=0,1,2, \ldots, 20$. Because we are examining the evolution of prison stocks between 1985 and 2005, we do not need to know anything about the release probabilities for $s>20$.

Above, item (1) is a single probability but items (2)-(6) are vectors of probabilities. We calculate all the elements of (1)-(6) separately for cells defined by the interaction of three race groups, 14 offense categories, and two geographies. The race groups are white, black, and other. The offense categories are those used in Tables 7a-7c, and we divide geography into California and our other six NCRP states. California is a large state that, not only in recent years but also in 1985, followed corrections policies that are notably different than those followed by our other NCRP states.

In sum, for each of the $(14 \times 3 \times 2)$ cells, we calculate a commitment probability, a vector of parole revocation probabilities, and four vectors of prison release probabilities. Given any hypothetical cohort of arrested offenders for any crime in any year within any (race*geography) cell, we can simulate the transitions for these offenders that follow their arrests, i.e. transitions to prison, transitions from prison to supervised parole release, transitions from parole back to prison due to parole revocation, and transitions from prison to release without parole supervision. We do not attempt to measure transitions from release without supervision back to prison because these transitions begin as future arrests.

Now, if we assume that the punishments arrested offenders receive in year $t$ do not affect the number of arrested offenders or the characteristics of arrested offenders in future years, then, we can feed different sequences of hypothetical annual arrest levels through our simulation and track the resulting evolution of prison populations in each of our $(14 \times 3 \times 2)$ cells from 1985 through the end of 2005.

This implies that, given our 1985-2005 data on arrests from the UCR files and the estimated probabilities described above, we can address the following counterfactual:

How would prison populations in our NCRP states have evolved over time if the probabilities described above had been held fixed at their 1985 levels, assuming that crime rates and resulting arrest rates evolve independently of sentencing or parole polices?

To understand how we build the counterfactual answer to this question, note first that we can use NCRP data to estimate the initial stocks of persons in prison and on parole at the beginning of $1985,{ }^{43}$ and we can also record all subsequent releases from these initial stocks of inmates and parolees. In addition, because the probabilities above fully characterize the dynamics of flows in and out of prison and parole, we can track the flows that we expect into prison, out to parole, back to prison from parole, etc. from each sample of arrested

\footnotetext{
${ }^{43}$ The aggregate prison stocks implied by these estimates match the stocks reported for 1985 by the NPS fairly well.
} 
offenders for 1985 and subsequent years. Further, we can also track the movements we expect for persons on parole in 1985 who subsequently entered prison because they violated their parole conditions. Thus, we can build a counterfactual time path for prison populations under the assumption that the probabilities described above govern the movements into and out of prison and parole for all cohorts of arrested offenders and parolees from 1985 forward.

Figure 3 presents the results of this exercise and makes our main point clear. Prison populations in our NCRP states grew from about 104,500 at the beginning of 1986 to roughly 325,500 at the beginning of 2006. However, taking the arrest series since 1985 as given, our counterfactual simulation suggests that at the beginning of 2006, the stock of prisoners would have been just less than 165,000 if the 1985 corrections regime had remained in effect. Put differently, roughly $73 \%$ of the growth in prison populations in these states between the beginning of 1986 and the beginning of 2006 resulted from changes in policy.

Some may view this figure as an upper bound because we have assumed away the possibility that arrest rates would have been higher in recent years if courts and parole boards had not become more punitive. The most straightforward way to address this concern is to allow for the possibility that, ceteris paribus, the number of arrests in each year is a decreasing function of the stock of incarcerated persons at the beginning of the year. When creating the counterfactual prison populations associated with holding corrections policies constant at 1985 values, one can simply include additional arrests for years 1987 and beyond to reflect the fact that arrests would have been higher in these years if the 1985 policies had been in place and fewer potential criminals had been in prison.

The existing literature does not speak with one voice concerning the optimal way to parameterize this adjustment. Therefore, we adopt parameters that we believe yield conservative estimates of the contribution of changes in correction policies to prison growth. Among the studies we have reviewed, Levitt (1996) reports by far the largest, in absolute value, estimated elasticities between prison stocks and crime rates. ${ }^{44}$ He uses court orders concerning prison overcrowding as instruments for changes in prison populations and concludes that, at the state level, the elasticity of crimes rates in year $t$ with respect to incarceration rates in year $t-1$ is -.4 for violent crimes and -.3 for property crimes. These estimates are more than double, in absolute value, most estimates in the related literature. Thus, if we adjust the simulation results in Figure 3 for incapacitation and deterrence effects using these elasticities, the resulting counterfactual prison populations for our NCRP states are likely upper bounds on the prison populations that would have been realized post-1985 if the 1985 corrections policies regime had remained in place.

Here, we assume that, within each crime category, there is a constant ratio of arrests to reported crime over time. This allows us to treat Levitt's estimated elasticities of crime with

\footnotetext{
${ }^{44}$ See Johnson and Raphael (2012), Lofstrom and Raphael (2013), Marvell and Moody (1996), McCrary and Sanga (2012), and Owens (2009).
} 
respect to lagged prison stocks as estimates of the corresponding elasticities of arrests with respect to lagged prison stocks.

Figure 4 presents the results. In each year from 1987 forward, we inflate arrest rates to account for the fact that crime rates may have been higher under the 1985 corrections regime since prison populations would have been lower. The results indicate that prison populations in these states would have grown from 104,500 at the beginning of 1986 to just over 189,000 at the beginning of 2006 if 1985 corrections policies had remained in effect. Thus, even when we use Levitt's results to account for incapacitation and deterrence, our results indicate that over 60 percent of the growth in prison populations between the beginning of 1986 and the beginning of 2006 is the result of changes in the policies that govern sentencing and time-served outcomes among arrested offenders.

In addition, it is important to note that prison populations in these seven states would have grown by more than 12,400, or just less than six percent, if the ratios of incarcerated persons to population had simply remained constant within cells defined by age, race, and gender. Thus, the implied contribution of more punitive corrections policies to changes in incarceration rates is even larger than Figures 3 and 4 suggest. If we subtract 12,400 from both actual and simulated stocks, we find that roughly $65 \%$ to $77 \%$ of the growth in prison populations that is not accounted for by changes in demography can be attributed to increases in the punitiveness of sentencing and corrections policies.

Criminologists typically adjust for demographic changes by expressing results in terms of incarceration rates per 100,000 people. The population of our seven states in 1985 was $58,742,684$, which yields an incarceration rate of 178 prisoners per 100,000 persons at the end of 1985. The 2005 population is 75,236,560, which yields an incarceration rate of 433 . The incarceration rates implied by the counterfactual results in Figures 3 and 4 are 219 and 252. Thus, our simulation results suggest that changes in the severity of sentencing and corrections policies generated between $71 \%$ and $84 \%$ of the growth in incarceration rates between 1985 and 2005 in our seven states.

We note above that Raphael and Stoll (2013) made similar calculations concerning changes in steady-state incarceration rates implied by criminal justice policies and arrest rates that prevailed in 1984 and 2004. In Figure 3.1 of their book, they report that $91 \%$ of the growth in these implied steady-states is attributable to changes in policy.

The key differences between our methods and those employed by Raphael and Stoll (2013) are that (i) they decomposed growth in implied steady-states rather than actual populations (ii) they did not restrict their analyses to states that report "clean" NCRP data and (iii) they used smaller adjustment factors, in absolute value, to correct for incapacitation and deterrence. 
It is not clear how the first two differences should impact the Raphael and Stoll (2013) results compared to ours. ${ }^{45}$ However, it is clear that they attribute a larger role to changes in sentencing and corrections policies, at least in part, because they assume that the effects of prison growth on arrest rates are significantly smaller than those reported by Levitt (1996). The methods they employ to create their estimates are defensible and produce results that are more in line with the rest of the literature. By using Levitt's estimates, we are most likely creating a conservative estimate of the impacts of more severe sentencing and corrections policies on prison growth. ${ }^{46}$

Yet, some may argue that Levitt's elasticities are still too small in absolute value because he exploits only year-to-year variation in prison populations induced by court orders. Because the court orders that induced these population changes may be less salient for potential criminals than sustained long-term shifts toward more punitive policies, Levitt's research design may not capture the full deterrence effects of recent prison growth on crime rates.

However, Nagin (2013) presents a comprehensive review of the literature on deterrence and concludes that the deterrence effects of shifts to longer prison terms are modest at best. For our purposes, the most relevant studies that he reviews are Helland and Tabarrok (2007) and Lee and McCrary (2009). ${ }^{47}$ The former finds that the large sentencing enhancements associated with potential conviction for a third "strikeable" offense under California's "Three Strikes and You're Out" regime did generate an almost twenty percent reduction in arrest rates. This effect is noteworthy, but the enhanced sentences associated with a third strike were quite severe. The latter study finds that the significant increases in expected punishment associated with being tried as an adult in Florida likely generate, at most, small deterrence effects. The Nagin (2013) review of these studies and others provides no reason to believe that introducing additional, yet plausible, deterrence effects into our simulations could materially change our conclusions about the primacy of sentencing and corrections policies as drivers of prison growth. In addition, while a sustained commitment to punitive policies may deter some potential offenders, it may also harden others. Several recent studies suggest that putting more offenders in prison and keeping them there longer may have criminogenic effects. $^{48}$

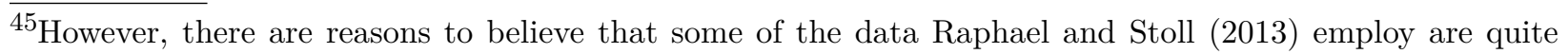
noisy. For example, Table 2.2 reports that in 2004 their data contain almost forty percent more prison admissions for murder than actual arrests for murder.

${ }^{46}$ Further, if one assumes heterogeneity in the propensity to persist in criminal activity, the tripling of prison populations in these states between 1985 and 2005 should also have impacted the marginal gains from incapacitation. In fact, Raphael and Lofstrom (2013) show that, when the Supreme Court recently forced California to substantially reduce its prison population during 2011 and 2012, crimes rates barely moved, and there is little evidence of a significant spatial relationship between the sizes of release flows and changes in local crime rates.

${ }^{47}$ See Durlauf and Nagin (2010) for more on the methodological challenges facing those who seek to measure incapacitation and deterrence effects separately.

${ }^{48}$ See Aizer and Doyle (2013), Bayer, Hjalmarsson, and Pozen (2009), Chen and Shapiro (2007), and Di Tella and Schargrodsky (2013).
} 
In Figure 3, we are tracking total and simulated prison populations. We have repeated the exercise while keeping separate track of the populations of prisoners who last entered prison following conviction for crime and the populations who last entered prison following parole revocations. The results show that, in most years, the number of prisoners associated with new court commitments is at least three times the number of prisoners associated with parole revocations. Further, at the beginning of 2006, both stocks of prisoners are roughly twice the levels implied by the simulations that impose the 1985 corrections policies throughout the sample period. Although there appear to have been some changes over time in how California made decisions concerning parole revocations, the key driver of growth in the number of persons serving prison terms that began as the result of parole revocations is growth in the stock of persons on parole and therefore at risk for revocation, and this growth in the stock of parolees was primarily driven by growth in the number of persons serving time for new convictions.

4.3.1. Race-Specific Results. We began by noting the low employment rates and high incarceration rates that now exist among black men, especially less-educated black men. We have shown that changes in sentencing and parole policies drove overall prison growth during the past several decades. Thus, we now ask whether these changes in sentencing and parole policies were implemented in a way that disproportionately affected blacks.

Figures 5 and 6 repeat the simulations in Figure 3 treating blacks and whites as separate populations. Here, we see dramatic growth in prison populations for both races that cannot be explained by trends in arrests. Further, at the beginning of 2006, the ratio of actual prisoners to the simulated stock based on 1985 corrections policies is greater for whites than blacks, 2.12 vs 1.75. Finally, Appendix Tables A6 and A7 present race-specific versions of Table 8. These tables also do not support the idea that changes in sentencing and parole policies after 1985 were more punitive in cases that involved black offenders. Most of the $\hat{k_{s j}}$ entries are, in fact, larger among whites.

While there is no evidence that the prison boom was driven by changes in sentencing and parole policies that were differentially punitive for blacks, ${ }^{49}$ policy changes that increase expected punishment for arrested offenders have a larger effect on blacks as a group because black arrest rates have been and remain much higher than white arrest rates. There is some suggestive evidence that, even in our base year 1985, black offenders were already more likely to receive significant prison time for some offenses, e.g. Robbery, Burglary, Motor Vehicle Theft, and Larceny, but this baseline differential is a minor part of the story. The policy change we describe above involved an across the board move to more punitive sentencing and parole policies for all offenders, and this change had more significant impacts on black

\footnotetext{
${ }^{49}$ However, because we cannot identify Hispanics in a consistent way over time and because the Hispanic population is growing over time, we cannot rule out the possibility that punishments applied to both black and Hispanic defendants became more severe over time relative to those applied to non-Hispanic white defendants.
} 
communities than white communities because black arrest rates have been at least four times greater than white rates from 1980 forward. ${ }^{50}$

\section{FEDERAL PRisons}

To this point, we have focused on growth in state prisons. The NCRP contains spotty data on federal prisons. So, we have pieced together information on growth in the stock of federal prison inmates from other sources. Tables 9a, 9b, and 9c present prison populations, admissions, and releases by offense category for the federal prison system from 1989 through 2010 .

In percentage terms, the federal prison population grew even more rapidly than state prison populations during the 1990s and 2000s. Between 1989 and 2010, the stock of federal prisoners increased by more than 250 percent.

However, the reasons for this growth are different. The Federal prison population increased by about 150,000 persons over this period, and increases for only three offense categories account for almost 90 percent of this growth. The number of persons imprisoned for drug offenses increased by almost 81,000, while the number imprisoned for weapons and immigration offenses increased by more than 29,000 and 21,000 respectively. The stock of prisoners in the other crime category increased by roughly 18,000 as well, while the stock of prisoners serving time for traditional violent and property crimes remained roughly constant. ${ }^{51}$

We do not have federal arrest data that is comparable to the arrest data we employ in analyzing the growth of state prisons. However, even if we had data on federal agency arrests, we could not compare trends in arrests to trends in crime for the federal crime categories that drove federal prison growth. UCR crime data do not include drugs, weapons, or immigration as offense categories. When an offender breaks into a home and steals jewelry, the owner of the jewelry may well file a police report. However, drug crimes, weapons crimes, and immigrations offenses typically involve episodes where all parties involved are violating the law. The persons who just bought illegal drugs or illegal weapons are not likely to report the sales to police, and the persons who helped illegal immigrants enter the country or obtain illegal employment have no interest in reporting the related immigration law violations to police. In this light, it is interesting to note that Federal prison admissions for drug offenses

\footnotetext{
${ }^{50}$ We are not claiming that racial disparities in charges filed against arrested offenders or sentences given to convicted defendants do not exist. In a recent paper, Rehavi and Starr (2013) not only review the substantial literature on racial disparities in sentencing but also provide clear evidence of discriminatory behavior by federal prosecutors prior to the sentencing stage. When dealing with comparable arrested offenders, federal prosecutors are more like to file formal charges that bring mandatory minimum sentence provisions into play if the offenders are black, and we cannot rule out the possibility that state prosecutors engage in the same biased behaviors. Still, our results provide no evidence that these types of discriminatory behaviors have become worse over time.

${ }^{51}$ We see large percentage increases in the stocks of prisoners incarcerated for rape, but this is an increase of only hundreds of people, and it appears to be driven by a change in the classification of what sexual crimes count as rapes.
} 
continued to rise long after the crack epidemic ended in most urban areas, and admissions for immigration violations are higher in the period 2008-2010 than in any previous period, even though rates of illegal immigration allegedly fell during the Great Recession. ${ }^{52}$

We also do not have time-served information for federal prisoners by offense because the NCRP records for the federal prison system are spotty. Thus, we cannot calculate proxies for the likelihood of serving various prison terms given arrest for specific federal offenses, and we cannot clearly assess the extent to which changes in federal corrections policies mirrored the changes we see at the state level.

Still, we can establish at least two important contrasts between patterns of growth in the federal prison system and the patterns we document for state prison growth. To begin, recent growth in the stock of federal prisoners did not involve significant growth within all offense categories. In fact, there was almost no growth in the numbers of prisoners serving time for offenses other than drug, weapons, and immigration violations. In addition, in contrast to our results for state prisons, federal prison growth was not the result of a color-blind shift toward more punitive sentencing. The Anti-Drug Abuse Act of 1986 was one of the major federal actions in the War on Drugs, and it established mandatory minimum sentences for drug possession that appeared to target blacks for particularly punitive punishment. For example, the act put in place mandatory prison sentences for drug possession, but the rules that mapped drugs amounts into sentences made huge distinctions between drugs that are chemically similar but used by different racial groups. The act specifies a five year minimum sentence for either possession of at least five grams of crack cocaine or possession at least 500 grams of powder cocaine. Because powder cocaine is the main ingredient in crack cocaine this 100 to 1 ratio has attracted much attention. Many legal scholars have noted that crack use is much higher in black communities while the prevalence of powder cocaine use is relatively higher in white communities, and they have alleged that the sentencing provisions of the Anti-Drug Abuse Act of 1986 targeted blacks for particularly punitive treatment. ${ }^{53}$

In 2010, President Obama signed the Fair Sentencing Act that greatly reduced but did not completely eliminate disparities in mandatory sentencing provisions among drugs that are chemically similar. However, the rules in the Anti-Drug Abuse Act of 1986 governed sentencing in federal drugs cases for more than two decades.

Also, Rehavi and Starr (2013) demonstrate that racial biases may exist in the Federal system that are not codified in any statutes or guidelines. These authors find evidence that black offenders receive almost $10 \%$ longer sentences than comparable white offenders arrested for the same crimes, and half of this gap can be explained by decisions made before defendants are convicted. Holding constant the characteristics of arrested offenders and the charges in their initial arrest files, federal prosecutors are more than twice as likely to file charges against black defendants that carry mandatory minimum prison sentences. Because

\footnotetext{
${ }^{52}$ See Figure 17 in Wasem (2013).

${ }^{53}$ See Alexander (2012) for an extensive discussion of this issue and related aspects of the War on Drugs.
} 
the Rehavi and Starr (2013) data set begins in 2006, it is not possible to know whether or not federal prosecutors became more biased over time, but the implications of the biases they identify for steady-state ratios of blacks to whites in federal prisons are significant.

In our analyses of state prison growth, we have no information about charges filed, plea bargains, acquittals, or convictions. We only have data on arrests and prison spells. As we note above, this limits our capacity to know which arrested offenders entered prison as convicted offenders found guilty of specific crimes. However, the Rehavi and Starr (2013) evidence points to an advantage of our approach. Their results demonstrate that judges and parole boards are not the only actors who influence the punitiveness of corrections policies. Prosecutorial decisions also matter, and in settings where many crimes are associated with sentences that are both presumptive and harsh, prosecutors may find it easier to extract guilty pleas to lesser charges. Thus, even if we had access to clean samples of convicted offenders and their convictions offenses that allowed us to build a more detailed model of the criminal justice system, we would still want to use samples of arrested offenders as the baseline inputs for our simulations.

\section{JAILS}

While federal prison population grew even faster than state prison populations over the past three decades, jail populations grew at similar rates, at least over the long term. Table 6 shows that in 1985, there were 1.8 inmates in state prisons for every inmate in local jails. In 1990, 1995, 2000, 2005, and 2011, this ratio equaled 1.74, 2.02, 1.99, 1.78, and 1.87 respectively. Thus, jail populations follow roughly the same long-term trends as state prison populations.

Without more detailed information on the movements of prisoners between jails and prisons, it is not possible to know exactly why jail stocks track prison stocks so closely. Some sentenced prisoners serve time in jail while awaiting transfer to state prisons, and other convicted prisoners with short sentences actually serve their entire sentences in jail without ever entering state prison. Thus, it seems reasonable to expect that the move to more punitive sentencing that caused prison populations to grow also increased jail populations. Nonetheless, more work is required to pin down the different sources of growing jail populations over the past several decades.

\section{InCARCERATION AND ECONOMiC OUtCOMES}

So far, we have established that changes in corrections policy drove the prison boom. Further, at least at the state level, these changes appear to be implemented in a roughly color-blind manner. These policy changes had a much greater impact on black communities than white communities because blacks have long been arrested at much higher rates than whites. 
Given these results, it is natural to ask how these changes in corrections policy have impacted the trajectory of black-white economic inequality, especially among men. We would like to know how the move toward more punitive corrections policies impacted long term trends in employment and earnings for less-skilled men overall and for black men relative to white men.

To examine these questions directly, we would need to isolate inter-state variation in the move toward more punitive corrections policies that is orthogonal to unmeasured variation in state labor market conditions. This data requirement is problematic for at least two reasons. To begin, only a handful of states report NCRP data that are clean enough to permit reliable measurement of how the punitiveness of corrections policies changed over time. Further, recent research suggests that correction policies are influenced by the health of state economies. States are less likely to build new prisons or incur other costs associated with prison expansion during times when the state economy is trending down. ${ }^{54}$

Nonetheless, there is a literature that explores many potential links between the severity of criminal justice policies and labor market outcomes, and we review this literature here before presenting analyses of recent trends in black-white labor market inequality that account for changes in the stock of incarcerated men over time.

In any discussion of the relationships between corrections policies and labor market outcomes, there are two different ways to define the parameters of interest. One could take a population of offenders as given and then explore how the punishments they receive impact their trajectories of employment, earnings, recidivism, and incarceration in the future. In addition however, one could also explore how corrections policies and beliefs about corrections policies impact the decisions of young persons to become involved in crime at all. The existing literature deals almost exclusively with the former exercise and devotes scant attention to the latter. The importance of this omission hinges on the degree to which young persons may be deterred from criminal activity by the prospects of future punishments.

We review not only studies that examine the future employment and earnings outcomes of offenders but also studies that explore recidivism. While our main focus is the link between corrections policies and future economic outcomes for offenders, we review the recidivism literature for two reasons. First, time spent in criminal activity is time not spent in legal employment. So, mechanisms that imply causal impacts of corrections policies on recidivism may simultaneously imply causal effects of corrections policies on future earnings and employment. Second, the decision of non-employed individuals to allocate time to criminal activity that could be allocated to market work or job search may be a signal that these individuals face bleak future prospects in the formal labor market.

It is logically possible that harsh criminal justice policies improve the labor market outcomes of less-skilled men. To the extent that harsh expected punishment lowers the expected

\footnotetext{
${ }^{54}$ See Pew Center on the States (2010).
} 
return from illegal work relative to legal work, punitive sentencing and corrections policies may induce young men to work more and build skills that make market work more rewarding in the future. Further, many prisoners have drug problems or mental health challenges that simultaneously make them less fit for market work and more prone to crime, and rehabilitation and counseling programs in prisons may help such prisoners. Finally, education and job training programs offered in prisons may give prisoners the opportunity to build skills that employers value.

However, there are also many reasons to expect that a move to more punitive corrections policies could harm the labor market outcomes of young men. To begin, decisions by prosecutors that increase the number of felony convictions holding constant the crimes committed by arrested offenders increase the number of future job seekers who have criminal records, and a number of studies demonstrate that many employers are reluctant to hire persons with prior felony convictions. Further, the decision to assign more offenders to prison directly lowers employment rates by creating forced separations from existing jobs. In addition, prison time prevents the accumulation of additional work experience and removes offenders from networks of employed people who may provide useful contacts. Finally, prison time may enhance the attachment of offenders to criminal careers. Young offenders who are given prison time instead of probation are exposed to career criminals who may strengthen their attachment to crime by teaching them how to be better criminals or by simply deepening their exposure to organized networks of criminals. ${ }^{55}$

7.1. Labor Market Impacts of Corrections Policies. Holzer (2009) provides an extensive review of the literature that examines how the severity of punishment for offenders affects their subsequent labor market opportunities, and we will not re-examine all of the studies that Holzer discusses here. Instead, we review several themes in the literature and a few studies that deserve particular attention.

Holzer (2009) distinguishes between studies that examine how employers treat ex-offenders and studies that directly measure employment and earnings outcomes for ex-offenders. He correctly notes that the existing literature shows that many employers investigate whether or not their applicants have criminal records, and these employers often state that they are hesitant to interview and hire persons who have been convicted of serious crimes. This literature does not speak to the effects of more frequent use of prison time as a sanction for convicted felons, per se, because the focus is on the effects of having a criminal record. However, sentencing laws may impact conviction rates through the plea bargaining process. When prosecutors are able to threaten arrested offenders with more severe potential punishments, they may be better able to extract guilty pleas that result in felony convictions, even if the offenders receive probation or short prison terms in exchange for their pleas.

\footnotetext{
${ }^{55}$ See Bayer, Hjalmarsson, and Pozen (2009).
} 
Holzer (2009) divides studies that evaluate the impacts of prison time on future labor outcomes into two categories: those that rely on panel data from surveys and those that rely on administrative data. He correctly notes that most of these studies find that increases in the severity of punishment offenders receive are associated with negative impacts on future labor market outcomes. ${ }^{56}$

However, one well-designed study did not fit this pattern. Kling (2006) finds that, given admission to prison, the length of time-served does not have important negative impacts on future labor market outcomes. The key concern about most studies in this literature is that the variation in the punishments that observationally similar offenders receive is correlated with unmeasured traits of the offenders that also impact labor market outcomes directly. To address this issue, Kling employs controls for earnings histories prior to prison entry, and he uses the identity of judges as a source of exogenous variation in sentence lengths. Kling's figures show a clear jump in employment and earnings in the year that sentences are scheduled to end, and these figures also show that earnings and employment rates converge to a common post-release level regardless of how long an offender stayed in prison before release. Kling's post-release panel is short, and his results do not rule out negative life-cycle impacts of enhanced sentences, but his study remains a noteworthy exception to the general pattern of results in this literature. ${ }^{57}$

In sum, the existing literature provides considerable evidence that some employers are hesitant to consider applications from convicted felons. Further, many studies provide suggestive evidence that punitive sanctions harm the future labor market prospects of offenders, and no studies provide evidence that serving time in prison as opposed to serving time on probation or parole improves the future labor market prospects of offenders. Nonetheless, the Kling (2006) study raises the possibility that, among those who enter prison, actual time-served is not an important determinant of future labor market outcomes. ${ }^{58}$

7.2. Market Level Impacts. As we note above, it is almost impossible to identify the causal impacts of a move to more punitive corrections policies on earnings and employment outcomes at the market level. However, Holzer, Offner, and Sorenson (2005) do show that,

\footnotetext{
${ }^{56}$ See Grogger (1995), Raphael (2007), and Western (2002) as examples.

${ }^{57}$ For those serving longer prison spells, the initial jumps in earnings upon release are higher and the declines from these peaks are faster and more dramatic. Because Kling has relatively few post-release observations for those who served sentences of four years or more, it is possible that the earnings and employment levels for these groups continued to decline beyond the end of the sample period even though the earnings and employment levels for those serving short sentences appear to stabilize before the end of the sample period. ${ }^{58}$ It is even more difficult to know how the prison boom has affected the spouses of inmates as well as their children, and how these effects will impact future generations. Wildeman and Western (2010) review the literature on this topic, and while they highlight the challenges of isolating truly causal effects of incarceration on families, they review many findings that point to the possibility that spouses and children may suffer when changes in criminal justice policies increase incarceration rates. This is particularly true of policies that increase incarceration rates for non-violent offenders. Johnson (2009) produces related findings using data from the Panel Survey of Income Dynamics.
} 
within states over time, changes in employment and labor force participations rate among less-educated, black men under age 35 are negatively correlated with past growth in prison populations. These correlations remain given many different controls for factors that may influence state-specific employment trends. Although these results do not establish a causal relationship between corrections policies and future employment rates for less-skilled men, they do show that, on average, the within state correlation between prison growth and future employment growth is what one would expect given the assumption that serving prison time does harm the labor market prospects of offenders.

7.3. Punitiveness and Recidivism. The Kling (2006) study is unique because few studies that address the links between punishments and future labor market outcomes actually have access to data on a plausibly exogenous source of variation in the severity of punishments. But, a number of recent recidivism studies also use judge assignment to isolate exogenous variation in the severity of punishments given the severity of offenses. We review these studies here because the choice of recidivists to engage in criminal activity may be correlated with failure to secure legal employment. In Chapter 7 of their book, Raphael and Stoll (2013) provide a more extensive review of the entire literature on causal links between incarceration rates and crimes rates.

Aizer and Doyle (2013) exploit random assignment of juvenile offenders to different judges to isolate exogenous variation in assignment to incarceration among observationally similar offenders. They find that the use of incarceration as a punishment for juveniles significantly increases the likelihood of adult incarceration. In contrast, Green and Winik (2010) follow over 1,000 drug defendants and conclude that variation in assignment to incarceration versus probation induced by random assignment to different judges did not impact future arrest rates. Di Tella and Schargrodsky (2013) employ a similar research design using data on adult offenders from Argentina. They conclude that the use of electronic monitoring as a substitute for incarceration significantly lowers rates of recidivism. ${ }^{59}$

The literature does not speak with one voice, but on balance, these studies suggest that when prosecutors and judges make decisions that result in prison time instead of probation for marginal offenders, these marginal offenders become more likely to engage in future criminal activity that leads to future arrests and incarceration. By definition, these periods of future incarceration cannot be periods of future employment and are thus suggestive evidence that the use of prison as punishment harms the labor market prospects of offenders.

Our analyses of NCRP data demonstrate that the rise in prison populations primarily reflects changes in public policies that shape the punishment of arrested offenders. The results in Tables 1-4 demonstrate that employment rates among less educated men generally, and less-educated black men in particular, have fallen dramatically as prison populations

\footnotetext{
${ }^{59}$ Chen and Shapiro (2007) employ a regression discontinuity model to examine the effects of assignment to federal prisons of different security levels. They find some evidence that harsher prison conditions do not deter future offending and may actually increase recidivism.
} 
have exploded. We are not able to make precise statements about how much recent changes in corrections policies contributed to changes in overall labor market inequality or blackwhite inequality in particular. However, the balance of the existing literature suggests that the policies that caused the prison boom may well have generated negative labor market consequences for those arrested in recent decades, and black men experienced much higher arrest rates than white men over this period.

Finally, whatever one believes about the causal impacts of corrections policies on the labor market outcomes of offenders, we demonstrate, in the next section, that researchers who seek to document recent labor market trends among men must account for the prison boom. Researchers can no longer construct accurate measures of overall inequality or blackwhite inequality without properly accounting for the missing data problem created by mass incarceration.

\section{Measuring Black-White Inequality Over Time}

Most of the Smith and Welch (1989) results came from 1940-1980 long-form census files, but they also provided results from the Current Population Surveys (CPS). Smith and Welch (1989) used CPS data from the 1980s to demonstrate that black-white wage inequality remained roughly constant during the period 1980-1986. They concluded that, although black men had not made further progress during the 1980s, they had not given back the gains made in previous decades. Thus, the almost half century period 1940-1986 contained a record of significant absolute and relative economic progress for blacks. ${ }^{60}$

The CPS program has long been the source of many government statistics on labor force participation, unemployment, and earnings, and CPS data were the best source of information about 1980 labor market trends available to Smith and Welch (1989). Yet, for more than a decade, subsequent scholars have argued that the prison boom, which began around 1980, has created an environment such that CPS data provide a grossly incomplete picture of labor market inequality among men. Because the CPS program draws samples from the non-institutionalized population, researchers who rely on CPS data to measure employment rates cannot count prisoners among the non-employed. Further, because prisoners tend to be less educated and from minority populations, standard measures of labor market inequality between racial and education groups may be significantly biased by the systematic omission of prisoners.

The literature on how race-specific trends in non-employment may contaminate measured trends in black-white gaps in earnings or wages begins with Butler and Heckman (1977). The literature is large, and we will not review it all here. Instead, we review a set of studies

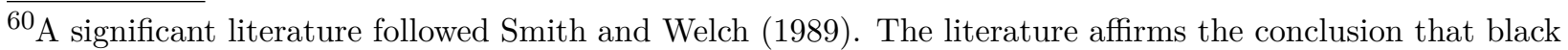
Americans made important relative economic progress during much of the 20th century. However, the literature contains serious debate over the relative importance of different forces as contributing factors to black progress. See Card and Krueger (1992) and Donohue and Heckman (1991).
} 
that came after the prison boom of the 1980s and devote specific attention to the growing number of incarcerated persons missing from the CPS sampling frame.

Chandra (2000) is among the first economists to raise the possibility that different trends in institutionalization rates by race are an important source of selection biases that contaminate standard measures of how black-white earnings differences have evolved over time. He uses data from the 1940-1990 census files, and he employs three different imputation rules for non-workers. The first follows the approach developed by Brown (1984). It assumes that all non-workers have wage offers from the bottom half of their race-specific unconditional offer distributions and that offers follow a log normal distribution. The results from this procedure imply that between 1970 and 1990, the black-white ratio of mean wage offers actually fell slightly between 1970 and 1990 even though the ratio of mean observed wages rose from .69 to .75. The other two methods involved within-cell imputations. Chandra (2000) defines cells using the intersection of age and education groups. The imputations involve either the mean or minimum of observed wages in each cell. These imputation rules do not produce estimates of black-white ratios of mean wage offers that differ dramatically from black-white ratios of observed wages. However, the results still imply that black-white wage ratios of observed mean wages are larger than the corresponding ratios of mean wage offers and that the gap between these two ratios grew between 1970 and 1990.

Neal (2006) employs data from the 1960-2000 census files. He divides the data into cells defined by the intersection of schooling levels and potential experience levels. He assumes that the mean log of potential earnings for those employed in the previous calendar year is .4 greater than the corresponding mean for those who are either institutionalized or simply not employed. The basic methodology is similar to the approach that Smith and Welch (1989) used to address the possibility that falling black employment rates after 1970 bias measures of trends in black wage growth after 1970. Neal settled on the 4 after examining the wages of men in the National Longitudinal Survey of Youth 1979 (NLSY79) who worked in some years but also reported no earnings for a number of calendar years.

For all but the groups with the most education and potential work experience, the Neal (2006) imputation rules imply that the absolute values of black-white gaps in log potential earnings are larger in 2000 than in 1970, and in most demographic cells, this pattern does not hold for gaps in observed log earnings among the employed. Further, by 2000, the differences between observed black-white earnings gaps and the implied gaps in potential earnings are often quite large among workers with a high-school education or less, i.e. these differences typically imply that the gap in potential earnings is from one fifth to one third larger.

Becky Petitt and Bruce Western, along with several co-authors, have done the most extensive work on this topic. ${ }^{61}$ Here, we review the results from one of their more recent and comprehensive efforts. Pettit, Sykes, and Wester (2009) depart from the approaches above

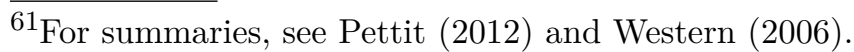


by employing different data. They do not use census files to capture the institutionalized population. Instead, they estimate the population characteristics of prisoners using several annual surveys of prisons and jails, and then assume that growth in the number of prisoners in various demographic groups follows the same trajectories as the trajectory of total prisoners. Then, they add estimates of the annual stocks of prisoners in different demographic cells to annual CPS samples and form adjusted wage measures by making different assumptions about the potential wages and earnings of incarcerated persons. The three imputation rules they employ are: (i) assign all non-workers the mean potential wages of workers who share the same race, age, gender, and education, (ii) follow assignment rule (i) for non-workers who are not institutionalized and assign mean potential wages for inmates based on several surveys of inmates that gathered information about labor market outcomes prior to imprisonment, and (iii) assign zero wages to all non-workers. They perform these analyses separately for ages 22-64 and ages 22-30. They produce results for years 1980-2008.

In all specifications, black-white gaps in mean log hourly wages are larger in absolute value in 2008 than in 1980. As a whole, the results clearly indicate that blacks fared relatively better during the 1990s than during the 1980s or the period 2000-2008. Still, it is hard to draw precise conclusions from these results. The implied amount of increase in black-white inequality is much larger given specification (iii) than specifications (i) or (ii). In fact, the black-white wage gap for 2008 based on (iii) is roughly double the gap that results from method (ii) even though the gap based on (iii) is only about 50\% larger in 1980 .

The first two approaches are conservative adjustments for selection. Non-workers who are not in prison always receive the average wages of similar workers as their wage offers, and the information used to form imputed wages for prisoners comes from those prisoners who were employed prior to entering prison. At the same time, the authors acknowledge that assigning wages of zero to all non-workers is an extreme adjustment for selection.

In sum, these methods all produce results that suggest standard measures of black-white wage inequality overstate the relative economic success of blacks in recent decades by ignoring the selection bias created by the prison boom. However, these results do not pin down how large this bias likely is.

8.1. Imputation Methods. Here, we also pursue an imputation strategy, but we do not focus on gaps in mean wages or mean log wages. Instead, we focus on the ratio of the median potential wage for black males to the median potential wage for white males in various demographic groups.

We focus on medians because medians have important robustness properties with respect to imputation rules that researchers use to deal with missing data problems. Suppose that a researcher has data on a sample of size $N$, and for $M$ observations in this sample, data on the variable $W$ is missing. If $\frac{N-M}{N}>.5$, the researcher can recover the true median of $W$ for the entire sample if the researcher knows only the fraction of the missing observations, 
$\alpha$, that fall above the true median. Given this information, the researcher can create an imputation sample by assigning the highest observed $W$ to $\alpha M$ of the records with missing values while assigning the lowest observed $W$ to the remaining $(1-\alpha) M$, and the median $W$ in this imputation sample will be the median of the true $W$ values over all records in the full sample. The researcher does not require any additional information about the distribution of the missing values. As long as $\frac{N-M}{N}>.5$, knowledge of $\alpha$ alone provides enough information to recover the median of $W$ over the full sample.

In Tables 10 and 11, we exploit this result to produce numerous estimates of ratios of black median potential weekly wages to white median potential weekly wages. Our goal here is to describe economic inequality that reflects inequality in labor market opportunities for men. Thus, we want to consider men who are in what should be their prime working years. We want to focus on persons who are finished with schooling and persons who are not in a period of transition to retirement. To this end, we group men by potential experience categories, and we focus on men with between 6 and 25 years of potential work experience.

We use data from the ACS and Census that describe earnings and weeks worked in the previous year, and we calculate weekly earnings as our wage measure. We do not compute hourly wages because data on hours worked from these sources is quite noisy and because we want to accommodate the possibility that some workers are willing but not able to secure full-time jobs.

For years 1980 and beyond, we also employ data from the CPS-Merged Outgoing Rotation Groups (MORG) files in combination with data from the Census or ACS. The Census and ACS are advantageous because they include both military and institutionalized populations. However, they are also pencil and paper surveys, while the MORG involves interaction with an interviewer and more probing questions about rates and modes of pay. Therefore, we drop all non-institutionalized civilians from the Census and ACS who are both employed during the survey week and employed during the previous calendar year. We then replace these observations with observations from the corresponding MORG files, and we multiply the sampling weights for these MORG observations by the ratio of the total populations represented by the two samples. Thus, the MORG observations that we insert represent the same number of persons that we drop from the ACS. Results based on these composite samples are presented in brackets to the right of our main results.

The thought experiment here is to describe black-white differences in median potential wages for samples of men defined by potential experience levels. For men who are not working and not institutionalized, we focus on the likelihood that the weekly wage they would earn if they took the best job available to them is above the median potential wage for men of their same race and potential experience. For men who are institutionalized and report no employment during the previous year, we take two different approaches. The first, presented in Table 10, treats institutionalized workers like any other non-employed persons. Here, we define "potential weekly wage" as the wage available to a given worker if the worker was 
not institutionalized, and we further assume that the distribution of potential wages among the institutionalized is the same as the distribution among other observationally similar men who are not employed.

Table 11 presents results from our second approach. Here, we define the "potential weekly wage" values among institutionalized men as the wages available at jobs they can claim within their institutions. Given the wages paid for jobs in prisons or homes for adults with disabilities, we feel confident that these potential wages are all below the relevant median potential wages for each race-experience cell.

Tables 10 and 11 follow the same format. Each panel presents results for samples of workers that share similar levels of potential work experience. Each row presents results for a different year. The data for 1960-2000 come from census long form files. The data for 2007 and 2010 come from the American Community Survey. We include the 2007 results to demonstrate the effects of the Great Recession on black-white inequality.

The columns describe different mixing rules. The column (10/25) presents results based on the assumption that 10 percent of black men in a given cell who do not work actually face wage offers above the median wage offer for the cell while the corresponding figure among white men who do not work is 25 percent. The column $(25 / 10)$ reverses these imputation rules by race. The column (15/15) uses a common imputation rule for white and black men. The Raw column presents the ratio of median observed black earnings to median observed white earnings. These results are equivalent to those one would obtain by using a (50/50) imputation procedure. The final six columns give the fractions of men who report employment, who are institutionalized and do not report employment in the previous year, and who are not institutionalized and do not report employment in the previous year. ${ }^{62}$

The (15/15) rule is our preferred specification based on exploratory analyses of the wage histories of men in the National Longitudinal Survey of Youth (1979). These men were ages 35-43 during their 2000 interviews, and for those who did not report employment in 2000, we look to the 1996, 1998, 2002, and 2004 surveys for information about their potential wages in 2000. The NLSY sample covers only seven birth cohorts, but the patterns in the 1996 to 2004 data suggest that the $(15 / 15)$ rule is a reasonable benchmark. We offer the $(10 / 25)$ and $(25 / 10)$ results to place what we contend are plausible bounds on black-white ratios of median wage offers given the reported wages, patterns of non-employment, and patterns of incarceration in the Census and ACS data. ${ }^{63}$

\footnotetext{
${ }^{62}$ Here, the relevant census employment question inquires about employment in the calendar year prior to the April administration of the census. In the ACS, the parallel question refers to employment in the twelve months prior to the respondent's interview date. Between 2000 and 2007, the decline in the fraction of men who are institutionalized and not working reflects, in part, a non-trivial increase in those who are institutionalized but yet report recent employment. We have no way to determine whether or not the different conventions used in the ACS and census to inquire about employment in the last year contribute to this pattern since the ACS did not include institutionalized persons until 2006.

${ }^{63}$ We use three rules to create a sample of wage offers for the NLSY79 men. First, we collect reported wages for those who report jobs in 2000. Second, for those who were not working in 2000 but did report a wage
} 
Several patterns stand out in Tables 10 and 11.

First, even in 1960, white male employment rates exceeded those of their black peers, and black-white gaps in median observed wages slightly overstated the relative potential wages of black men. However, black employment rates were around 90 percent for all four experience groups in both 1960 and 1970, so our results are not terribly sensitive to the imputation rules we employ.

Second, when assessing the relative progress of black men during the 1960s, our selection corrected results often imply even greater black relative progress during the 1960s than one would infer from changes in medians of observed wage distributions. This is clearly true for those with 11-25 years of potential experience. In these groups, institutionalization rates fell during the 1960s for both black and white men, but the declines were greater among black men. Further, among both white and black men, employment rates in these potential experience groups were roughly the same in 1970 as in 1960.

Third, after 1970, differences between the ratios of observed median wages and our selection corrected ratios grow over time. By 1990, we see noteworthy differences between the raw ratios of observed median wages by race and all of our selection corrected ratios. Note that the corrected ratios in the $(25 / 10)$ column likely overstate the relative wage offers of black men, but these ratios are less than the corresponding entries in the Raw column for all experiences groups in each year from 1990 through 2010, and if we consider the (15/15) results for 1990 in Tables 10 and 11, the differences between our selection corrected ratios and the ratios of raw observed medians range from roughly .06 to .10 in absolute values.

Fourth, among workers with less than 15 years of potential experience, it is hard to escape the conclusion that black-white ratios of median potential wages in 2010 were, at best, comparable to the corresponding ratios in 1970. Among workers in these first two experience groups, the entries in each of the first three columns of Table 11 are smaller in 2010 than in 1970, and the same pattern holds for four of six comparisons in Table 10. These results are particularly noteworthy since the ratios of observed median wages among employed men, i.e. the results in the Raw column, suggest that black men of all potential experience levels made significant relative progress during the 1970-2010 period.

Fifth, our selection corrected ratios suggest that, between 1970 and 2010, black men with 16-25 years of potential experience enjoyed trivial net growth in median potential wages relative to their white counterparts. This result holds even though employed black men made substantial wage gains relative to employed white men during this period. Within five of the six columns of Table 11 that describe results for workers with 16-25 years of

in 1996, 1998, 2002, or 2004, we record the wage report most proximate to the 2000 interview. Finally, for those who never report employment between 1996 and 2004, we impute wages of one dollar per hour. We divide this sample of wage offers by race and find that 14 percent of white men and 15 percent of black men who are not working in 2000 report a wage in the 1996, 1998, 2002, or 2004 samples that is above the median wage offer in our race-specific samples. The corresponding results for the 75 th percentile are 4 percent for white men and 7 percent for black men. 
experience, the absolute differences between our selection corrected ratios for 1970 and 2010 are less than .02 .

So far, we have discussed our results by examining different imputation rules while implicitly assuming that patterns of selection did not change over time, i.e. we have discussed patterns within the columns that describe our three imputations rules. However, it is possible that selection patterns did change over time and that, across years within a particular potential experience group, our best estimates do not come from a single column. Thus, we must ask whether or not it is possible to construct some scenarios involving changes in patterns of selection over time that imply significant relative black progress between 1970 and 2010.

The results in Table 11 suggest that it is difficult to pick any combinations of our results that imply significant and lasting improvement in black-white potential wages after 1970. Given observed black-white differences in employment and incarceration rates, the (10/25) results yield the smallest corrected ratios and the (25/10) results yield the largest corrected ratios for each cell defined by year and level of potential experience. Note that, among those with 15 years of potential experience or less, the (10/25) results for 1970 are within .01 of the $(25 / 10)$ results for 2010. Among those with 21-25 years of potential experience, the corresponding comparisons imply relative potential wage growth for black men of just over .03. And, while the same exercise for those with 16-20 years of potential experience does imply growth of almost .08, it is important to note that this figure falls to just over .01 if we instead compare the 10/25 results for 1970 to the $15 / 15$ results for 2010 .

In sum, when comparing 1970 and 2010, we can rule out any form of black relative progress in potential median wages that involves significant gains for black men in all potential experience groups. Further, only a rather extreme scenario that involves dramatic changes in patterns of selection over time allows us to entertain the possibility of significant gains for a single potential experience group.

Sixth, while our fourth and fifth points taken together point to the conclusion that black men likely made little relative economic progress between 1970 and 2010, it is important to note that there were ups and downs. Our results are squarely in line with the view that black relative progress was anemic at best in the 1970s and 1980s. However, for black men with 6-20 years of experience, the 1990s were a decade of noteworthy relative progress, and this result holds for all of our measures, even though black men with 21-25 years of experience appear not to have gained ground on white men during this same period. Our results show mixed and small changes in relative black potential wages during the period 2000-2007, but the decline in the labor market prospects of black men relative to white men during the Great Recession is quite dramatic.

Seventh, the patterns present in the composite files that contain MORG wage observations imply even bleaker trends for black men relative to their white counterparts. The MORG files are not available for 1970 and 1960, so we must restrict our composite analyses to the 
period 1980-2010. To begin, note that in every cell, the 1980 black-white ratio is higher given the composite data. However, more than half of the black-white ratios for 2010 are smaller given the composite data. Further, every set of selection corrected results based on the composite data imply that the relative wages of black men either remained roughly constant or fell notably between 1980 and 2010. Finally, given each of our three imputation rules, the results based on composite data imply even worse relative trends for black men with between 6 and 25 years of experience.

The type of imputation methods we employ here are not the right vehicles for assessing movements in the lower quantiles of potential wages distributions. In 2010, black nonemployment rates were more than 25 percent in all four experience groups, so it is not even possible to recover black-white ratios at the 25 th percentile of potential wage distribution using imputation procedures like ours. However, Tables 3 and 4 provide clear indications that less skilled black men have lost ground relative to their white counterparts since 1970. Employment rates have fallen and institutionalization rates have risen for less skilled men of all races, but these trends have been truly dramatic among less skilled black men. Recent gaps in employment rates and institutionalization rates between black and white high school dropouts are quite large and strongly suggest that less skilled black men are now worse off relative to their white counterparts than they were in 1970.

Taken as a whole, the representative working-age black man (in terms of medians) appears to have made no potential wage gains relative to his white counterpart during the 1970-2010 period, while less-skilled black men saw their employment rates fall and their incarceration rates rise relative to their white counterparts. Unless black men at the top of the skill distribution enjoyed large gains, it seems quite likely that black men lost ground relative to white men between 1970 and 2010 .

In Table 12, we present results for the ratio of black wages to white wages at the 75 th and 90th quantiles of the respective potential wage distributions. We present four sets of results for the ratios of 75 th percentile wage offers. The first, $(0,5)$, imposes the assumption that five percent of the missing white wage observations are above the corresponding 75 th percentile values in the white distributions of potential wages. The $(0,0)$ column imposes the assumption that none of the missing wages are above the race-specific 75 th percentiles in the corresponding potential wage distributions. The $(5,0)$ column reverses the rule used in the first column. The Raw column presents ratios of the 75 th percentile observations in the racespecific distributions of observed wages. For the 90th percentile, we consider only the $(0,0)$ imputation rule. In both cases, these imputation rules apply to missing wages among those who are not institutionalized. We restrict the potential wages of institutionalized persons to be below the 75 th or 90 th percentiles of the corresponding potential wage distributions, respectively.

The theme of Table 12 is quite clear. The 1970s were a time of significant progress for black men in the top quarter of the black potential wage distribution. However, black men 
at the top of the potential wage distribution lost ground relative to whites between 1980 and 2010, and in many cases, these losses were noteworthy. Over the entire period 1970 to 2010, we see no relative black improvement at the 75 th percentile, and at the 90 th percentile, we only see noteworthy black relative gains among workers with more than 15 years of potential experience.

\section{CONCLUSION}

More than two decades ago, Smith and Welch (1989) used the 1940 through 1980 census files to document important relative black economic progress among men, but this progress did not continue. Our analyses of labor market outcomes suggest that, although there were periods of relative progress for black men after 1970, black-white differences in potential wages among most groups of men in 2010 were comparable to the corresponding differences observed in 1970 and greater, in absolute value, than those recorded in 1980.

Since 1980, prison populations have grown tremendously in the United States, and here, we show that, at least for the seven states that provide fairly reliable NCRP data, this growth was driven by changes in policy that influenced the distribution of punishments that arrested offenders expect to receive. This move toward more punitive treatment of offenders involved a shift toward harsher punishment for those arrested in each major crime category. Further, although these changes in policy increased expected punishments for arrested offenders of all races, they have had a much larger impact on black communities than white communities because arrest rates have historically been much greater for blacks than whites.

Many factors other than the prison boom affected wage inequality overall and between blacks and whites in recent decades. A significant literature explores the role of technical change as a driver of labor market inequality in recent decades, ${ }^{64}$ and the Great Recession has had important impacts on both black-white inequality and overall earnings inequality. Nonetheless, the literature we review in section 7 provides much suggestive evidence that prison spells harm the future labor market prospects of arrested offenders, and black men likely now face worse labor market prospects relative to white men than they faced when policy shifts in the late 1970s and early 1980s ignited the prison boom. More research is needed to determine whether or not the changes in corrections policy that drove prison growth have significantly harmed the employment and earnings prospects of less skilled men, and less-skilled black men in particular. In addition, economists need to carefully investigate the intergenerational consequences for families and communities of policy changes that promote mass incarceration.

\footnotetext{
${ }^{64}$ See Acemoglu and Autor (2011).
} 


\section{REFERENCES}

Acemoglu, D., And D. Autor (2011): "Skills, Tasks and Technologies: Implications for Employment and Earnings," in Handbook of Labor Economics, Vol. 4, ed. by O. Ashenfelter, and D. E. Card, pp. 1043-1171. Elsevier.

Aizer, A., And J. J. Doyle (2013): "Juvenile Incarceration, Human Capital, and Future Crime: Evidence from Randomly-Assigned Judges," NBER Working Paper 19102.

Alexander, M. (2012): The New Jim Crow: Mass Incarceration in the Age of Colorblindness. The New Press, New York, NY.

Auerhahn, K. (2002): "Selective Incapacitation, Three Strikes, and the Problem of Aging Prison Populations: Using Simulation Modeling to See the Future," Criminology \& Public Policy, 1(3), 353-388.

Bayer, P., R. Hualmarsson, and D. Pozen (2009): "Building Criminal Capital Behind Bars: Peer Effects in Juvenile Corrections," Quarterly Journal of Economics, 124(1), 105147.

Blumstein, A., And A. J. Beck (1999): "Population Growth in U.S. Prisons, 1980-1996," Crime and Justice, 26, 17-61.

Bonczar, T. P., And A. J. BeCK (1997): "Lifetime Likelihood of Going to State or Federal Prison," Bureau of Justice Statistics.

Brown, C. (1984): "Black-White Earnings Ratios Since the Civil Rights Act of 1964: The Importance of Labor Market Dropouts," Quarterly Journal of Economics, 99(1), 31-44.

Butler, R., And J. J. Heckman (1977): "The Impact of the Government on the Labor Market Status of Black Americans: A Critical Review," in Equal Rights and Industrial Relations, ed. by L. J. Hausman, and F. E. Bloch, pp. 235-81. Industrial Relations Research Association, Madison, WI.

Card, D., and A. B. Krueger (1992): "School Quality and Black-White Relative Earnings: A Direct Assessment," Quarterly Journal of Economics, 107(1), 151-200.

Chandra, A. (2000): "Labor-Market Dropouts and the Racial Wage Gap: 1940 - 1990," American Economic Review, 90(2), 333-338.

Chen, K. M., and J. M. Shapiro (2007): "Do Harsher Prison Conditions Reduce Recidivism? A Discontinuity-based Approach," American Law and Economics Review, 9(1), $1-29$.

DAnsky, K. (2008): "Understanding California Sentencing," University of San Francisco Law Review, 43(2), 45-86.

Di Tella, R., and E. Schargrodsky (2013): "Criminal Recidivism after Prison and Electronic Monitoring," Journal of Political Economy, 121(1), 28-73.

Ditton, P. M., And D. J. Wilson (1999): "Truth in Sentencing in State Prisons," Bureau of Justice Statistics. 
Donohue, J. J., And J. Heckman (1991): "Continuous Versus Episodic Change: The Impact of Civil Rights Policy on the Economic Status of Blacks," Journal of Economic Literature, 29(4), 1603-1643.

Durlauf, S. N., And D. S. Nagin (2010): "The Deterrent Effect of Imprisonment," in Controlling Crime: Strategies and Tradeoffs, ed. by P. J. Cook, J. Ludwig, and J. McCrary, pp. 43-94. University of Chicago Press, Chicago, IL.

Flanagan, A., And D. Grissmer (2002): "The Role of Federal Resources in Closing the Achievement Gap," in Bridging the Achievement Gap, ed. by J. E. Chubb, and T. Loveless. Brookings Institution, Washington, DC.

Frase, R. S. (2005): "State Sentencing Guidelines: Diversity, Consensus, and Unresolved Policy Issues," Columbia Law Review, 105(4), 1190-1232.

Gould, E. D., B. A. Weinberg, and D. B. Mustard (2002): "Crime Rates and Local Labor Market Opportunities in the United States: 1979 - 1997," Review of Economics and Statistics, 84(1), 45-61.

Green, D. P., And D. WiniK (2010): "Using Random Judge Assignments to Estimate the Effects of Incarceration and Probation on Recidivism Among Drug Offenders," Criminology, 48(2), 357-387.

Grogger, J. (1995): "The Effect of Arrests on the Employment and Earnings of Young Men," Quarterly Journal of Economics, 110(1), 51-71.

756-91.

Harcourt, B. E. (2006): "From the Asylum to the Prison: Rethinking the Incarceration Revolution," Texas Law Review, 84, 1751-1786.

Helland, E., and A. Tabarrok (2007): "Does Three Strikes Deter?: A Nonparametric Estimation," Journal of Human Resources, 42(2), 309-330.

Holzer, H. J. (2009): "Collateral Costs: Effects of Incarceration on Employment and Earnings among Young Workers," in Do Prisons Make Us Safer? The Benefits and Costs of the Prison Boom, ed. by S. Raphael, and M. A. Stoll, pp. 239-268. Russell Sage Foundation Publications, New York, NY.

Holzer, H. J., P. Offner, and E. Sorenson (2005): "Declining Employment among Young Black Less-Educated Men: The Role of Incarceration and Child Support," Journal of Policy Analysis and Management, 49(2), 329-350.

Johnson, R. C. (2009): "Ever-Increasing Levels of Parental Incarceration and the Consequences for Children," in Do Prisons Make Us Safer? The Benefits and Costs of the Prison Boom, ed. by S. Raphael, and M. A. Stoll, pp. 177-206. Russell Sage Foundation Publications, New York, NY.

Johnson, R. C., and S. Raphael (2012): "How Much Crime Reduction Does the Marginal Prisoner Buy?," Journal of Law and Economics, 55(2), 275-310. 
Kling, J. R. (2006): "Incarceration Length, Employment, and Earnings," American Economic Review, 96(3), 863-876.

Langan, P. A. (1991): “America's Soaring Prison Population," Science, 251(5001), 15681573.

Lee, D. S., And J. MCCRARY (2009): "The Deterrence Effects of Prison: Dynamic Theory and Evidence," Working Paper.

Levitt, S. D. (1996): "The Effect of Prison Population Size on Crime Rates: Evidence from Prison Overcrowding Litigation," Quarterly Journal of Economics, 111(2), 319-351.

Lofstrom, M., and S. Raphael (2013): "Incarceration and Crime: Evidence from California's Realignment Sentencing Reform," Working Paper.

Marvell, T. B. (1995): "Sentencing Guidelines and Prison Population Growth," Journal of Criminal Law 8 Criminology, 85(3), 696-709.

Marvell, T. B., And C. E. Moody (1996): "Determinate Sentencing and Abolishing Parole: The Long-Term Impacts on Prisons and Crime," Criminology, 34(1), 107-128.

MCCRARY, J. (2010): "Dynamic Perspectives on Crime," in Handbook of the Economics of Crime, ed. by B. L. Benson, and P. R. Zimmerman, pp. 82-106. Edward Elgar Publishing.

MCCrary, J., AND S. SANGa (2012): "General Equilibrium Effects of Prison on Crime: Evidence from International Comparisons," Cato Papers on Public Policy, 2, 165-193.

Murnane, R. J. (2013): "U.S. High School Graduation Rates: Patterns and Explanations," Journal of Economic Literature, 51(2), 370-422.

Myrdal, G. (1944): An American Dilemma. Harper and Brothers, New York, NY.

Nagin, D. S. (2013): "Deterrence: A Review of the Evidence by a Criminologist for Economists," Annual Review of Economics, 5, 83-105.

Neal, D. A. (2006): "Why Has Black-White Skill Convergence Stopped?," in Handbook of the Economics of Education, Vol. 1, ed. by E. A. Hanushek, and F. Welch, pp. 511-576. Elsevier.

Nicholson-Crotty, S. (2004): "The Impact of Sentencing Guidelines on State-Level Sanctions: An Analysis Over Time," Crime 8 Delinquency, 50(3), 395-411.

Owens, E. G. (2009): "More Time, Less Crime? Estimating the Incapacitative Effect of Sentence Enhancements," Journal of Law and Economics, 52(3), 511-579.

Pettit, B. (2012): Invisible Men: Mass Incarceration and the Myth of Black Progress. Russell Sage Foundation Publications, New York, NY.

Pettit, B., B. Sykes, And B. Wester (2009): "Technical Report on Revised Population Estimates and NLSY79 Analysis Tables for the Pew Public Safety and Mobility Project," Working Paper.

Pfaff, J. F. (2011): "The Myths and Realities of Correctional Severity: Evidence from the National Corrections Reporting Program on Sentencing Practices," American Law and Economics Review, 13(2), 491-531. 
Raphael, S. (2007): "Early Incarceration Spells and the Transition to Adulthood," in The Price of Independence, ed. by S. Danzinger, F. Furstenberg, and C. Rouse. Russell Sage Foundation Publications, New York, NY.

Raphael, S., and M. Stoll (2013): Why Are So Many Americans in Prison? Russell Sage Foundation Publications, New York, NY.

Rehavi, M. M., and S. B. Starr (2013): "Racial Disparity in Federal Criminal Charging and its Sentencing Consequences," Working Paper.

Reitz, K. R. (2006): "Don't Blame Determinacy: U.S. Incarceration Growth Has Been Driven by Other Forces," Texas Law Review, 84(7), 1787-1802.

Smith, J. P., And F. R. Welch (1989): "Black Economic Progress After Myrdal," Journal of Economic Literature, 27(2), 519-564.

Stemen, D., And A. F. Rengifo (2011): "Policies and Imprisonment: The Impact of Structured Sentencing and Determinate Sentencing on State Incarceration Rates, 1978 2004," Justice Quarterly, 28(1), 174-201.

Stemen, D., A. F. Rengifo, and J. Wilson (2006): "Of Fragmentation and Ferment: The Impact of State Sentencing Policies on Incarceration Rates, 1975-2002," Working Paper.

The Bureau of Justice Assistance (1996): National Assessment of Structured Sentencing. US Department of Justice, Washington, D.C.

The Pew Center on the States (2010): Prison Count 2010: State Population Declines for First Time in 38 Years. Washington, DC.

The Pew Charitable Trusts (2010): Collateral Costs: Incarceration's Effect on Economic Mobility. Washington, DC.

- (2012): Time Served: The high Cost, Low Return of Longer Prison Terms. Washington, DC.

Wasem, R. E. (2013): "U.S. Immigration Policy: Chart Book of Key Trends," Congressional Research Service.

Western, B. (2002): "The Impact of Incarceration on Wage Mobility and Inequality," American Sociological Review, 67(4), 526-546.

(2006): Punishment and Inequality in America. Russell Sage Foundation Publications, New York, NY.

Wildeman, C., And B. Western (2010): "Incarceration in Fragile Families," The Future of Children, 20(2), 157-177.

Wilson, W. J. (1987): The Truly Disadvantaged: The Inner City, the Underclass, and Public Policy. The University of Chicago Press, Chicago.

Zhang, Y., C. D. Maxwell, and M. S. Vaughn (2009): "The impact of state sentencing policies on the U.S. prison population," Journal of Criminal Justice, 37(2), 190-199. 
Figure 1

\section{Prison Populations for Three Samples}

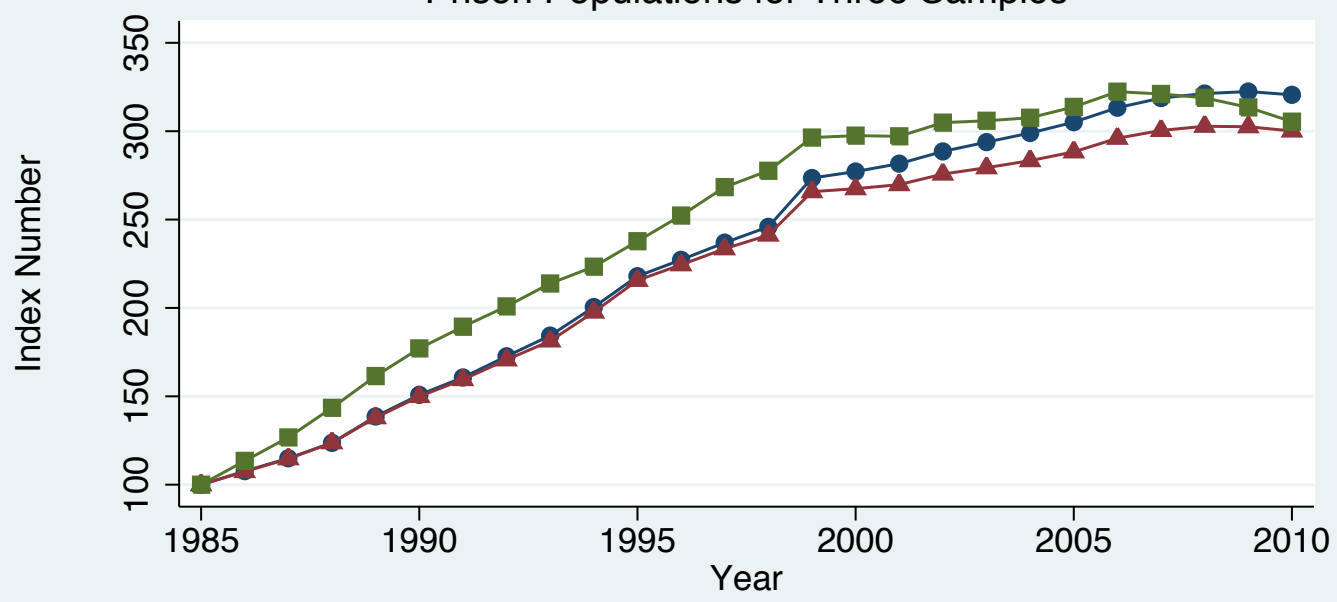

Ths figure shows prison populations for 3 different scopes of the prison system. All data taken from the National Prisoner Statistics program.

The vertical axis is indexed such that 1985 is 100 . 


\section{Figure 2a}

\section{Violent Crimes}

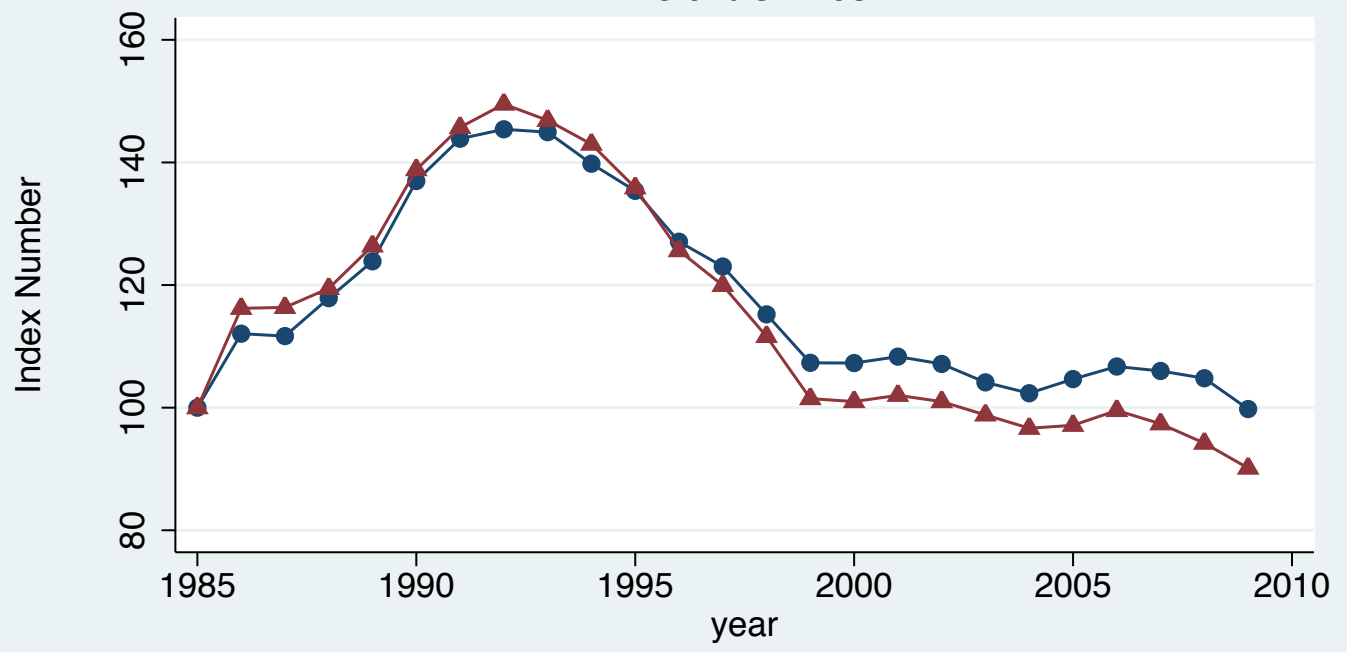

National Estimates

$\mathrm{CA}, \mathrm{CO}, \mathrm{MI}, \mathrm{NJ}, \mathrm{SC}, \mathrm{WA}, \mathrm{WI}$

This figure plots reports of violent offenses (murder, rape, robbery, and assault) as calculated from the FBl's Uniform Crime Reporting program.

The vertical axis is indexed such that 1985 is 100. 


\section{Figure $2 b$}

\section{Violent Arrests}

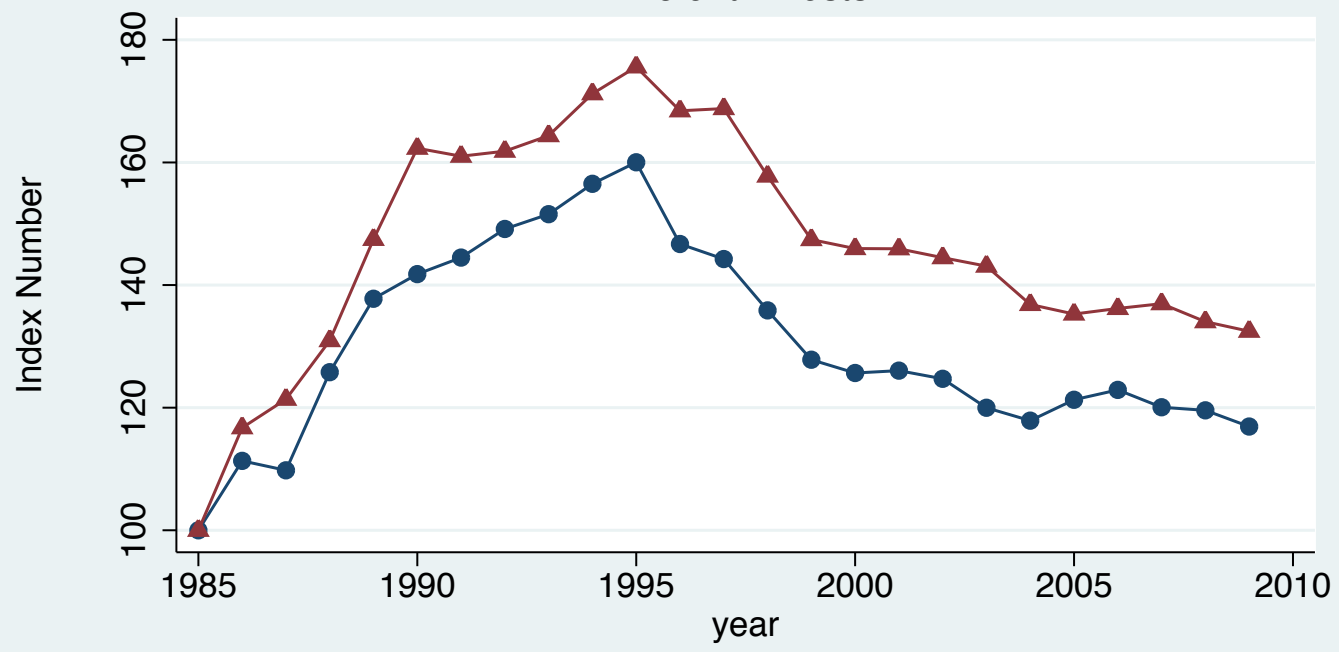

National Estimates

CA, CO, MI, NJ, SC, WA, WI

This figure plots arrests for violent offenses (murder, rape, robbery, and assault) as calculated from the FBI's Uniform Crime Reporting program.

The vertical axis is indexed such that 1985 is 100. 


\section{Figure 2c \\ Property Crimes}

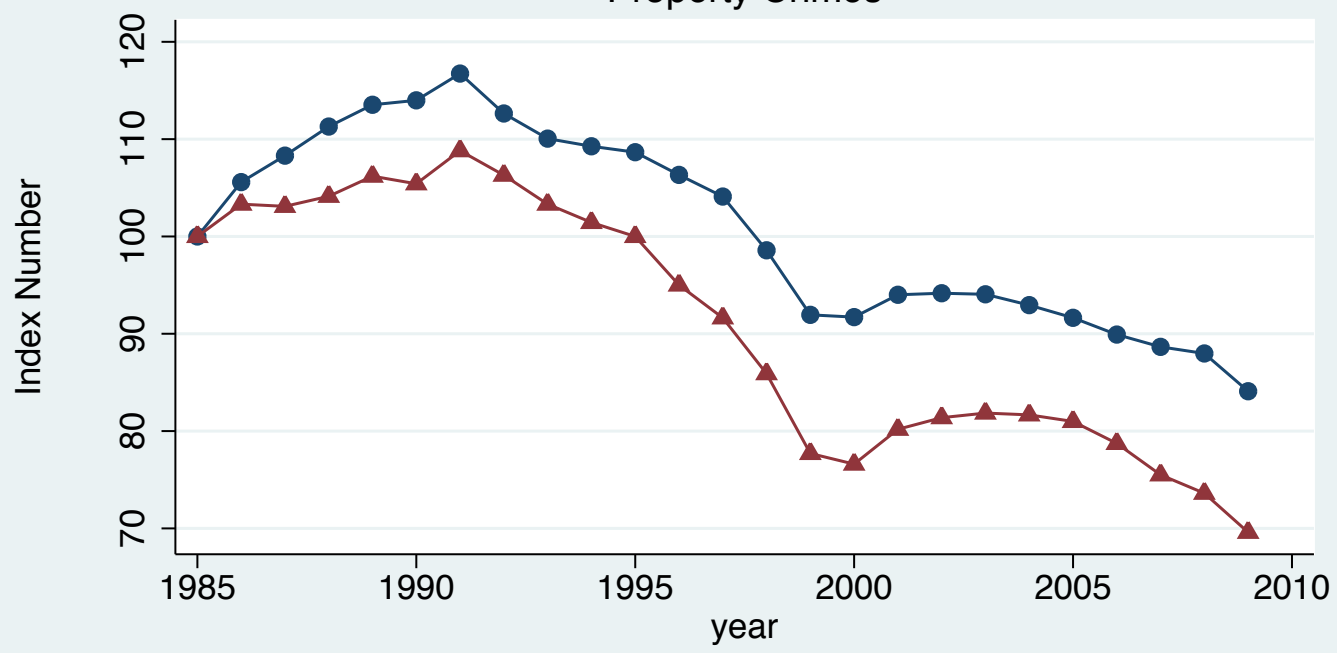

National Estimates

CA, CO, MI, NJ, SC, WA, WI

This figure plots reports of property offenses (burglary, larceny, and motor vehicle theft) as calculated from the FBI's Uniform Crime Reporting program.

The vertical axis is indexed such that 1985 is 100. 


\section{Figure 2d \\ Property Arrests}

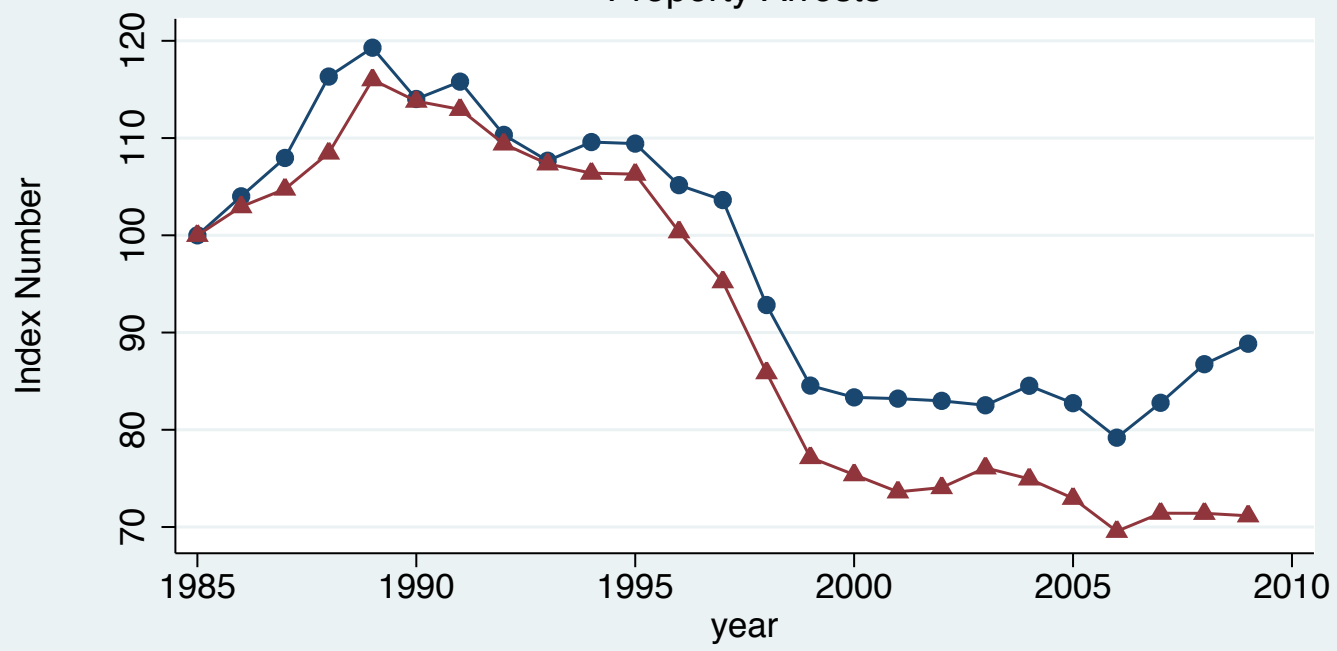

National Estimates

$\mathrm{CA}, \mathrm{CO}, \mathrm{MI}, \mathrm{NJ}, \mathrm{SC}, \mathrm{WA}, \mathrm{WI}$

This figure plots arrests for property offenses (burglary, larceny, and motor vehicle theft) as calculated from the FBI's Uniform Crime Reporting program.

The vertical axis is indexed such that 1985 is 100 . 


\section{Figure $2 \mathrm{e}$ \\ Drug Arrests}

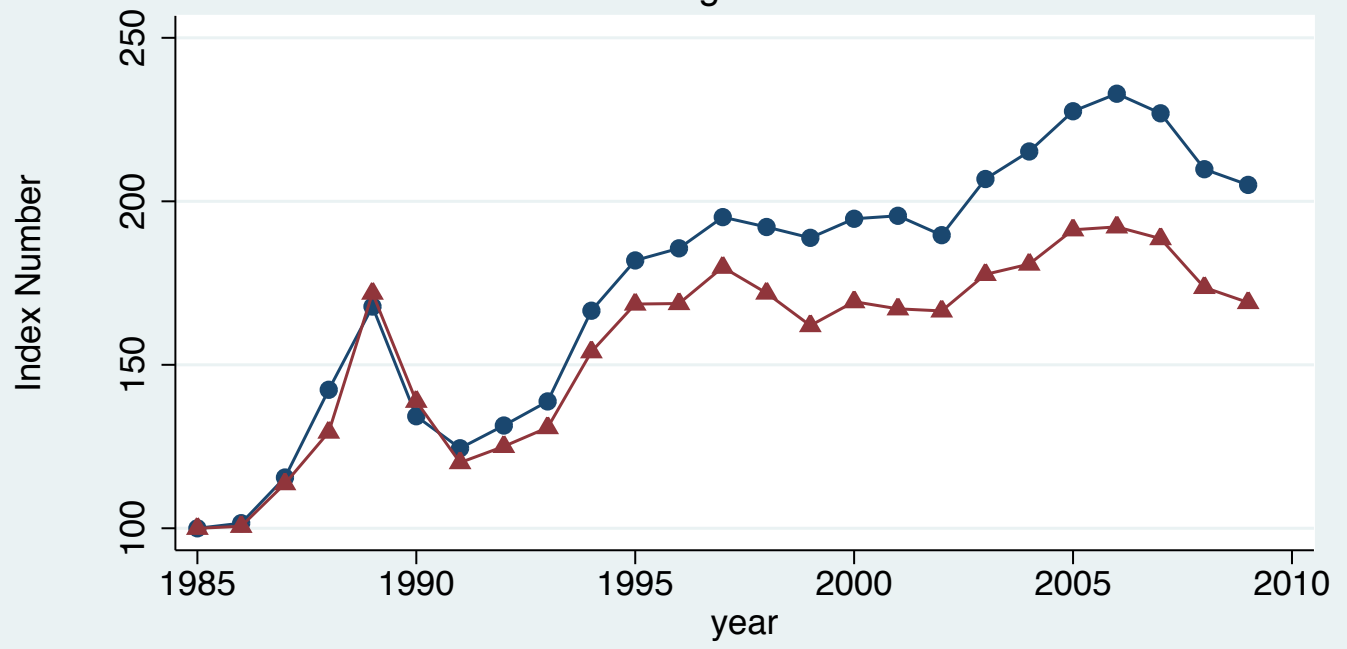

National Estimates

$\mathrm{CA}, \mathrm{CO}, \mathrm{MI}, \mathrm{NJ}, \mathrm{SC}, \mathrm{WA}, \mathrm{WI}$

This figure plots arrests for drug offenses (trafficking and possession) as calculated from the FBI's Uniform Crime Reporting program.

The vertical axis is indexed such that 1985 is 100 . 


\section{Figure 3}

\section{Counterfactual Prison Populations: Baseline}

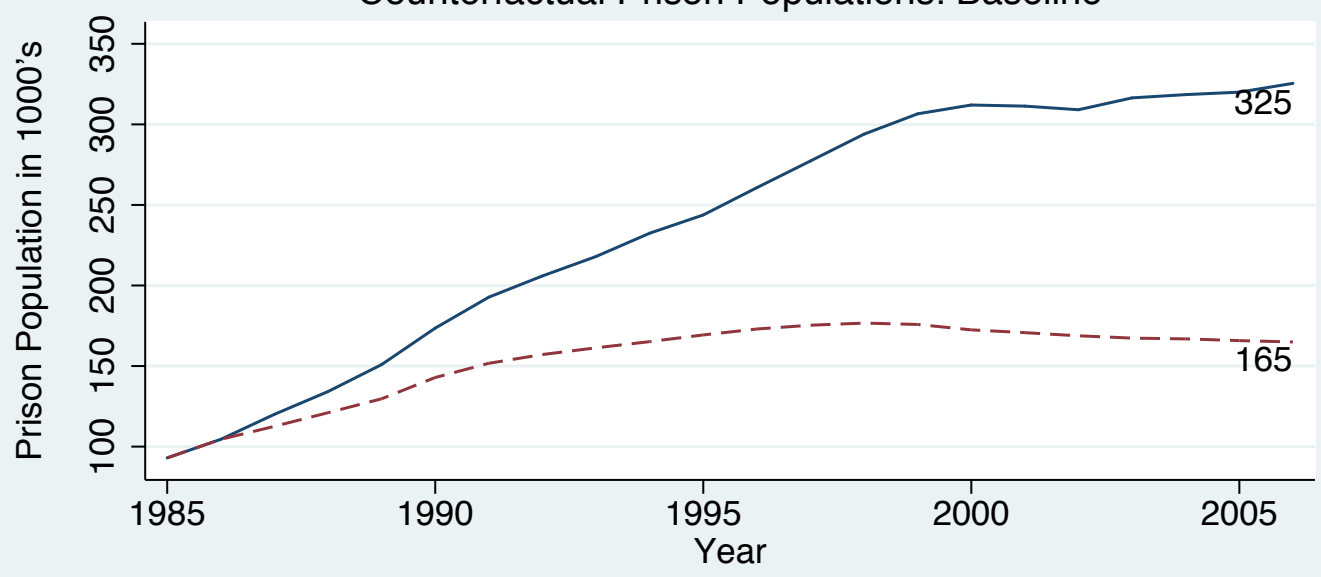

\section{- Prison Population in NCRP States - - - - - Counterfactual Prison Population (under 1985 policies)}

This figure shows the growth of prison populations over time in the 7 states we examine. The solid line plots the observed populations in the NCRP for those states while the dashed line plots the counterfactual growth under the assumption that incarceration policies do not change from their 1985 baselines. 


\section{Figure 4}

\section{Counterfactual Prison Populations: Adjusted for Incapacitation}

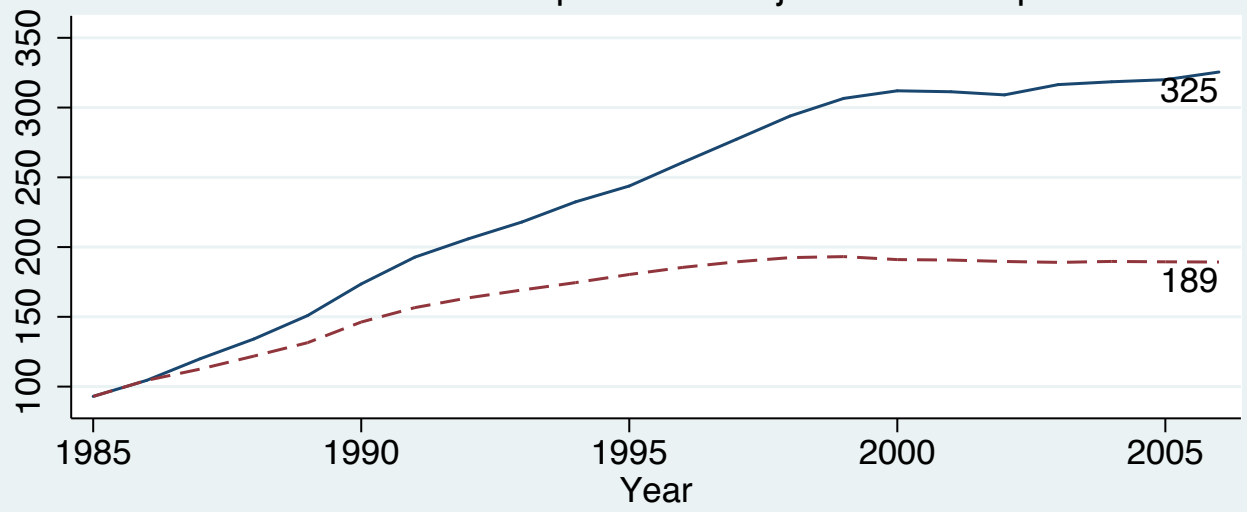

- Prison Population in NCRP States

- - - - - Counterfactual Prison Population (under 1985 policies)

This figure shows the growth of prison populations over time in the 7 states we examine. The solid line plots the observed populations in the NCRP for those states while the dashed line plots the counterfactual growth under the assumption that incarceration policies do not change from their 1985 baselines. This figure also accounts for the incapacitation effects of imprisonment, whereby a smaller prison population implies a larger population of potential criminals. 


\section{Figure 5}

\section{Counterfactual Prison Populations: Whites}

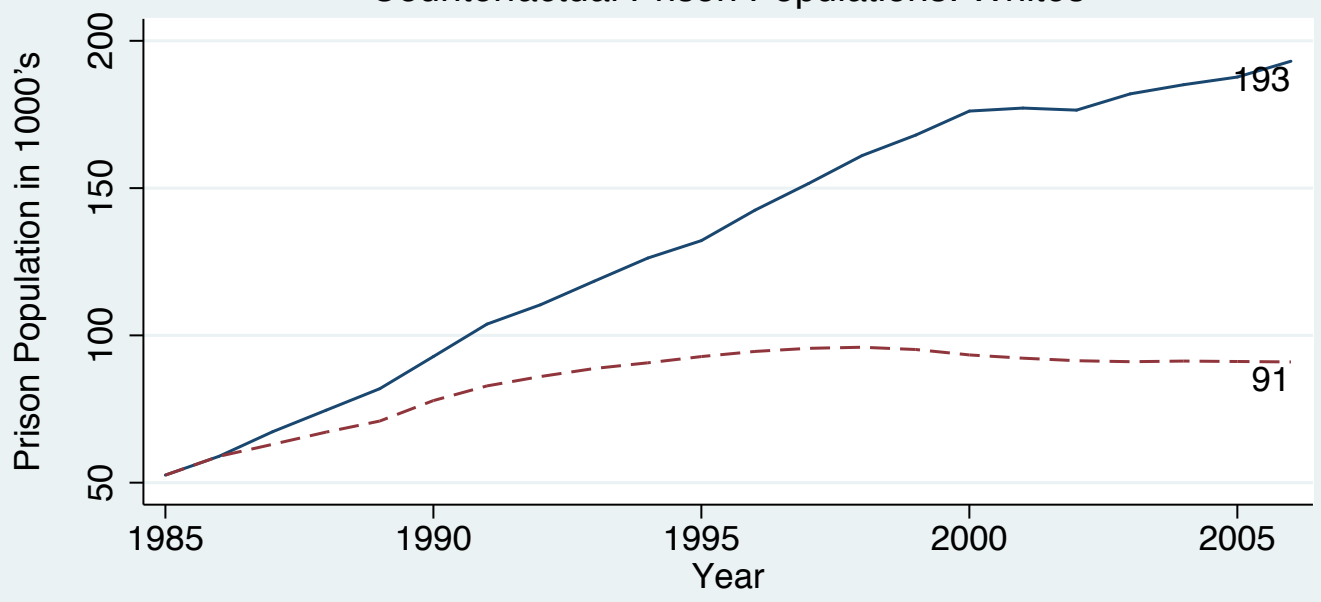

\section{- Prison Population in NCRP States \\ - - - - - Counterfactual Prison Population (under 1985 policies)}

The solid line plots the observed populations in the NCRP for our seven-state sample while the dashed line plots the counterfactual growth under the assumption that incarceration policies do not change from their 1985 baselines. 
Figure 6

\section{Counterfactual Prison Populations: Blacks}

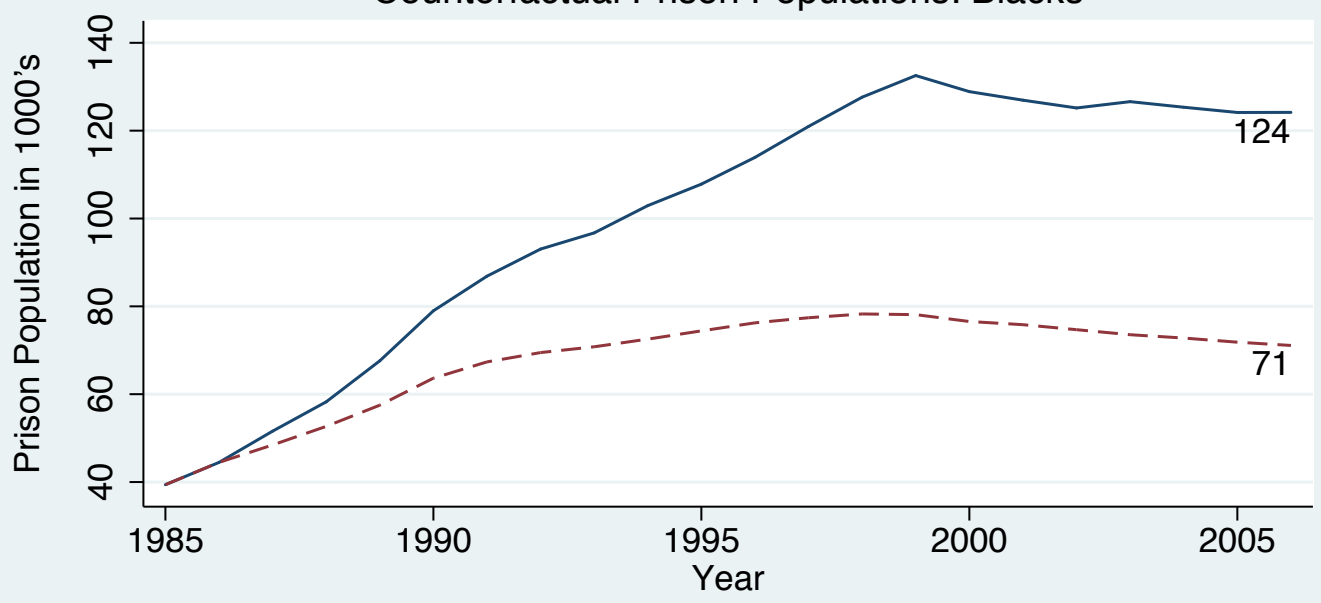

\section{- Prison Population in NCRP States \\ - - - - - Counterfactual Prison Population (under 1985 policies)}

The solid line plots the observed populations in the NCRP for our seven-state sample while the dashed line plots the counterfactual growth under the assumption that incarceration policies do not change from their 1985 baselines. 


\section{Table 1}

Employment and Institutionalization Rates Black Males

\begin{tabular}{|c|c|c|c|c|c|c|}
\hline \multirow[t]{2}{*}{ Birth Year } & \multicolumn{6}{|c|}{ Age } \\
\hline & $20-24$ & $25-29$ & $30-34$ & $35-39$ & $40-44$ & $45-49$ \\
\hline $1910-1914$ & & & & & & $\begin{array}{l}0.827 \\
0.028\end{array}$ \\
\hline $1915-1919$ & & & & & $\begin{array}{l}0.825 \\
0.038\end{array}$ & \\
\hline 1920-1924 & & & & $\begin{array}{l}0.828 \\
0.044\end{array}$ & & $\begin{array}{l}0.823 \\
0.025\end{array}$ \\
\hline 1925-1929 & & & $\begin{array}{l}0.818 \\
0.054\end{array}$ & & $\begin{array}{l}0.842 \\
0.028\end{array}$ & \\
\hline 1930-1934 & & $\begin{array}{l}0.807 \\
0.053\end{array}$ & & $\begin{array}{l}0.856 \\
0.038\end{array}$ & & $\begin{array}{l}0.782 \\
0.016\end{array}$ \\
\hline $1935-1939$ & $\begin{array}{l}0.696 \\
0.048\end{array}$ & & $\begin{array}{l}0.846 \\
0.040\end{array}$ & & $\begin{array}{l}0.794 \\
0.021\end{array}$ & \\
\hline 1940-1944 & & $\begin{array}{l}0.811 \\
0.054\end{array}$ & & $\begin{array}{l}0.792 \\
0.031\end{array}$ & & $\begin{array}{l}0.748 \\
0.029\end{array}$ \\
\hline $1945-1949$ & $\begin{array}{l}0.647 \\
0.055\end{array}$ & & $\begin{array}{l}0.761 \\
0.044\end{array}$ & & $\begin{array}{l}0.748 \\
0.044\end{array}$ & \\
\hline 1950-1954 & & $\begin{array}{l}0.710 \\
0.053\end{array}$ & & $\begin{array}{l}0.725 \\
0.065\end{array}$ & & $\begin{array}{l}0.660 \\
0.057\end{array}$ \\
\hline $1955-1959$ & $\begin{array}{l}0.569 \\
0.048\end{array}$ & & $\begin{array}{l}0.703 \\
0.083\end{array}$ & & $\begin{array}{l}0.658 \\
0.079\end{array}$ & \\
\hline 1960-1964 & & $\begin{array}{l}0.679 \\
0.095\end{array}$ & & $\begin{array}{l}0.661 \\
0.100\end{array}$ & & $\begin{array}{l}0.640 \\
0.066\end{array}$ \\
\hline 1965-1969 & $\begin{array}{l}0.574 \\
0.085\end{array}$ & & $\begin{array}{l}0.657 \\
0.115\end{array}$ & & $\begin{array}{l}0.650 \\
0.079\end{array}$ & \\
\hline 1970-1974 & & $\begin{array}{l}0.625 \\
0.122\end{array}$ & & $\begin{array}{l}0.662 \\
0.084\end{array}$ & & \\
\hline 1975-1979 & $\begin{array}{l}0.509 \\
0.116\end{array}$ & & $\begin{array}{l}0.607 \\
0.108\end{array}$ & & & \\
\hline 1980-1984 & & $\begin{array}{l}0.571 \\
0.110\end{array}$ & & & & \\
\hline 1985-1989 & $\begin{array}{l}0.445 \\
0.086 \\
\end{array}$ & & & & & \\
\hline
\end{tabular}

The top number is the employment rate and the bottom number is the institutionalization rate. This table was created using 1960-2000 census data and the 2010 ACS from IPUMS. The IPUMS website is available at http://usa.ipums.org/usa. The IPUMS variables for employment and institutionalization were EMPSTAT $(=1)$ and GQTYPE (=1 for 1990 and later; =2, 3, 4 for 1980 and earlier). After the 1980 census, the data no longer distinguish between different types of institutionalization. Thus, to be consistent we calculate total institutionalization rates for all years. All samples are weighted by the IPUMS variable PERWT. 
Table 2

Employment and Institutionalization Rates

White Males

\begin{tabular}{|c|c|c|c|c|c|c|}
\hline \multirow[t]{2}{*}{ Birth Year } & \multicolumn{6}{|c|}{ Age } \\
\hline & $20-24$ & $25-29$ & $30-34$ & $35-39$ & $40-44$ & $45-49$ \\
\hline $1910-1914$ & & & & & & $\begin{array}{l}0.919 \\
0.012\end{array}$ \\
\hline 1915-1919 & & & & & $\begin{array}{l}0.928 \\
0.011\end{array}$ & \\
\hline $1920-1924$ & & & & $\begin{array}{l}0.936 \\
0.011\end{array}$ & & $\begin{array}{l}0.923 \\
0.008\end{array}$ \\
\hline $1925-1929$ & & & $\begin{array}{l}0.932 \\
0.011\end{array}$ & & $\begin{array}{l}0.934 \\
0.009\end{array}$ & \\
\hline 1930-1934 & & $\begin{array}{l}0.900 \\
0.012\end{array}$ & & $\begin{array}{l}0.939 \\
0.009\end{array}$ & & $\begin{array}{l}0.899 \\
0.006\end{array}$ \\
\hline $1935-1939$ & $\begin{array}{l}0.783 \\
0.015\end{array}$ & & $\begin{array}{l}0.934 \\
0.009\end{array}$ & & $\begin{array}{l}0.913 \\
0.006\end{array}$ & \\
\hline $1940-1944$ & & $\begin{array}{l}0.901 \\
0.011\end{array}$ & & $\begin{array}{l}0.918 \\
0.007\end{array}$ & & $\begin{array}{l}0.890 \\
0.007\end{array}$ \\
\hline 1945-1949 & $\begin{array}{l}0.738 \\
0.013\end{array}$ & & $\begin{array}{l}0.906 \\
0.008\end{array}$ & & $\begin{array}{l}0.900 \\
0.009\end{array}$ & \\
\hline $1950-1954$ & & $\begin{array}{l}0.865 \\
0.010\end{array}$ & & $\begin{array}{l}0.900 \\
0.011\end{array}$ & & $\begin{array}{l}0.852 \\
0.010\end{array}$ \\
\hline $1955-1959$ & $\begin{array}{l}0.732 \\
0.011\end{array}$ & & $\begin{array}{l}0.896 \\
0.013\end{array}$ & & $\begin{array}{l}0.856 \\
0.015\end{array}$ & \\
\hline 1960-1964 & & $\begin{array}{l}0.873 \\
0.016\end{array}$ & & $\begin{array}{l}0.853 \\
0.019\end{array}$ & & $\begin{array}{l}0.811 \\
0.014\end{array}$ \\
\hline 1965-1969 & $\begin{array}{l}0.757 \\
0.015\end{array}$ & & $\begin{array}{l}0.851 \\
0.020\end{array}$ & & $\begin{array}{l}0.826 \\
0.016\end{array}$ & \\
\hline $1970-1974$ & & $\begin{array}{l}0.833 \\
0.021\end{array}$ & & $\begin{array}{l}0.835 \\
0.020\end{array}$ & & \\
\hline 1975-1979 & $\begin{array}{l}0.735 \\
0.022\end{array}$ & & $\begin{array}{l}0.824 \\
0.022\end{array}$ & & & \\
\hline $1980-1984$ & & $\begin{array}{l}0.788 \\
0.024\end{array}$ & & & & \\
\hline $1985-1989$ & $\begin{array}{l}0.654 \\
0.020\end{array}$ & & & & & \\
\hline
\end{tabular}

See notes for Table 1. 


\section{Table 3}

Employment and Institutionalization Rates Black Males With Less Than HS

\begin{tabular}{|c|c|c|c|c|c|c|}
\hline \multirow[t]{2}{*}{ Birth Year } & \multicolumn{6}{|c|}{ Age } \\
\hline & $20-24$ & $25-29$ & $30-34$ & $35-39$ & $40-44$ & $45-49$ \\
\hline $1910-1914$ & & & & & & $\begin{array}{l}0.816 \\
0.029\end{array}$ \\
\hline $1915-1919$ & & & & & $\begin{array}{l}0.810 \\
0.041\end{array}$ & \\
\hline $1920-1924$ & & & & $\begin{array}{l}0.808 \\
0.048\end{array}$ & & $\begin{array}{l}0.799 \\
0.029\end{array}$ \\
\hline $1925-1929$ & & & $\begin{array}{l}0.799 \\
0.061\end{array}$ & & $\begin{array}{l}0.820 \\
0.031\end{array}$ & \\
\hline $1930-1934$ & & $\begin{array}{l}0.783 \\
0.067\end{array}$ & & $\begin{array}{l}0.821 \\
0.051\end{array}$ & & $\begin{array}{l}0.718 \\
0.022\end{array}$ \\
\hline 1935-1939 & $\begin{array}{l}0.680 \\
0.067\end{array}$ & & $\begin{array}{l}0.801 \\
0.058\end{array}$ & & $\begin{array}{l}0.727 \\
0.030\end{array}$ & \\
\hline $1940-1944$ & & $\begin{array}{l}0.752 \\
0.086\end{array}$ & & $\begin{array}{l}0.700 \\
0.051\end{array}$ & & $\begin{array}{l}0.617 \\
0.044\end{array}$ \\
\hline 1945-1949 & $\begin{array}{l}0.580 \\
0.095\end{array}$ & & $\begin{array}{l}0.640 \\
0.078\end{array}$ & & $\begin{array}{l}0.598 \\
0.069\end{array}$ & \\
\hline $1950-1954$ & & $\begin{array}{l}0.562 \\
0.108\end{array}$ & & $\begin{array}{l}0.528 \\
0.110\end{array}$ & & $\begin{array}{l}0.439 \\
0.117\end{array}$ \\
\hline $1955-1959$ & $\begin{array}{l}0.453 \\
0.099\end{array}$ & & $\begin{array}{l}0.462 \\
0.172\end{array}$ & & $\begin{array}{l}0.414 \\
0.169\end{array}$ & \\
\hline 1960-1964 & & $\begin{array}{l}0.394 \\
0.214\end{array}$ & & $\begin{array}{l}0.379 \\
0.242\end{array}$ & & $\begin{array}{l}0.369 \\
0.174\end{array}$ \\
\hline 1965-1969 & $\begin{array}{l}0.329 \\
0.212\end{array}$ & & $\begin{array}{l}0.337 \\
0.323\end{array}$ & & $\begin{array}{l}0.333 \\
0.218\end{array}$ & \\
\hline $1970-1974$ & & $\begin{array}{l}0.302 \\
0.331\end{array}$ & & $\begin{array}{l}0.344 \\
0.239\end{array}$ & & \\
\hline 1975-1979 & $\begin{array}{l}0.278 \\
0.298\end{array}$ & & $\begin{array}{l}0.290 \\
0.278\end{array}$ & & & \\
\hline $1980-1984$ & & $\begin{array}{l}0.249 \\
0.322\end{array}$ & & & & \\
\hline 1985-1989 & $\begin{array}{l}0.192 \\
0.264\end{array}$ & & & & & \\
\hline
\end{tabular}

See notes for Table 1. This table was created using only data for Black males whose value for the IPUMS variable EDUCD was either less than or equal to 50 (completed less than 12 years of schooling). GED recipients are not included in this sample. 
Table 4

Employment and Institutionalization Rates

White Males With Less Than HS

\begin{tabular}{|c|c|c|c|c|c|c|}
\hline \multirow[t]{2}{*}{ Birth Year } & \multicolumn{6}{|c|}{ Age } \\
\hline & $20-24$ & $25-29$ & $30-34$ & $35-39$ & 40-44 & $45-49$ \\
\hline $1910-1914$ & & & & & & $\begin{array}{l}0.892 \\
0.016\end{array}$ \\
\hline 1915-1919 & & & & & $\begin{array}{l}0.893 \\
0.018\end{array}$ & \\
\hline 1920-1924 & & & & $\begin{array}{l}0.896 \\
0.019\end{array}$ & & $\begin{array}{l}0.883 \\
0.015\end{array}$ \\
\hline 1925-1929 & & & $\begin{array}{l}0.894 \\
0.021\end{array}$ & & $\begin{array}{l}0.894 \\
0.016\end{array}$ & \\
\hline 1930-1934 & & $\begin{array}{l}0.861 \\
0.026\end{array}$ & & $\begin{array}{l}0.890 \\
0.019\end{array}$ & & $\begin{array}{l}0.816 \\
0.013\end{array}$ \\
\hline 1935-1939 & $\begin{array}{l}0.782 \\
0.034\end{array}$ & & $\begin{array}{l}0.879 \\
0.023\end{array}$ & & $\begin{array}{l}0.822 \\
0.014\end{array}$ & \\
\hline 1940-1944 & & $\begin{array}{l}0.852 \\
0.029\end{array}$ & & $\begin{array}{l}0.816 \\
0.020\end{array}$ & & $\begin{array}{l}0.750 \\
0.018\end{array}$ \\
\hline 1945-1949 & $\begin{array}{l}0.745 \\
0.044\end{array}$ & & $\begin{array}{l}0.793 \\
0.027\end{array}$ & & $\begin{array}{l}0.742 \\
0.028\end{array}$ & \\
\hline 1950-1954 & & $\begin{array}{l}0.756 \\
0.036\end{array}$ & & $\begin{array}{l}0.746 \\
0.032\end{array}$ & & $\begin{array}{l}0.629 \\
0.029\end{array}$ \\
\hline 1955-1959 & $\begin{array}{l}0.693 \\
0.036\end{array}$ & & $\begin{array}{l}0.747 \\
0.039\end{array}$ & & $\begin{array}{l}0.649 \\
0.041\end{array}$ & \\
\hline 1960-1964 & & $\begin{array}{l}0.734 \\
0.045\end{array}$ & & $\begin{array}{l}0.656 \\
0.047\end{array}$ & & $\begin{array}{l}0.653 \\
0.033\end{array}$ \\
\hline 1965-1969 & $\begin{array}{l}0.688 \\
0.051\end{array}$ & & $\begin{array}{l}0.664 \\
0.052\end{array}$ & & $\begin{array}{l}0.684 \\
0.042\end{array}$ & \\
\hline 1970-1974 & & $\begin{array}{l}0.677 \\
0.052\end{array}$ & & $\begin{array}{l}0.715 \\
0.048\end{array}$ & & \\
\hline 1975-1979 & $\begin{array}{l}0.659 \\
0.056\end{array}$ & & $\begin{array}{l}0.710 \\
0.058\end{array}$ & & & \\
\hline 1980-1984 & & $\begin{array}{l}0.674 \\
0.067\end{array}$ & & & & \\
\hline 1985-1989 & $\begin{array}{l}0.576 \\
0.070 \\
\end{array}$ & & & & & \\
\hline
\end{tabular}

See notes for Table 3. 
Table 5

\begin{tabular}{|c|c|c|c|}
\hline & $\begin{array}{l}\text { Abolish / Restrict } \\
\text { Discretionary Parole }\end{array}$ & $\begin{array}{l}\text { Sentencing } \\
\text { Commission }\end{array}$ & $\begin{array}{l}\text { Truth In } \\
\text { Sentencinge }\end{array}$ \\
\hline AL & & $19982000^{d, f}$ & \\
\hline AK & 1980 (partial) $^{a}$ & $1980^{c}$ & Other \\
\hline $\mathbf{A Z}$ & $1994^{b}$ & & $85 \%$ \\
\hline AR & 1994 (partial) $^{a}$ & $1994^{c}$ & Other \\
\hline CA & $1976^{b}$ & & $85 \%$ \\
\hline $\mathrm{CO}$ & $1979-85^{b}$ & & Other \\
\hline CT & $1981-90^{b}$ & $2010^{f}$ & $85 \%$ \\
\hline $\mathrm{DE}$ & $1990^{a, b}$ & $1987^{c}$ & $85 \%$ \\
\hline $\mathbf{F L}$ & $1983^{a, b}$ & $1983-98^{c}$ & $85 \%$ \\
\hline GA & & & $85 \%$ \\
\hline \multicolumn{4}{|l|}{$\mathrm{HI}$} \\
\hline ID & & & $100 \%$ \\
\hline IL & $1978^{b}$ & $2010^{f}$ & $85 \%$ \\
\hline IN & $1977^{\mathrm{b}}$ & & $50 \%$ \\
\hline IA & & & $85 \%$ \\
\hline KS & $1993^{a, b}$ & $1993^{c}$ & $85 \%$ \\
\hline KY & & & $85 \%$ \\
\hline LA & & $2010^{f}$ & $85 \%$ \\
\hline ME & $1976^{b}$ & & $85 \%$ \\
\hline MD & & $1983^{c} 1996^{d}$ & $50 \%$ \\
\hline MA & & $1994^{f}$ & $75 \%$ \\
\hline MI & & $1984^{c} 1995-2002^{d}$ & $85 \%$ \\
\hline MN & $1980^{a, b}$ & $1980^{c}$ & $85 \%$ \\
\hline MS & $1995^{\mathrm{b}}$ & & $85 \%$ \\
\hline MO & & $1997^{c}$ & $85 \%$ \\
\hline \multicolumn{4}{|l|}{ MT } \\
\hline NE & & & $50 \%$ \\
\hline NV & & & $100 \%$ \\
\hline NH & & & $100 \%$ \\
\hline NJ & & & $85 \%$ \\
\hline NM & $1977^{\mathrm{b}}$ & $1978^{f}$ & \\
\hline NY & & $2010^{f}$ & $85 \%$ \\
\hline NC & $1994^{a}$ & $1994^{c}$ & $85 \%$ \\
\hline ND & & & $85 \%$ \\
\hline
\end{tabular}




\begin{tabular}{|c|l|l|r|} 
& $\begin{array}{l}\text { Abolish / Restrict } \\
\text { Discretionary Parole }\end{array}$ & $\begin{array}{l}\text { Sentencing } \\
\text { Commission }\end{array}$ & $\begin{array}{l}\text { Truth In } \\
\text { Sentencing }\end{array}$ \\
\hline OH & $1996^{\mathrm{a}, \mathrm{b}}$ & $1996^{\mathrm{c}}$ & $85 \%$ \\
\hline OK & & & $85 \%$ \\
\hline OR & $1989^{\mathrm{a}, \mathrm{b}}$ & $1989^{\mathrm{c}}$ & $85 \%$ \\
\hline PA & & $1982^{\mathrm{c}}$ & $85 \%$ \\
\hline RI & & & $85 \%$ \\
\hline SC & & & $50 \%$ \\
\hline SD & & & $85 \%$ \\
\hline TN & 1989 (partial) $^{\mathrm{a}}$ & $1989-95^{\mathrm{c}}$ & \\
\hline TX & & & $85 \%$ \\
\hline UT & & $1979^{\mathrm{c}} \mathbf{1 9 8 3}^{\mathrm{d}}$ & $85 \%$ \\
\hline VT & & & \\
\hline VA & 1995 (partial $^{\mathrm{a}, \mathrm{b}}$ & $1991 \mathbf{1 9 9 5}^{\mathrm{c}, \mathrm{d}}$ & \\
\hline WA & $1984^{\mathrm{a}, \mathrm{b}}$ & $1984^{\mathrm{c}}$ & \\
\hline WV & & & \\
\hline WI & $1999^{\mathrm{b}}$ & $1985-5^{\mathrm{c}} \mathbf{2 0 0 2}-7^{\mathrm{f}}$ & \\
\hline WY & & & \\
\hline
\end{tabular}

\section{Notes:}

a: Listed in Table 1 of Frase (2005) as abolishing parole release in the given year.

b. Listed in tables 1-3 of Stemen et al. (2006) as having enacted determinate sentencing in the given year. Date ranges are used when indeterminate sentencing was reinstated in a later year. Mississippi reinstated indeterminate sentencing for first-time non-violent offenses in 2000.

c: Listed in Table 1 of Frase (2005) as establishing a state sentencing commission in the given year. Date ranges are used when a sentencing commission was abolished.

d: First year is date when commission was first established. Bolded date is the year when the commission was made permanent. In all other cases, the commission was permanent when established.

e: Listed in Table 1 of Ditton (1999) as requiring prisoners to serve the listed percentage of their minimum sentence.

f: Sources gathered from state sentencing commission and legislative websites. For more information, see Appendix D. 
Table 6

Estimated National Crimes, Arrests, and Admissions in Thousands: 1970-2011

\begin{tabular}{|c|c|c|c|c|c|c|c|c|c|c|c|c|}
\hline \multirow[t]{2}{*}{ Year } & \multicolumn{2}{|c|}{ Crimes } & \multicolumn{4}{|c|}{ Arrests } & \multicolumn{2}{|c|}{ Admissions } & \multicolumn{4}{|c|}{ Stocks } \\
\hline & Violent & Property & Violent & Property & Drug & Other & $\begin{array}{l}\text { State } \\
\text { Prison }\end{array}$ & $\begin{array}{c}\text { Federal } \\
\text { Prison }\end{array}$ & Jail & $\begin{array}{l}\text { State } \\
\text { Prison }\end{array}$ & $\begin{array}{c}\text { Federal } \\
\text { Prison }\end{array}$ & Total \\
\hline 1970 & 739 & 7359 & 288 & 1260 & 416 & 6155 & - & - & - & 184 & 21 & - \\
\hline 1971 & 817 & 7772 & 323 & 1381 & 492 & 6444 & - & - & - & 185 & 22 & - \\
\hline 1972 & 835 & 7414 & 350 & 1370 & 527 & 6465 & - & - & 142 & 182 & 23 & 346 \\
\hline 1973 & 876 & 7842 & 381 & 1449 & 629 & 6570 & - & - & - & 189 & 24 & - \\
\hline 1974 & 975 & 9279 & 429 & 1731 & 642 & 6253 & - & - & - & 205 & 23 & - \\
\hline 1975 & 1040 & 10253 & 451 & 1844 & 601 & 6377 & - & - & - & 226 & 25 & - \\
\hline 1976 & 1004 & 10346 & 412 & 1747 & 689 & 6761 & - & - & - & 246 & 28 & - \\
\hline 1977 & 1030 & 9955 & 436 & 1787 & 643 & 7324 & - & - & - & 258 & 30 & - \\
\hline 1978 & 1086 & 10123 & 470 & 1815 & 629 & 7358 & 146 & 16 & 158 & 277 & 30 & 465 \\
\hline 1979 & 1208 & 11042 & 468 & 1859 & 559 & 7320 & 157 & 16 & - & 288 & 26 & - \\
\hline 1980 & 1345 & 12064 & 475 & 1863 & 581 & 7539 & 169 & 14 & - & 305 & 24 & - \\
\hline 1981 & 1362 & 12062 & 490 & 1930 & 560 & 7876 & 198 & 14 & - & 342 & 28 & - \\
\hline 1982 & 1322 & 11652 & 526 & 2045 & 676 & 8901 & 215 & 16 & - & 384 & 30 & - \\
\hline 1983 & 1258 & 10851 & 499 & 1930 & 661 & 8624 & 232 & 18 & 228 & 405 & 32 & 664 \\
\hline 1984 & 1273 & 10609 & 494 & 1866 & 708 & 8518 & 229 & 17 & 231 & 428 & 34 & 693 \\
\hline 1985 & 1329 & 11103 & 498 & 1945 & 811 & 8704 & 252 & 19 & 265 & 462 & 40 & 768 \\
\hline 1986 & 1489 & 11723 & 554 & 2023 & 824 & 9087 & 285 & 20 & 266 & 501 & 44 & 810 \\
\hline 1987 & 1484 & 12025 & 546 & 2100 & 937 & 9142 & 320 & 20 & 290 & 537 & 48 & 875 \\
\hline 1988 & 1566 & 12357 & 626 & 2263 & 1155 & 9782 & 361 & 19 & 336 & 578 & 50 & 964 \\
\hline 1989 & 1646 & 12605 & 685 & 2320 & 1362 & 9990 & 437 & 23 & 387 & 653 & 59 & 1099 \\
\hline 1990 & 1820 & 12656 & 705 & 2218 & 1090 & 10204 & 474 & - & 408 & 708 & 66 & 1182 \\
\hline 1991 & 1912 & 12961 & 719 & 2253 & 1010 & 10249 & 480 & - & 423 & 754 & 72 & 1248 \\
\hline 1992 & 1932 & 12506 & 742 & 2146 & 1066 & 10139 & 496 & - & 442 & 802 & 80 & 1324 \\
\hline 1993 & 1926 & 12219 & 754 & 2094 & 1126 & 10076 & 493 & 25 & 466 & 880 & 90 & 1435 \\
\hline 1994 & 1858 & 12132 & 779 & 2132 & 1351 & 10401 & 514 & 27 & 480 & 960 & 95 & 1534 \\
\hline 1995 & 1799 & 12064 & 796 & 2129 & 1476 & 10731 & 535 & 27 & 510 & 1026 & 100 & 1636 \\
\hline 1996 & 1689 & 11805 & 730 & 2046 & 1506 & 10891 & 526 & 30 & 515 & 1076 & 106 & 1697 \\
\hline 1997 & 1635 & 11558 & 718 & 2016 & 1584 & 10974 & 550 & 34 & 557 & 1128 & 113 & 1797 \\
\hline 1998 & 1531 & 10945 & 676 & 1806 & 1559 & 10493 & 576 & 39 & 594 & 1184 & 123 & 1901 \\
\hline 1999 & 1426 & 10208 & 636 & 1645 & 1532 & 10240 & 582 & 44 & 608 & 1228 & 135 & 1972 \\
\hline 2000 & 1425 & 10183 & 625 & 1621 & 1580 & 10160 & 618 & 48 & 618 & 1249 & 145 & 2013 \\
\hline 2001 & 1439 & 10437 & 627 & 1618 & 1587 & 9871 & 601 & 48 & 626 & 1247 & 157 & 2030 \\
\hline 2002 & 1424 & 10455 & 621 & 1614 & 1539 & 9977 & 619 & 50 & 652 & 1277 & 164 & 2092 \\
\hline 2003 & 1384 & 10443 & 597 & 1605 & 1678 & 9766 & 644 & 53 & 681 & 1296 & 173 & 2149 \\
\hline 2004 & 1360 & 10319 & 587 & 1644 & 1747 & 9964 & 655 & 54 & 706 & 1317 & 180 & 2203 \\
\hline 2005 & 1391 & 10175 & 604 & 1609 & 1846 & 10039 & 683 & 58 & 733 & 1338 & 188 & 2259 \\
\hline 2006 & 1418 & 9984 & 612 & 1540 & 1890 & 10341 & 697 & 57 & 756 & 1376 & 193 & 2325 \\
\hline 2007 & 1408 & 9843 & 597 & 1610 & 1841 & 10163 & 699 & 55 & 774 & 1397 & 200 & 2371 \\
\hline 2008 & 1393 & 9768 & 595 & 1687 & 1703 & 10022 & 696 & 55 & 777 & 1407 & 201 & 2385 \\
\hline 2009 & 1326 & 9337 & 582 & 1728 & 1664 & 9716 & 680 & 57 & 768 & 1407 & 208 & 2383 \\
\hline 2010 & 1251 & 9113 & 552 & 1644 & 1639 & 9287 & 654 & 55 & 749 & 1404 & 210 & 2362 \\
\hline 2011 & 1206 & 9053 & 535 & 1640 & 1531 & 8704 & 612 & 62 & 727 & 1382 & 216 & 2325 \\
\hline
\end{tabular}


Crime and arrest data are FBI estimates of national totals as published in Crime in the United States (1970-2011) and collected by The Disaster Center and the Bureau of Justice Statistics in recent years. Admission data are National Prisoner Statistics (NPS) counts of admissions to state and federal prisons (1978-2011). Jail data are average daily population counts taken from the Census of Jails and Annual Jail Survey (1978-2011) and the 1972 Survey of Inmates of Local Jails (1972). State and federal prison stock data are NPS counts of prisoners with any length of sentence (1978-2011) and Historical Statistics on Prisoners in State and Federal Institutions, Yearend 1925-86 (HSPSFI) (1970-77). Stock data from before 1978 are inflated to account for lower coverage rates of HSPSFI relative to NPS. The inflation factor is calculated by regressing stock counts from HSPFI for the years 197886 on the 1978-86 data from NPS. The inflation factor for the stock data is 1.04 with an $R^{2}$ of .999. 
Table 7a: Sentencing and Time Served Outcomes (Violent Crime)

Admission Types: Court Commitments and Probation Revocations

Races: $\quad$ All

States:

CA, CO, MI, NJ, SC, WA, WI

Prior Jail Time: $\quad$ Excluded

\begin{tabular}{|c|c|c|c|c|c|c|c|c|c|c|c|c|c|c|c|c|c|c|c|c|c|c|c|c|c|c|c|c|c|c|}
\hline \multirow[b]{3}{*}{ Year } & \multicolumn{6}{|c|}{ Murder and Homicide } & \multicolumn{6}{|c|}{ Forcible Rape } & \multicolumn{6}{|c|}{ Robbery } & \multicolumn{6}{|c|}{ Aggravated Assault } & \multicolumn{6}{|c|}{ Other Assault } \\
\hline & \multirow[b]{2}{*}{$\begin{array}{l}\text { Arrests } \\
\text { in } 1000 \mathrm{~s}\end{array}$} & \multirow[b]{2}{*}{$\begin{array}{c}\text { Prs. } \\
\text { adm. in } \\
1000 \mathrm{~s}\end{array}$} & \multirow[b]{2}{*}{\begin{tabular}{|c|} 
Adm. \\
per \\
1000 \\
arr. \\
\end{tabular}} & \multicolumn{3}{|c|}{$\begin{array}{l}\text { Prisoners. left per } \\
1000 \mathrm{adm} . \\
\end{array}$} & \multirow[b]{2}{*}{$\begin{array}{c}\text { Arrests } \\
\text { in } 1000 \mathrm{~s}\end{array}$} & \multirow[b]{2}{*}{$\begin{array}{c}\text { Prs. } \\
\text { adm. in } \\
1000 \text { s }\end{array}$} & \multirow[b]{2}{*}{$\begin{array}{c}\text { Adm. } \\
\text { per } \\
1000 \\
\text { arr. }\end{array}$} & \multicolumn{3}{|c|}{$\begin{array}{l}\text { Prisoners. left per } \\
1000 \mathrm{adm} .\end{array}$} & \multirow[b]{2}{*}{$\begin{array}{l}\text { Arrests } \\
\text { in } 1000 \mathrm{~s}\end{array}$} & \multirow[b]{2}{*}{$\begin{array}{c}\text { Prs. } \\
\text { adm. in } \\
1000 \text { s }\end{array}$} & \multirow[b]{2}{*}{$\begin{array}{c}\text { Adm. } \\
\text { per } \\
1000 \\
\text { arr. }\end{array}$} & \multicolumn{3}{|c|}{$\begin{array}{l}\text { Prisoners. left per } \\
1000 \mathrm{adm} . \\
\end{array}$} & \multirow[b]{2}{*}{\begin{tabular}{|l} 
Arrests \\
in 1000s
\end{tabular}} & \multirow[b]{2}{*}{\begin{tabular}{c|} 
Prs. \\
adm. in \\
$1000 \mathrm{~s}$
\end{tabular}} & \multirow[b]{2}{*}{\begin{tabular}{|c|} 
Adm. \\
per \\
1000 \\
arr. \\
\end{tabular}} & $\begin{array}{r}\text { Prison } \\
10 \\
\end{array}$ & $\begin{array}{l}\text { ners. lef } \\
000 \mathrm{adm}\end{array}$ & $\begin{array}{l}\text { t per } \\
\text { t. }\end{array}$ & & & & $\begin{array}{r}\text { Prison } \\
10 \\
\end{array}$ & $\begin{array}{l}\text { eers. left } \\
00 \mathrm{adm}\end{array}$ & $\begin{array}{l}\text { ft per } \\
\text { n. }\end{array}$ \\
\hline & & & & 2 & 5 & 10 & & & & 2 & 5 & 10 & & & & 2 & 5 & 10 & & & & 2 & 5 & 10 & $\begin{array}{l}\text { Arrests } \\
\text { in 1000s }\end{array}$ & $\mid \begin{array}{c}\text { Prs. } \\
\text { adm. in } \\
1000 \mathrm{~s}\end{array}$ & \begin{tabular}{|c|} 
Adm. \\
per \\
1000 \\
arr. \\
\end{tabular} & 2 & 5 & 10 \\
\hline 1985 & 6.2 & 2.7 & 437 & 786 & 548 & 385 & 10.5 & 1.3 & 123 & 751 & 315 & 125 & 40.7 & 5.3 & 131 & 508 & 155 & 55 & 83.2 & 2.7 & 33 & 363 & 84 & 33 & 171.2 & 0.5 & 3 & 220 & 44 & \\
\hline 1986 & 6.4 & 2.9 & 452 & 800 & 558 & 389 & 10.7 & 1.3 & 117 & 768 & 356 & 153 & 40.7 & 5.4 & 133 & 507 & 169 & 64 & 106.7 & 3.1 & 29 & 359 & 86 & 35 & 192.9 & 0.6 & 3 & 330 & 71 & 44 \\
\hline 1987 & 6.7 & 3.0 & 440 & 830 & 590 & 429 & 10.9 & 1.1 & 103 & 752 & 357 & 149 & 38.0 & 5.6 & 146 & 491 & 174 & 72 & 115.8 & 3.2 & 27 & 391 & 96 & 43 & 199.2 & 0.6 & 3 & 361 & 78 & 40 \\
\hline 1988 & 7.0 & 3.2 & 449 & 825 & 595 & 440 & 11.0 & 1.0 & 92 & 766 & 378 & 181 & 38.7 & 5.4 & 140 & 503 & 172 & 75 & 128.2 & 3.5 & 27 & 386 & 97 & 46 & 213.1 & 0.6 & 3 & 325 & 86 & 59 \\
\hline 1989 & 7.9 & 3.3 & 417 & 829 & 596 & 440 & 11.3 & 1.2 & 102 & 777 & 374 & 181 & 43.7 & 5.8 & 133 & 497 & 180 & 84 & 145.7 & 4.0 & 27 & 380 & 111 & 50 & 236.1 & 0.6 & 2 & 243 & 98 & 81 \\
\hline 1990 & 8.2 & 3.6 & 435 & 835 & 612 & 441 & 11.6 & 1.3 & 113 & 718 & 352 & 158 & 50.1 & 6.5 & 131 & 491 & 175 & 79 & 159.5 & 4.5 & 28 & 369 & 100 & 47 & 248.2 & 0.7 & 3 & 207 & 84 & 53 \\
\hline 1991 & 8.0 & 3.8 & 472 & 841 & 618 & 444 & 11.3 & 1.3 & 119 & 747 & 410 & 196 & 50.1 & 7.2 & 143 & 512 & 188 & 78 & 158.0 & 4.9 & 31 & 383 & 115 & 50 & 241.8 & 0.9 & 4 & 284 & 111 & 55 \\
\hline 1992 & 7.3 & 4.0 & 548 & 869 & 659 & 474 & 10.8 & 1.4 & 130 & 751 & 423 & 192 & 48.8 & 7.6 & 156 & 523 & 198 & 77 & 161.4 & 5.1 & 31 & 373 & 118 & 48 & 248.7 & 1.0 & 4 & 269 & 95 & 48 \\
\hline 1993 & 7.4 & 4.0 & 540 & 870 & 673 & 481 & 10.3 & 1.4 & 134 & 755 & 429 & 181 & 48.0 & 7.7 & 160 & 536 & 201 & 70 & 166.3 & 5.1 & 31 & 379 & 123 & 48 & 262.8 & 1.2 & 4 & 269 & 117 & 43 \\
\hline & 6.9 & 3.7 & 530 & 874 & 686 & 499 & 9.9 & 13 & 129 & 742 & 409 & 183 & & 7.2 & 152 & 571 & 240 & I & 177 & 5 & & & 126 & & & 1.4 & 5 & 257 & 94 & 41 \\
\hline 1995 & 6.5 & .8 & 586 & 885 & 702 & 514 & 9.2 & 1.3 & 138 & 798 & 449 & 193 & 46.5 & 7.3 & 157 & 571 & 269 & 99 & 185.6 & 5.8 & 31 & 415 & 165 & 5 & 296.1 & 1.6 & 5 & 254 & 101 & 40 \\
\hline 1996 & 6.1 & 9 & 631 & 890 & 738 & 555 & 9.3 & 1.4 & 152 & 844 & 513 & 248 & & 7.5 & 171 & 584 & 295 & 112 & 179.2 & .3 & 35 & 26 & 172 & 56 & 295.7 & 1.8 & 6 & 259 & 101 & 29 \\
\hline 1997 & 5.6 & 6 & 643 & 908 & 753 & 589 & 8.8 & 1.3 & 151 & 860 & 536 & 277 & 40.5 & 7.1 & 176 & 599 & 294 & 113 & 183.3 & 6.5 & 36 & 421 & 158 & 57 & 291.7 & 2.1 & 7 & 273 & 87 & 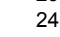 \\
\hline 1998 & 5.5 & 5 & 63 & 899 & 760 & 584 & 8.4 & 1.3 & 1 & 8 & 531 & 282 & 4 & 7.0 & 191 & 583 & $3 c$ & 136 & 172.2 & 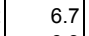 & 39 & 427 & 1 & & ? & 2.4 & 8 & 74 & 84 & 22 \\
\hline 1999 & 4.8 & 1 & 654 & 904 & 772 & 599 & .9 & 1.3 & 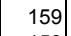 & 863 & 530 & 273 & & 6.4 & 196 & 594 & 331 & 162 & 16 & 6. & 39 & 4 & 166 & 58 & 2 & 2.2 & 8 & 255 & 80 & 21 \\
\hline 2000 & 4.7 & 0 & 625 & 891 & 765 & 603 & 7.6 & 1.2 & 153 & 840 & 524 & 295 & 3 & 6.1 & 198 & 635 & 352 & 183 & 163.0 & 6.2 & 38 & 32 & 176 & 63 & 2 & 2.3 & 9 & 269 & 75 & 16 \\
\hline 20 & 4.3 & .1 & 711 & 884 & 749 & & 7.2 & 1.2 & 162 & 827 & 525 & & 30.4 & 6.0 & 196 & 670 & 367 & & 164.5 & 6.4 & 39 & 423 & 166 & & 3 & 2.4 & 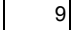 & 67 & 72 & \\
\hline 20 & 4.2 & .1 & 751 & 892 & 757 & & 7.3 & 1.2 & 0 & 803 & 550 & & & 6.2 & 204 & 676 & 382 & & 162.5 & 6 & 41 & 425 & 16 & & 2 & .7 & 10 & 260 & 67 & \\
\hline $2 c$ & 4.1 & .1 & 758 & 881 & 753 & & 1 & 1.3 & 181 & 805 & 578 & & & 6.2 & 203 & 685 & 371 & & 160.4 & 1.0 & 44 & 405 & 168 & & 265.3 & 2.9 & 11 & 237 & 80 & \\
\hline 2004 & 4.0 & 3.0 & 741 & 872 & 744 & & 6.6 & 1.2 & 184 & 800 & 571 & & 30.6 & 6.2 & 203 & 672 & 346 & & 151.8 & 7.2 & 47 & 383 & 151 & & 251.9 & 3.0 & 12 & 225 & 72 & \\
\hline 2005 & 3.9 & 3.3 & 857 & 874 & 756 & & 6.3 & 1.2 & 183 & 818 & 664 & & 31.2 & 5.9 & 190 & 656 & 367 & & 149.2 & 7.2 & 48 & 399 & 191 & & 247.9 & 2.9 & 12 & 212 & 81 & \\
\hline $\begin{array}{l}\text { rentage } \\
\text { ange } \\
35-2000\end{array}$ & $-24 \%$ & $9 \%$ & $43 \%$ & $13 \%$ & $40 \%$ & $57 \%$ & $-28 \%$ & $-10 \%$ & $24 \%$ & $12 \%$ & $67 \%$ & $136 \%$ & $-24 \%$ & $15 \%$ & $51 \%$ & $25 \%$ & $127 \%$ & $6 \%$ & $96 \%$ & $127 \%$ & $16 \%$ & $19 \%$ & $111 \%$ & $90 \%$ & $56 \%$ & $367 \%$ & $200 \%$ & $22 \%$ & $70 \%$ & $-34 \%$ \\
\hline
\end{tabular}

\begin{tabular}{l}
\hline (1) Arrests and prison admissions reported in 1000's. Rates reported in percent. (2) If states stop reporting before 2009 (MI(2006), NJ(2005), WI(2007)), calculations are based on the assum \\
match the cohort hazard rates for our full seven-state sample. Arrest figures from FBI Uniform Crime Reports; admissions and time-served figures from National Corrections Reporting Program.
\end{tabular} 
Table 7b: Sentencing and Time Served Outcomes (Property Crime)

Admission Types: Court Commitments and Probation Revocations

Races:

All

States:

CA, CO, MI, NJ, SC, WA, WI

Prior Jail Time: $\quad$ Excluded

\begin{tabular}{|c|c|c|c|c|c|c|c|c|c|c|c|c|c|c|c|c|c|c|c|c|c|c|c|c|}
\hline \multirow[b]{3}{*}{ Year } & \multicolumn{6}{|c|}{ Burglary } & \multicolumn{6}{|c|}{ Motor Vehicle Theft } & \multicolumn{6}{|c|}{ Larceny/Theft } & \multicolumn{6}{|c|}{ Other Property Crime } \\
\hline & \multirow[b]{2}{*}{$\begin{array}{c}\text { Arrests } \\
\text { in } 1000 \mathrm{~s}\end{array}$} & \multirow[b]{2}{*}{$\begin{array}{c}\text { Prs. } \\
\text { adm. in } \\
1000 \mathrm{~s}\end{array}$} & \multirow[b]{2}{*}{$\begin{array}{c}\text { Adm. } \\
\text { per } \\
1000 \\
\end{array}$} & \multicolumn{3}{|c|}{$\begin{array}{l}\text { Prisoners. left per } \\
1000 \mathrm{adm} \text {. }\end{array}$} & \multirow[b]{2}{*}{$\begin{array}{c}\text { Arrests } \\
\text { in } 1000 \mathrm{~s}\end{array}$} & \multirow[b]{2}{*}{$\begin{array}{c}\text { Prs. } \\
\text { adm. in } \\
1000 s\end{array}$} & \multirow[b]{2}{*}{$\begin{array}{c}\text { Adm. } \\
\text { per } \\
1000 \\
\text { arr. }\end{array}$} & \multicolumn{3}{|c|}{$\begin{array}{l}\text { Prisoners. left per } \\
1000 \mathrm{adm} .\end{array}$} & \multirow[b]{2}{*}{$\begin{array}{c}\text { Arrests } \\
\text { in } 1000 \mathrm{~s}\end{array}$} & \multirow[b]{2}{*}{$\begin{array}{c}\text { Prs. } \\
\text { adm. in } \\
1000 \mathrm{~s}\end{array}$} & \multirow[b]{2}{*}{$\begin{array}{c}\text { Adm. } \\
\text { per } \\
1000 \\
\text { arr. }\end{array}$} & \multicolumn{3}{|c|}{$\begin{array}{l}\text { Prisoners. left per } \\
1000 \mathrm{adm} .\end{array}$} & \multirow[b]{2}{*}{$\begin{array}{c}\text { Arrests } \\
\text { in 1000s }\end{array}$} & \multirow[b]{2}{*}{$\begin{array}{c}\text { Prs. } \\
\text { adm. in } \\
1000 s\end{array}$} & \multirow[b]{2}{*}{$\begin{array}{c}\text { Adm. } \\
\text { per } \\
1000 \\
\text { arr. }\end{array}$} & \multicolumn{3}{|c|}{$\begin{array}{l}\text { Prisoners. left per } \\
1000 \text { adm. }\end{array}$} \\
\hline & & & & 2 & 5 & 10 & & & & 2 & 5 & 10 & & & & 2 & 5 & 10 & & & & 2 & 5 & 10 \\
\hline 1985 & 134.4 & \begin{tabular}{|c|}
7.9 \\
\end{tabular} & \begin{tabular}{|c|}
59 \\
\end{tabular} & 258 & 54 & 22 & 44.4 & 0.9 & 21 & 125 & 28 & 21 & 408.4 & 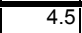 & $\overline{11}$ & 158 & $\overline{34}$ & 13 & 76.2 & 0.5 & $\overline{6 \mid}$ & 326 & $\overline{50}$ & \\
\hline 1986 & .1 & 8.7 & 67 & 291 & 73 & 29 & 51.4 & 1.1 & 22 & 112 & 27 & 17 & 422.1 & 4.9 & 12 & 173 & 35 & 20 & 77.0 & 0.6 & 7 & 274 & 39 & \\
\hline 198 & & 9.2 & 73 & 297 & 75 & 28 & 55.5 & 2 & 22 & 119 & 37 & 28 & & 5.3 & & & 39 & & 60 & P & 8 & 72 & 48 & \\
\hline 1988 & & 9.2 & 73 & 294 & 74 & 27 & 63.7 & 1.4 & 22 & 116 & 32 & 19 & 447.8 & 5.8 & 13 & 171 & 35 & 20 & 80.1 & 0.6 & 7 & 293 & 67 & \\
\hline 1989 & 13 & 7 & 72 & 281 & 75 & 33 & 71.9 & 1.7 & 23 & 114 & 42 & 32 & 475.9 & 6.2 & 13 & 164 & 33 & 21 & 85.9 & 0.7 & 8 & 306 & 65 & \\
\hline 1990 & & 9.5 & 73 & 273 & 74 & 34 & 69.4 & 9 & 28 & 144 & 42 & 30 & 470.2 & 6.4 & 14 & 148 & 35 & 18 & 89.9 & & 8 & 320 & 70 & \\
\hline 1991 & & 9.3 & 73 & 285 & 85 & 32 & 67.1 & 2.4 & 36 & 146 & 38 & 25 & 465.0 & 6.6 & 14 & 141 & 29 & 14 & 89.7 & & 8 & 30 & 50 & \\
\hline 1992 & & 7 & 77 & 277 & 83 & 29 & 65.6 & 2.7 & 41 & 138 & 37 & 18 & 445.5 & 6.6 & 15 & 144 & 41 & 15 & 89.8 & 0.7 & 8 & 266 & 58 & \\
\hline 1993 & & 9.6 & 79 & 281 & 86 & 29 & 63.0 & 2.6 & 41 & 132 & 44 & 20 & 441.6 & 6.5 & 15 & 139 & 41 & 14 & 95.2 & 0.7 & 7 & 05 & 74 & \\
\hline 195 & & 9. & 79 & 302 & 97 & 30 & & & 45 & 135 & 36 & 10 & & . & 15 & & 31 & & 96. & & 7 & & 84 & \\
\hline 1995 & 11 & 4 & 83 & 313 & 106 & 37 & 57.8 & 3.1 & 53 & 162 & 42 & 17 & 449.1 & 7.9 & 18 & 174 & 36 & 11 & 94.7 & 7 & 7 & 00 & 91 & \\
\hline 1996 & & 9.4 & 87 & 318 & 110 & 40 & & 2.8 & 57 & 182 & 36 & 10 & 42 & 8.2 & 19 & 17 & 35 & 10 & 92.3 & & 7 & 34 & 118 & \\
\hline 1997 & 102.2 & 9.0 & 88 & 327 & 106 & 40 & 45.0 & 2.8 & 62 & 169 & 34 & 13 & & 7.9 & 20 & $1 \varepsilon$ & 37 & 11 & 88.3 & 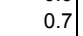 & 8 & 46 & 98 & \\
\hline 1998 & 94.9 & 1 & 95 & 338 & 109 & 45 & 39.2 & 2.9 & 74 & 181 & 38 & 11 & 361.4 & 7.8 & 21 & 17 & 31 & & 83.1 & 0.7 & 9 & 54 & 112 & \\
\hline 1999 & & & 98 & 331 & 96 & 38 & & & 76 & 153 & 34 & 10 & & 7.4 & 23 & & 1 & & & & 9 & 1 & 97 & \\
\hline 200 & 81.4 & 7.9 & $\begin{array}{l}97 \\
\end{array}$ & 342 & 100 & 39 & 36.0 & 2.5 & 70 & 144 & 25 & & 319.0 & 7.1 & 22 & 181 & 32 & & 79.4 & .7 & 8 & 332 & 106 & \\
\hline 2001 & 80 & 8.1 & 100 & 315 & 96 & & 38.5 & 2.7 & 71 & 164 & 32 & & 3 & 7.3 & 24 & 19 & 32 & & 76.8 & 7 & 10 & 41 & 91 & \\
\hline 2002 & & 8.5 & 103 & 316 & 90 & & 40 & 3.3 & 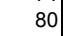 & 3 & 26 & & & 8.0 & 26 & 17 & 25 & & & & 2 & 5 & 102 & \\
\hline 2003 & & 9 & 104 & 299 & 98 & & 43.8 & 3.8 & 87 & 125 & 21 & & 314.8 & 8.4 & 27 & 155 & 22 & & 78.8 & 0.8 & 11 & 18 & 104 & \\
\hline 2004 & 0 & 9.3 & 111 & 286 & 90 & & 43.8 & 4.3 & 99 & 104 & 13 & & 308.2 & 9.0 & 29 & 159 & 17 & & 73.9 & 1.0 & 13 & 281 & 88 & \\
\hline 2005 & 84.6 & 9.3 & 110 & 314 & 112 & & 45.6 & 4.6 & 102 & 108 & 20 & & 294.2 & 9.1 & 31 & 169 & 28 & & 74.8 & 1.0 & 13 & 298 & 60 & \\
\hline centage & & & & & & & & & & & & & & & & & & & & & & & & \\
\hline $\begin{array}{l}\text { ange } \\
35-2000\end{array}$ & $-39 \%$ & $-1 \%$ & $64 \%$ & $33 \%$ & $86 \%$ & $76 \%$ & $-19 \%$ & $168 \%$ & $231 \%$ & $15 \%$ & $-8 \%$ & $-56 \%$ & $-22 \%$ & $59 \%$ & $103 \%$ & $14 \%$ & $-7 \%$ & $\%$ & $4 \%$ & $39 \%$ & $33 \%$ & $2 \%$ & $113 \%$ & \\
\hline
\end{tabular}

See notes to table $7 \mathrm{a}$ 
Table 7c: Sentencing and Time Served Outcomes (Drug-Related And Other Crime)

Admission Types: Court Commitments and Probation Revocations

Races:

All

States:

CA, CO, MI, NJ, SC, WA, WI

Prior Jail Time:

Excluded

\begin{tabular}{|c|c|c|c|c|c|c|c|c|c|c|c|c|c|c|c|c|c|c|c|c|c|c|c|c|c|c|c|c|c|c|}
\hline \multirow[b]{3}{*}{ Year } & \multicolumn{6}{|c|}{ Drug Trafficking } & \multicolumn{6}{|c|}{ Druq Possession/Use } & \multicolumn{6}{|c|}{ Other Sex Crime } & \multicolumn{6}{|c|}{ White Collar Crime } & \multicolumn{6}{|c|}{ Other Crime } \\
\hline & \multirow[b]{2}{*}{$\begin{array}{c}\text { Arrests } \\
\text { in } 1000 \mathrm{~s}\end{array}$} & \multirow[b]{2}{*}{$\begin{array}{c}\text { Prs. } \\
\text { adm. in } \\
1000 \mathrm{~s}\end{array}$} & \multirow[b]{2}{*}{$\begin{array}{c}\text { Adm. } \\
\text { per } \\
1000 \\
\text { arr. }\end{array}$} & \multicolumn{3}{|c|}{$\begin{array}{l}\text { Prisoners. left per } \\
1000 \mathrm{adm} .\end{array}$} & \multirow[b]{2}{*}{$\begin{array}{l}\text { Arrests } \\
\text { in } 1000 \mathrm{~s}\end{array}$} & \multirow[b]{2}{*}{$\begin{array}{l}\text { Prs. } \\
\text { adm. in } \\
1000 \text { s }\end{array}$} & \multirow[b]{2}{*}{$\begin{array}{c}\text { Adm. } \\
\text { per } \\
1000 \\
\text { arr. }\end{array}$} & \multicolumn{3}{|c|}{$\begin{array}{l}\text { Prisoners. left per } \\
1000 \mathrm{adm} .\end{array}$} & \multirow[b]{2}{*}{$\begin{array}{c}\text { Arrests } \\
\text { in } 1000 \mathrm{~s}\end{array}$} & \multirow[b]{2}{*}{\begin{tabular}{|c} 
Prs. \\
adm. in \\
$1000 \mathrm{~s}$
\end{tabular}} & \multirow[b]{2}{*}{\begin{tabular}{|c|} 
Adm. \\
per \\
1000 \\
arr.
\end{tabular}} & \multicolumn{3}{|c|}{$\begin{array}{l}\text { Prisoners. left per } \\
1000 \mathrm{adm} .\end{array}$} & \multirow[b]{2}{*}{$\begin{array}{c}\text { Arrests } \\
\text { in } 1000 \mathrm{~s}\end{array}$} & & \multicolumn{3}{|c|}{$\begin{array}{l}\text { Prisoners. left per } \\
1000 \mathrm{adm} . \\
\end{array}$} & & & & $\begin{array}{r}\text { Prisor } \\
10\end{array}$ & $\begin{array}{l}\text { ers. Ie } \\
00 \mathrm{adr}\end{array}$ & $\begin{array}{l}\text { ft per } \\
\text { n. }\end{array}$ \\
\hline & & & & 2 & 5 & 10 & & & & 2 & 5 & 10 & & & & 2 & 5 & 10 & & $\begin{array}{c}\text { Prs. } \\
\text { adm. in } \\
1000 \mathrm{~s}\end{array}$ & $\begin{array}{c}\text { Adm. } \\
\text { per } \\
1000 \\
\text { arr. }\end{array}$ & 2 & 5 & 10 & $\begin{array}{c}\text { Arrests } \\
\text { in } 1000 \mathrm{~s}\end{array}$ & $\begin{array}{c}\text { Prs. } \\
\text { adm. in } \\
1000 \text { s }\end{array}$ & \begin{tabular}{|c|} 
Adm. \\
per \\
1000 \\
arr.
\end{tabular} & 2 & 5 & 10 \\
\hline 1985 & 56.2 & 4.2 & 74 & 190 & 47 & 29 & 211.9 & 2.2 & 10 & 108 & 45 & 35 & 34.2 & 2.7 & 78 & 652 & 252 & 105 & 78.6 & 1.9 & 24 & 129 & 17 & & $\mid 1830.8$ & 4.9 & 3 & 155 & 54 & \\
\hline 1986 & 59.1 & 5.8 & 98 & 188 & 41 & 23 & 211.1 & 3.0 & 14 & 91 & 39 & 32 & 34.4 & 2.9 & 84 & 645 & 263 & 132 & 82.9 & 2.2 & 26 & 132 & 18 & & 1866.9 & 5.5 & 3 & 169 & 52 & 31 \\
\hline 1987 & 72.7 & 7.9 & 109 & 209 & 44 & 21 & 234.0 & 4.3 & 18 & 92 & 35 & 24 & 34.2 & 2.9 & 84 & 641 & 261 & 133 & 83.7 & 2.2 & 26 & 149 & 17 & & 1928.0 & 6.1 & 3 & 175 & 53 & 31 \\
\hline 1988 & 90.2 & 10.8 & 120 & 231 & 40 & 20 & 259.1 & 6.1 & 23 & 100 & 30 & 18 & 32.8 & 3.1 & 95 & 662 & 269 & 140 & 87.4 & 2.3 & 26 & 155 & 16 & & 1945.0 & 6.9 & 4 & 176 & 54 & 34 \\
\hline 1989 & 136.2 & 15.4 & 113 & 252 & 44 & 22 & 329.9 & 8.2 & 25 & 96 & 25 & 16 & 33.9 & 3.1 & 92 & 640 & 281 & 139 & 91.3 & 2.6 & 28 & 138 & 16 & & 2072.5 & 9.3 & 4 & 137 & 42 & 25 \\
\hline 1990 & 121.6 & 17.9 & 147 & 240 & 43 & 20 & 254.6 & 8.0 & 31 & 100 & 28 & 16 & 36.2 & 3.5 & 95 & 652 & 307 & 156 & 93.8 & 2.6 & 28 & 136 & 18 & & 2148.4 & 11.3 & 5 & 115 & 38 & 23 \\
\hline 1991 & 106.7 & 17.9 & 168 & 237 & 48 & 20 & 216.7 & 7.0 & 32 & 99 & 32 & 18 & 34.4 & 3.6 & 104 & 684 & 338 & 159 & 98.2 & 2.6 & 27 & 127 & 18 & 6 & 2029.7 & 11.7 & 6 & 127 & 44 & 24 \\
\hline 1992 & 103.5 & 18.5 & 179 & 248 & 52 & 20 & 232.5 & 7.3 & 31 & 106 & 36 & 15 & 34.1 & 3.8 & 112 & 678 & 331 & 156 & 96.6 & 2.9 & 30 & 136 & 24 & & 1913.3 & 12.0 & 6 & 130 & 42 & 22 \\
\hline 1993 & 100.4 & 19.0 & 189 & 261 & 58 & 16 & 250.5 & 7.6 & 31 & 96 & 37 & 15 & 32.7 & 4.1 & 126 & 710 & 345 & 152 & 103.1 & 2.8 & 27 & 132 & 27 & & 1890.0 & 12.9 & 7 & 145 & 47 & 22 \\
\hline 1994 & 104.4 & 18.5 & 177 & 264 & 55 & 14 & 307.4 & 8.0 & 26 & 94 & 27 & 10 & 31.3 & 3.8 & 121 & 721 & 347 & 156 & 107.4 & 2.8 & 26 & 124 & 23 & & 1916.9 & 12.5 & 7 & 160 & 50 & 22 \\
\hline 1995 & 109.7 & 19.7 & 180 & 281 & 66 & 16 & 337.8 & 9.9 & 29 & 119 & 27 & & 28.7 & 3.8 & 131 & 760 & 386 & 176 & 108.2 & 2.6 & 24 & 170 & 33 & & 1949.2 & 11.7 & 6 & 201 & 66 & 27 \\
\hline 1996 & 109.7 & 20.0 & 182 & 274 & 59 & 14 & 337.0 & 10.3 & $31 \mid$ & 124 & 28 & 10 & 29.9 & 3.9 & 129 & 738 & 378 & 176 & 112.6 & 3.2 & 28 & 145 & 29 & & 2104.3 & 11.9 & 6 & 202 & 63 & 24 \\
\hline 1997 & 107.4 & 19.4 & 181 & 291 & 57 & 12 & 3 & 11.9 & 32 & 125 & 26 & & 30.9 & 4.2 & 135 & 735 & 399 & 197 & 107.5 & 6 & 34 & 162 & 29 & & 2107.5 & 11.9 & 6 & 227 & 67 & 30 \\
\hline 1998 & 103.9 & 20.1 & 194 & 311 & 58 & 12 & 353.6 & 12.3 & 35 & 131 & 27 & & 29.5 & 4.3 & 145 & 740 & 391 & 189 & 97.7 & 3.7 & 38 & 151 & 20 & & 2075.7 & 12.2 & 6 & 234 & 64 & 26 \\
\hline 1999 & 86.6 & 18.4 & 213 & 303 & 54 & 10 & 343.3 & 12.0 & 35 & 131 & 26 & 6 & 28.4 & 4.1 & 144 & 727 & 386 & 189 & 3.3 & 3.4 & 37 & 15 & 19 & & 1981.7 & 12.0 & 6 & 228 & 63 & 25 \\
\hline 2000 & 95.2 & 16.8 & 176 & 310 & 54 & 11 & 35 & 11.6 & 33 & 138 & 26 & & 27.7 & 4.5 & 163 & 720 & 386 & 100 & 94.8 & 3.5 & 37 & 15 & 18 & & 1962.4 & 12.3 & 6 & 241 & 63 & $2 t$ \\
\hline 2001 & 92.3 & 16.5 & 178 & 311 & 56 & & 348.0 & 9.8 & 28 & 152 & 26 & & 27.5 & 4.4 & 159 & 702 & 379 & & 93.6 & 3.9 & 42 & 146 & 20 & & 1874.1 & 13.6 & 7 & 242 & 65 & \\
\hline 2002 & 85.4 & 16.8 & 196 & 306 & 64 & & 351.6 & 9.2 & 26 & 157 & 28 & & 28.6 & 4.6 & 162 & 706 & 404 & & 98.7 & 4.5 & 46 & 136 & 18 & & 1887.0 & 15.1 & 8 & 235 & 69 & \\
\hline 2003 & 88.5 & 16.9 & 191 & 282 & 68 & & 381.7 & 10.4 & 27 & 150 & 26 & & 27.4 & 4.6 & 169 & 670 & 387 & & 92.8 & 4.9 & 52 & 13 & 20 & & & 15.6 & . & 230 & 71 & \\
\hline 2004 & 86.9 & 16.6 & 191 & 285 & 55 & & & 11.9 & 31 & 143 & 18 & & & 4.5 & 165 & 674 & 380 & & 9 & 5.0 & 52 & 119 & 15 & & 1910.5 & 16.4 & 9 & 223 & 70 & \\
\hline 2005 & 87.1 & 16.6 & 191 & 268 & 66 & & 419.4 & 12.6 & 30 & 126 & 20 & & 25.9 & 4.7 & 181 & 666 & 416 & & 93.6 & 4.9 & 52 & 117 & 15 & & 1932.1 & 16.9 & 9 & 258 & 85 & \\
\hline of & & & & & & & & & & & & & & & & & & & & & & & & & & & & & & \\
\hline $\begin{array}{l}\text { hange } \\
85-2000\end{array}$ & $69 \%$ & $305 \%$ & $139 \%$ & $63 \%$ & $13 \%$ & $-60 \%$ & $67 \%$ & $428 \%$ & $217 \%$ & $28 \%$ & $2 \%$ & $-83 \%$ & $-19 \%$ & $70 \%$ & $110 \%$ & $11 \%$ & $53 \%$ & $101 \%$ & $21 \%$ & $85 \%$ & $54 \%$ & $17 \%$ & $8 \%$ & $11 \%$ & $7 \%$ & $153 \%$ & $136 \%$ & $55 \%$ & $18 \%$ & $26 \%$ \\
\hline
\end{tabular}

See notes to table $7 a$. 
Table 8

Number of Persons per 1000 Arrests Who Serve Prison Terms of $t$ All Races

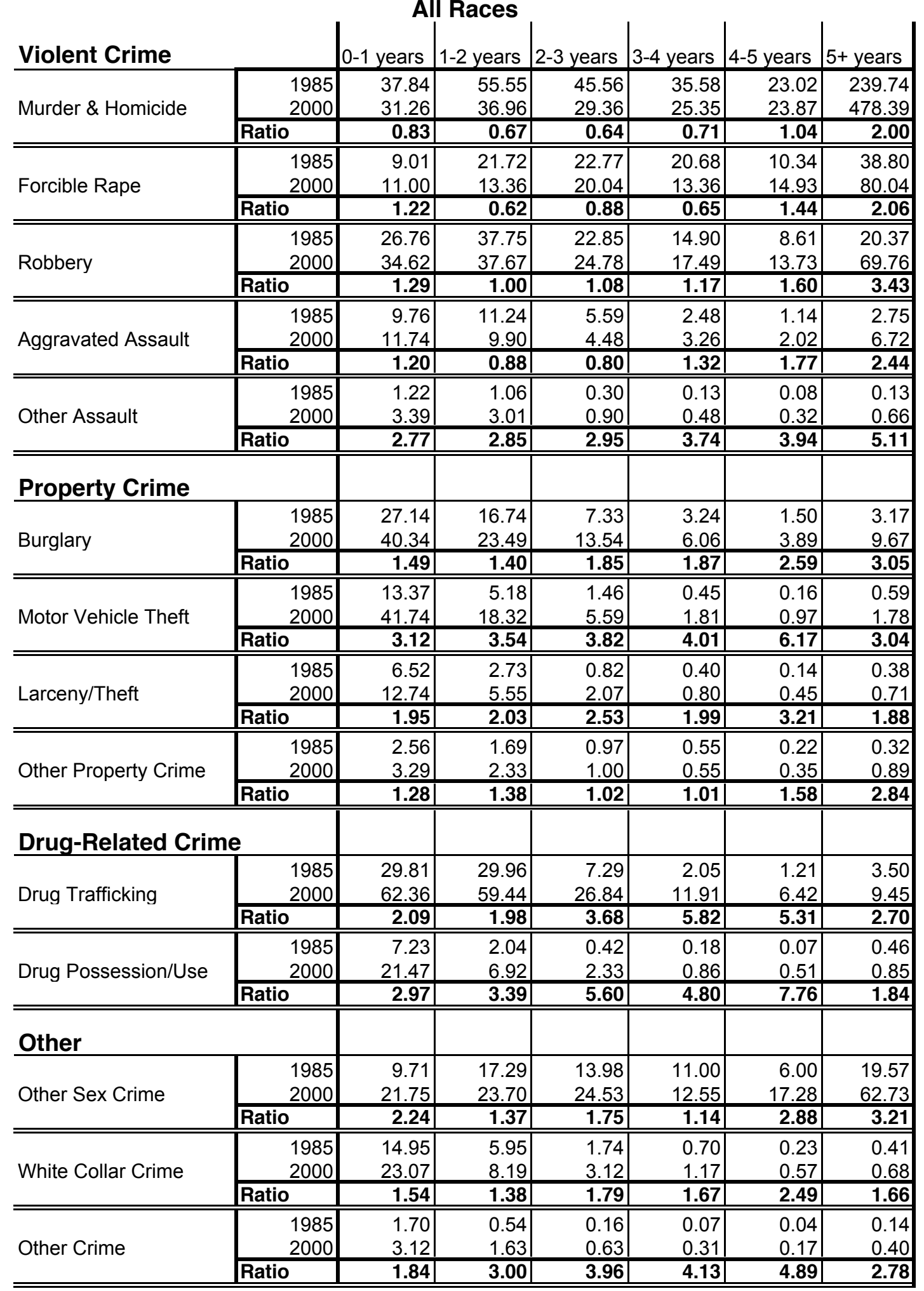

Data Source: National Corrections Reporting Program. Entries are the numbers of arrested offenders per thousand who serve terms of particular lengths (column). 
Table 9a

Adjusted Federal Prison Stocks

\begin{tabular}{|c|c|c|c|c|c|c|c|c|c|c|c|c|}
\hline Year & Murder & Rape & Robbery & Assault & Burglary & Larceny & Motor & Drug & Weapon & Immigration & Other & |Total \\
\hline 1989 & $1552(100)$ & $543(100)$ & $6108(100)$ & $2398(100)$ & $579(100)$ & $1869(100)$ & $507(100)$ & $28488(100)$ & $2802(100)$ & $2210(100)$ & $12118(100)$ & $59171(100)$ \\
\hline 1990 & $1418(91)$ & $506(93)$ & 5931 (97) & 2258 (94) & $508(88)$ & $1597(85)$ & $427(84)$ & 35034 (123) & $3533(126)$ & 1987 (90) & $12327(102)$ & $65526(111)$ \\
\hline \multicolumn{13}{|l|}{$1991^{*}$} \\
\hline 1992 & $1145(74)$ & $219(40)$ & 6755 (111) & 2509 (105) & $391(68)$ & 14 & $378(75)$ & $3(188)$ & 223) & 109) & 2051 (17) & 136) \\
\hline 1993 & $939(61)$ & $168(31)$ & $7108(116)$ & 2562 (107) & $273(47)$ & 1110 (59) & $292(58)$ & 53079 (186) & $7058(252)$ & $2351(106)$ & $14647(121)$ & $89587(151)$ \\
\hline 1994 & $1086(70)$ & $133(25)$ & 9413 (154) & 702 (29) & $204(35)$ & $46(51)$ & $242(48)$ & $56978(200)$ & 7631 (272) & 2801 (127) & $14899(123)$ & 95035 (161) \\
\hline 1995 & $1208(78)$ & $136(25)$ & 9472 (155) & $711(30)$ & 200 & $47(45)$ & $224(44)$ & $3(210)$ & 301) & 3867 & $154 \varepsilon$ & 169) \\
\hline 1996 & $1235(80)$ & $140(26)$ & 155) & (31) & 206 & 44) & $200(40)$ & 221) & 313) & 509 & 159 & 105 \\
\hline 1997 & $1159(75)$ & $129(24)$ & 9664 (158) & $765(32)$ & $207(36)$ & 798 (43) & $242(48)$ & $66920(235)$ & 9228 (329) & (282) & 1763 & 191) \\
\hline 1998 & $1518(98)$ & (27) & 99 & )) & ) & (46) & (46) & 50) & & 80) & 196 & 123 \\
\hline 1999** & $1700(110)$ & 972 (179) & 10615 (174) & $1017(42)$ & 1) & (44) & 40) & $2(272)$ & $10773(385)$ & $11525(522)$ & $19689(162)$ & 135 \\
\hline 2000 & $1264(81)$ & 907 (167) & $10625(174)$ & $959(40)$ & $315(54)$ & $1038(56)$ & $256(51)$ & $82518(290)$ & 11977 (427) & 15377 (696) & 20179 (167) & $145416(246)$ \\
\hline 2001 & $1426(92)$ & $1128(208)$ & 10906 (179) & $1067(45)$ & $296(51)$ & 1099 (59) & $269(53)$ & 88870 (312) & 13985 (499) & $17279(782)$ & $20668(171)$ & $156993(265)$ \\
\hline 2002 & $1430(92)$ & 1135 (209) & 10959 (179) & $1092(46)$ & $263(45)$ & $1028(55)$ & $257(51)$ & 92667 (325) & $15692(560)$ & $17802(806)$ & $21203(175)$ & $163528(276)$ \\
\hline 2003 & $1427(92)$ & $1150(212)$ & $10843(178)$ & $1090(45)$ & $270(47)$ & 1035 (55) & 249 (49) & $97381(342)$ & 18178 (649) & $19187(868)$ & $22251(184)$ & $173059(292)$ \\
\hline 2004 & 1515 (98) & $1267(234)$ & $10431(171)$ & $1051(44)$ & $207(36)$ & $826(44)$ & $189(37)$ & 99968 (351) & 22114 (789) & $20983(950)$ & $21775(180)$ & $180328(305)$ \\
\hline 2005 & $1527(98)$ & 1350 (249) & $10237(168)$ & 1089 (45) & $220(38)$ & 777 (42) & $166(33)$ & 101969 (358) & 24986 (892) & 22641 (1025) & $22656(187)$ & $187618(317)$ \\
\hline 2006 & $1551(100)$ & $1343(248)$ & 9926 (163) & $1128(47)$ & $203(35)$ & 705 (38) & $140(28)$ & 104949 (368) & 27264 (973) & $22228(1006)$ & $23611(195)$ & $193046(326)$ \\
\hline 2007 & 1585 (102) & $1326(244)$ & 9347 (153) & $1082(45)$ & $200(35)$ & $681(36)$ & $121(24)$ & $108552(381)$ & 28999 (1035) & $22586(1022)$ & 25139 (207) & $199618(337)$ \\
\hline 2008 & $1590(102)$ & $1316(243)$ & 9025 (148) & 1118 (47) & $202(35)$ & $673(36)$ & $114(22)$ & $107117(376)$ & 30381 (1084) & 22494 (1018) & $27250(225)$ & $201280(340)$ \\
\hline 2009 & $1558(100)$ & $1282(236)$ & 8684 (142) & 1131 (47) & $184(32)$ & $749(40)$ & $124(24)$ & $109229(383)$ & 31487 (1124) & 24863 (1125) & $28826(238)$ & $208118(352)$ \\
\hline 2010 & $1568(101)$ & $1251(231)$ & 8479 (139) & $1205(50)$ & $167(29)$ & $775(41)$ & $117(23)$ & $109213(383)$ & 32239 (1151) & 24197 (1095) & $30560(252)$ & $209771(355)$ \\
\hline
\end{tabular}

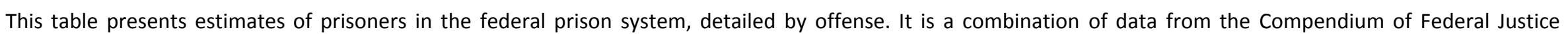

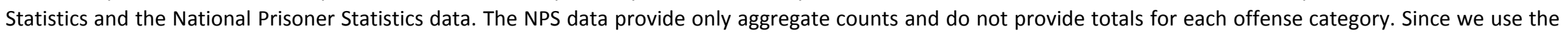

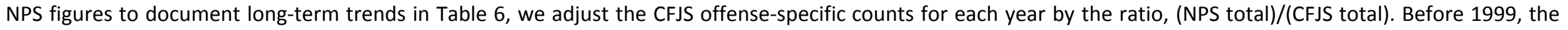

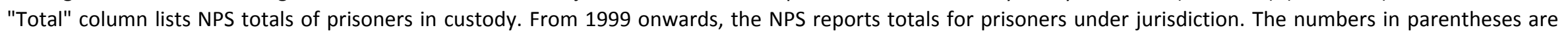

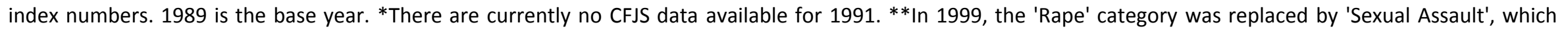
carries a broader definition. 


\section{Table 9b}

\section{Federal Prison Admissions}

\begin{tabular}{|c|c|c|c|c|c|c|c|c|c|c|c|c|}
\hline Year & nurder & Rape & Robbery & Assa & Burlgary & arceny & Motor & Drug & Weapons & Immigration & Other & Total \\
\hline 1989 & $250(100)$ & 90 (100) & $1484(100)$ & $669(100)$ & $191(100)$ & $1750(100)$ & $224(100)$ & $13803(100)$ & $1736(100)$ & $7128(100)$ & $11144(100)$ & $38460(10$ \\
\hline 1990 & $203(81)$ & $4(60)$ & 1788 (120) & $12(106)$ & 214 (112) & 103) & 269 (120) & 16355 (118) & 233 & 10) & 08) & 100 \\
\hline & & & & & & & & & & & & \\
\hline & $4(77)$ & $31(34)$ & 2271 (153) & 848 (127) & 212 & 101) & & 191 & & & 94) & \\
\hline 象 & & & 2618 (176) & & & & & & & & & \\
\hline 1994 & & & 338 & & & & & & & & & \\
\hline כנטג & 08) & & 293 & & & & & & & & & \\
\hline 1996 & $80(72)$ & & 285 & & & & & 19 & & & & \\
\hline 1997 & & & & & & & & 21 & & & & \\
\hline 1998 & 296 & & 335 & & & & & 234 & & & & \\
\hline 1999* & 351 & 426 & 328 & & 382 & & & 265 & & & 6) & \\
\hline 2000 & $254(102)$ & 438 & 299 & & & & & 264 & & & & \\
\hline 001 & 274 (110) & 449 (499) & 2882 (194) & & 21 & & & 273 & & & & \\
\hline 002 & 277 (111) & $488(542)$ & 3061 (206) & 123) & 23 & (81) & 71) & 284 & & & 41) & \\
\hline 03 & 257 (103) & 499 (554) & 302 & 18) & 23 & & & 295 & & & & \\
\hline 004 & & $546(607)$ & (194) & 137) & $216(11$ & & & 288 & & & & \\
\hline 05 & 263 (105) & $579(643)$ & 2885 (194) & 138) & & & & 289 & & & & \\
\hline 006 & 267 (107) & 446 (496) & 2664 (180) & 871 (130) & $165(86)$ & $1067(61)$ & 77 (34) & 294 & & & 142) & \\
\hline 2007 & 247 (99) & 321 (357) & $1888(127)$ & $613(92)$ & $123(64)$ & 739 (42) & $68(30)$ & 27210 (197) & (490) & $18806(264)$ & 120) & 71 \\
\hline 2008 & $202(81)$ & $300(333)$ & $1728(116)$ & $617(92)$ & $113(59)$ & $711(41)$ & $102(46)$ & 25786 (187) & 8495 (489) & $19785(278)$ & $13824(124)$ & $71663(186$ \\
\hline 2009 & 172 (69) & 295 (328) & 1604 (108) & $678(101)$ & $101(53)$ & $764(44)$ & $117(52)$ & $25708(186)$ & 8544 (492) & 22563 (317) & $13790(124)$ & 74336 (193) \\
\hline 2010 & 199 (80) & 268 (298) & 1619 (109) & 660 (99) & $85(45)$ & 744 (43) & $84(38)$ & 24508 (178) & $8336(480)$ & $21520(302)$ & 13949 (125) & 71972 (187 \\
\hline
\end{tabular}

This table contains data on federal prison admissions from the annual Compendia of Federal Justice Statistics. In contrast to Table 9a, we do not adjust these numbers to match the NPS reports because the NPS does not report data on federal admissions and releases after 1998 . The numbers in parentheses are index numbers. 1989 is the base year. *There are currently no CFJS data available for 1991. **In 1999, the 'Rape' category was replaced by 'Sexual Assault', which carries a broader definition. 
Table 9c

Federal Prison Releases

\begin{tabular}{|c|c|c|c|c|c|c|c|c|c|c|c|c|}
\hline ear & Murder & Rape & Robbery & Assault & Burlgary & Larceny & Motor & Drug & Weapons & Immigration & Other & Total \\
\hline 1989 & $150(100)$ & 35 (100) & 1494 (100) & 644 (100) & $171(100)$ & $1826(100)$ & 79 (100) & $9311(100)$ & $1278(100)$ & $6816(100)$ & $10802(100)$ & $32606(100)$ \\
\hline 1990 & 349 (233) & $96(274)$ & 2056 (138) & 878 (136) & 286 (167) & 2069 (113) & 348 (441) & 11194 (120) & 1754 (137) & 8097 (119) & 12064 (112) & 39191 (120) \\
\hline 1991* & & & & & & & & & & & & \\
\hline 1992 & 443 (295) & 83 (237) & $2272(152)$ & 940 (146) & $283(165)$ & 1977 (108) & 295 (373) & 13096 (141) & 2002 (157) & 5589 (82) & 8577 & $36170(111)$ \\
\hline 1993 & 229 (153) & 40 (114) & 2205 (148) & 860 (134) & 208 (122) & 1704 (93) & 282 (357) & 14425 (155) & 2010 (157) & 500 & 13007 (120) & 3997 \\
\hline 1994 & 218 (145) & $30(86)$ & 2731 (183) & $524(81)$ & 197 (115) & $1660(91)$ & 267 (338) & 15370 (165) & 2140 (167) & 505 & 12624 (117) & $40812(125)$ \\
\hline 1995 & 174 (116) & $29(83)$ & 2743 (184) & $547(85)$ & $161(94)$ & $1484(81)$ & $220(278)$ & $15308(164)$ & 2227 (174) & 4889 (72) & 12524 (116) & 40306 (124) \\
\hline 1996 & 211 (141) & $22(63)$ & 2901 (194) & $580(90)$ & $140(82)$ & 1407 (77) & 206 (261) & $16722(180)$ & 2650 (207) & $5092(75)$ & 12822 (119) & 42964 (132) \\
\hline 1997 & 196 (131) & $28(80)$ & 2919 (195) & $630(98)$ & 181 (106) & 1443 (79) & 185 (234) & 17535 (188) & 2526 (198) & 6355 (93) & 13029 (121) & $45027(138)$ \\
\hline 1998 & 212 (141) & 24 (69) & 2954 (198) & $626(97)$ & 204 (119) & $1418(78)$ & 179 (227) & 18575 (199) & $2561(200)$ & 7792 (114) & $14000(130)$ & 48545 (149) \\
\hline $1999 * *$ & 207 (138) & 374 (1069) & 2968 (199) & 728 (113) & $258(151)$ & $1419(78)$ & 195 (247) & $20578(221)$ & 2751 (215) & 8851 (130) & 14143 & $52472(161)$ \\
\hline 2000 & 281 (187) & 421 (1203) & 2982 (200) & 733 (114) & $253(148)$ & $3(75)$ & $171(216)$ & 22058 (237) & 3082 (241) & 149) & 33) & 55876 \\
\hline 2001 & 279 (186) & 428 (1223) & 2934 (196) & 1765 (274) & 259 (151) & 1352 (74) & 167 (211) & $23252(250)$ & 3253 (255) & 172) & 29) & 593 \\
\hline 2002 & 261 (174) & 462 (1320) & 2901 (194) & 795 (123) & 254 (149) & $1481(81)$ & 181 (229) & $24370(262)$ & 3892 (305) & 1099 & 152 & 608 \\
\hline 2003 & 236 (157) & 476 (1360) & 3058 (205) & 808 (125) & 242 (142) & $1389(76)$ & 156 (197) & $25372(272)$ & 4761 (373) & 11946 (175) & $15288(142)$ & 637 \\
\hline 2004 & 250 (167) & 443 (1266) & 3006 (201) & 806 (125) & 205 (120) & $1327(73)$ & 120 (152) & 25697 (276) & 5627 (440) & 13769 (202) & 14985 (139) & 3438 \\
\hline 2005 & 230 (153) & 432 (1234) & 2839 (190) & 798 (124) & 172 (101) & 1219 (67) & 124 (157) & 26209 (281) & 6594 (516) & 16050 (235) & 14891 (138) & $69558(213)$ \\
\hline 2006 & 232 (155) & 466 (1331) & 2702 (181) & 765 (119) & 179 (105) & $1090(60)$ & 98 (124) & 24971 (268) & 7089 (555) & 17526 (257) & 14439 (134) & $69557(213)$ \\
\hline 2007 & 185 (123) & 334 (954) & 2284 (153) & $590(92)$ & $123(72)$ & 783 (43) & 89 (113) & $23628(254)$ & $6900(540)$ & $18842(276)$ & 11868 (110) & $65626(201)$ \\
\hline 2008 & $203(135)$ & 317 (906) & 2003 (134) & 572 (89) & 115 (67) & $728(40)$ & 105 (133) & $26556(285)$ & 7448 (583) & 20564 (302) & 11716 (108) & $70327(216)$ \\
\hline 2009 & 199 (133) & 333 (951) & 1849 (124) & 610 (95) & $114(67)$ & 712 (39) & 111 (141) & $23651(254)$ & 7638 (598) & 21256 (312) & 12294 (114) & $68767(211)$ \\
\hline 2010 & 213 (142) & $296(846)$ & 1805 (121) & $592(92)$ & $97(57)$ & 739 (40) & 113 (143) & 24831 (267) & $8073(632)$ & 22752 (334) & 12605 (117) & 72116 (221) \\
\hline
\end{tabular}

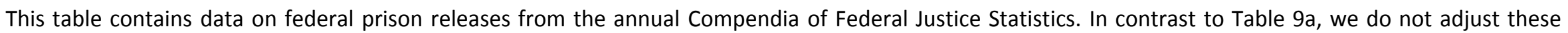

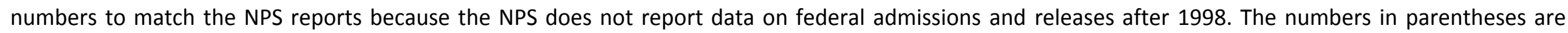

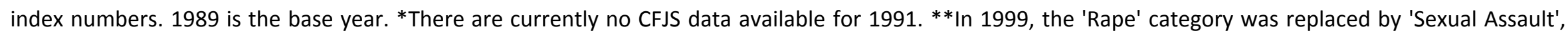
which carries a broader definition. 
Table 10. Ratio of Median Black and Median White Weekly Wages, Males Only

Mixing Over All Nonworkers

\begin{tabular}{|c|c|c|c|c|c|c|c|c|c|c|c|}
\hline \multirow{2}{*}{$\begin{array}{l}\text { Years of } \\
\text { Potential } \\
\text { Experience }\end{array}$} & \multirow[b]{2}{*}{ Year } & \multirow[b]{2}{*}{$10 / 25$} & \multirow[b]{2}{*}{$15 / 15$} & \multirow[b]{2}{*}{$25 / 10$} & \multirow[b]{2}{*}{ Raw } & \multicolumn{2}{|c|}{ Percent Workers } & \multicolumn{2}{|c|}{$\begin{array}{l}\text { Percent Inst. } \\
\text { Nonworkers }\end{array}$} & \multicolumn{2}{|c|}{$\begin{array}{c}\text { Percent Other } \\
\text { Nonworkers }\end{array}$} \\
\hline & & & & & & Black & White & Black & White & Black & White \\
\hline \multirow[t]{5}{*}{$6-10$} & 1960 & 0.567 & 0.567 & 0.588 & 0.606 & $90.1 \%$ & $96.7 \%$ & $3.6 \%$ & $0.9 \%$ & $6.3 \%$ & $2.4 \%$ \\
\hline & 1970 & 0.642 & 0.666 & 0.669 & 0.689 & $89.6 \%$ & $96.4 \%$ & $3.8 \%$ & $0.7 \%$ & $6.6 \%$ & $2.8 \%$ \\
\hline & 1990 & $0.667[0.650]$ & $0.668[0.675]$ & $0.721[0.700]$ & $0.738[0.750]$ & $79.0 \%$ & $94.1 \%$ & $6.7 \%$ & $1.0 \%$ & $14.3 \%$ & $5.0 \%$ \\
\hline & 2000 & $0.700[0.690]$ & $0.714[0.703]$ & $0.760[0.740]$ & $0.828[0.764]$ & $74.2 \%$ & $92.1 \%$ & $10.7 \%$ & $1.7 \%$ & $15.1 \%$ & $6.2 \%$ \\
\hline & 2007 & $0.706[0.673]$ & 0.733 [0.699] & $0.770[0.733]$ & $0.812[0.781]$ & $77.8 \%$ & $92.5 \%$ & $8.1 \%$ & $1.5 \%$ & $14.1 \%$ & $6.0 \%$ \\
\hline \multirow[t]{7}{*}{$11-15$} & 1960 & 0.578 & 0.581 & 0.585 & 0.601 & $91.1 \%$ & $97.2 \%$ & $3.3 \%$ & $0.9 \%$ & $5.6 \%$ & $1.9 \%$ \\
\hline & 1970 & 0.665 & 0.683 & 0.684 & 0.669 & $91.1 \%$ & $97.0 \%$ & $2.9 \%$ & $0.7 \%$ & $6.0 \%$ & $2.2 \%$ \\
\hline & 1980 & $0.644[0.661]$ & 0.666 [0.673] & 0.697 [0.708] & $0.712[0.742]$ & $83.8 \%$ & $95.2 \%$ & $3.7 \%$ & $0.7 \%$ & $12.5 \%$ & $4.1 \%$ \\
\hline & 1990 & $0.615[0.613]$ & $0.630[0.632]$ & $0.680[0.645]$ & $0.713[0.701]$ & $79.7 \%$ & $94.2 \%$ & $6.2 \%$ & $0.9 \%$ & $14.1 \%$ & $4.9 \%$ \\
\hline & 2000 & $0.697[0.657]$ & $0.718[0.705]$ & $0.768[0.750]$ & $0.785[0.787]$ & $76.3 \%$ & $92.4 \%$ & $10.5 \%$ & $1.7 \%$ & $13.2 \%$ & $5.8 \%$ \\
\hline & 2007 & $0.667[0.673]$ & $0.711[0.694]$ & $0.737[0.721]$ & $0.750[0.769]$ & $79.6 \%$ & $93.2 \%$ & $8.3 \%$ & $1.5 \%$ & $12.1 \%$ & $5.3 \%$ \\
\hline & 2010 & $0.591[0.571]$ & $0.652[0.585]$ & 0.694 [0.662] & $0.750[0.695]$ & $71.1 \%$ & $89.2 \%$ & $8.9 \%$ & $1.7 \%$ & $20.0 \%$ & $9.1 \%$ \\
\hline & 1990 & $0.605[0.615]$ & $0.634[0.621]$ & 0.673 [0.655] & 0.709 [0.685] & $80.0 \%$ & $93.8 \%$ & $4.9 \%$ & $0.8 \%$ & $15.1 \%$ & $5.4 \%$ \\
\hline & 2000 & $0.675[0.652]$ & $0.694[0.683]$ & $0.722[0.713]$ & $0.788[0.757]$ & $76.6 \%$ & $91.7 \%$ & $9.1 \%$ & $1.7 \%$ & $14.3 \%$ & $6.6 \%$ \\
\hline & 2007 & $0.690[0.643]$ & $0.726[0.670]$ & $0.774[0.700]$ & $0.791[0.697]$ & $80.8 \%$ & $92.6 \%$ & $7.5 \%$ & $1.3 \%$ & $11.7 \%$ & $6.1 \%$ \\
\hline & 2010 & 0.651 [0.663] & $0.690[0.694]$ & $0.721[0.734]$ & $0.782[0.746]$ & $74.2 \%$ & $89.0 \%$ & $7.1 \%$ & $1.5 \%$ & $18.7 \%$ & $9.5 \%$ \\
\hline \multirow[t]{7}{*}{$21-25$} & 1960 & 0.575 & 0.575 & 0.589 & 0.619 & $90.4 \%$ & $96.3 \%$ & $3.0 \%$ & $1.0 \%$ & $6.6 \%$ & $2.7 \%$ \\
\hline & 1970 & 0.640 & 0.647 & 0.661 & 0.641 & $89.8 \%$ & $96.1 \%$ & $2.5 \%$ & $0.8 \%$ & $7.8 \%$ & $3.1 \%$ \\
\hline & 1980 & 0.653 [0.678] & $0.663[0.686]$ & 0.669 [0.714] & $0.707[0.722]$ & $84.1 \%$ & $93.9 \%$ & $1.8 \%$ & $0.6 \%$ & $14.1 \%$ & $5.5 \%$ \\
\hline & 1990 & $0.637[0.636]$ & $0.661[0.642]$ & $0.686[0.667]$ & $0.750[0.705]$ & $80.1 \%$ & $92.6 \%$ & $3.8 \%$ & $0.8 \%$ & $16.2 \%$ & $6.6 \%$ \\
\hline & 2000 & 0.608 [0.629] & $0.641[0.659]$ & $0.681[0.686]$ & $0.750[0.693]$ & $75.4 \%$ & $90.8 \%$ & $7.5 \%$ & $1.4 \%$ & $17.2 \%$ & $7.8 \%$ \\
\hline & 2007 & $0.646[0.656]$ & 0.689 [0.689] & $0.711[0.726]$ & $0.735[0.728]$ & $79.8 \%$ & $90.9 \%$ & $6.4 \%$ & $1.3 \%$ & $13.9 \%$ & $7.8 \%$ \\
\hline & 2010 & $0.633[0.601]$ & $0.667[0.650]$ & $0.693[0.687]$ & $0.760[0.722]$ & $71.8 \%$ & $87.5 \%$ & $7.0 \%$ & $1.3 \%$ & $21.2 \%$ & $11.2 \%$ \\
\hline
\end{tabular}

Data come from IPUMS. The last six columns provide the percent of respondents whom we classify as workers, institutionalized nonworkers, and other nonworkers. Workers are those who report employment in the previous year. Among nonworkers, the institutionalized are those who reside in institutions at the time of the survey. Columns one through four contain the ratio of black to white median wages. For each column, the heading indicates what percent of black and white nonworkers were assumed to have potential wages above the corresponding median. For example, the 10/25 column calculates the ratio of median potential wages assuming that $10 \%$ of black nonworkers, and $25 \%$ of white nonworkers, have potential wages above the median potential wages for their race*experience*year cells. Column 4 calculates the ratio of median wages ignoring non-workers (equivalent to mixing 50/50). For the bracketed results, we exclude civilian workers from the IPUMS sample who also worked in the past week and were not institutionalized. We then replace these workers with matching respondents from the CPSMORG data, and we use the sampling weights from the two samples to reweight these replacement observations. CPSMORG data are not available for 1960 and 1970. 
Table 11. Ratio of Median Black and Median White Weekly Wages, Males Only

Mixing Over Only Non-Institutionalized Nonworkers

\begin{tabular}{|c|c|c|c|c|c|c|c|c|c|c|c|}
\hline \multirow{2}{*}{$\begin{array}{l}\text { Years of } \\
\text { Potential } \\
\text { Experience } \\
\end{array}$} & \multirow[b]{2}{*}{ Year } & \multirow[b]{2}{*}{$10 / 25$} & \multirow[b]{2}{*}{$15 / 15$} & \multirow[b]{2}{*}{$25 / 10$} & \multirow[b]{2}{*}{ Raw } & \multicolumn{2}{|c|}{ Percent Workers } & \multicolumn{2}{|c|}{$\begin{array}{l}\text { Percent Inst. } \\
\text { Nonworkers }\end{array}$} & \multicolumn{2}{|c|}{$\begin{array}{l}\text { Percent Other } \\
\text { Nonworkers }\end{array}$} \\
\hline & & & & & & Black & White & Black & White & Black & White \\
\hline \multirow[t]{5}{*}{ 6-10 } & 1960 & 0.553 & 0.567 & 0.567 & 0.606 & $90.1 \%$ & $96.7 \%$ & $3.6 \%$ & $0.9 \%$ & $6.3 \%$ & $2.4 \%$ \\
\hline & 1970 & 0.643 & 0.650 & 0.666 & 0.689 & $89.6 \%$ & $96.4 \%$ & $3.8 \%$ & $0.7 \%$ & $6.6 \%$ & $2.8 \%$ \\
\hline & 1990 & $0.644[0.648]$ & $0.673[0.650]$ & $0.677[0.680]$ & $0.738[0.750]$ & $79.0 \%$ & $94.1 \%$ & $6.7 \%$ & $1.0 \%$ & $14.3 \%$ & $5.0 \%$ \\
\hline & 2000 & 0.679 [0.673] & $0.704[0.686]$ & $0.730[0.703]$ & $0.828[0.764]$ & $74.2 \%$ & $92.1 \%$ & $10.7 \%$ & $1.7 \%$ & $15.1 \%$ & $6.2 \%$ \\
\hline & 2007 & $0.696[0.667]$ & $0.722[0.673]$ & $0.733[0.705]$ & $0.812[0.781]$ & $77.8 \%$ & $92.5 \%$ & $8.1 \%$ & $1.5 \%$ & $14.1 \%$ & $6.0 \%$ \\
\hline \multirow[t]{7}{*}{$11-15$} & 1960 & 0.578 & 0.578 & 0.581 & 0.601 & $91.1 \%$ & $97.2 \%$ & $3.3 \%$ & $0.9 \%$ & $5.6 \%$ & $1.9 \%$ \\
\hline & 1970 & 0.666 & 0.672 & 0.684 & 0.669 & $91.1 \%$ & $97.0 \%$ & $2.9 \%$ & $0.7 \%$ & $6.0 \%$ & $2.2 \%$ \\
\hline & 1980 & 0.635 [0.659] & 0.657 [0.675] & 0.688 [0.692] & $0.712[0.742]$ & $83.8 \%$ & $95.2 \%$ & $3.7 \%$ & $0.7 \%$ & $12.5 \%$ & $4.1 \%$ \\
\hline & 1990 & $0.606[0.601]$ & 0.635 [0.619] & $0.650[0.636]$ & $0.713[0.701]$ & $79.7 \%$ & $94.2 \%$ & $6.2 \%$ & $0.9 \%$ & $14.1 \%$ & $4.9 \%$ \\
\hline & 2000 & $0.667[0.662]$ & $0.700[0.667]$ & $0.717[0.700]$ & $0.785[0.787]$ & $76.3 \%$ & $92.4 \%$ & $10.5 \%$ & $1.7 \%$ & $13.2 \%$ & $5.8 \%$ \\
\hline & 2007 & $0.673[0.668]$ & $0.684[0.681]$ & $0.711[0.697]$ & $0.750[0.769]$ & $79.6 \%$ & $93.2 \%$ & $8.3 \%$ & $1.5 \%$ & $12.1 \%$ & $5.3 \%$ \\
\hline & 2010 & $0.591[0.573]$ & $0.617[0.583]$ & $0.667[0.618]$ & $0.750[0.695]$ & $71.1 \%$ & $89.2 \%$ & $8.9 \%$ & $1.7 \%$ & $20.0 \%$ & $9.1 \%$ \\
\hline & 1990 & $0.600[0.615]$ & $0.622[0.615]$ & $0.651[0.631]$ & 0.709 [0.685] & $80.0 \%$ & $93.8 \%$ & $4.9 \%$ & $0.8 \%$ & $15.1 \%$ & $5.4 \%$ \\
\hline & 2000 & $0.658[0.647]$ & $0.692[0.657]$ & $0.694[0.685]$ & $0.788[0.757]$ & $76.6 \%$ & $91.7 \%$ & $9.1 \%$ & $1.7 \%$ & $14.3 \%$ & $6.6 \%$ \\
\hline & 2007 & $0.698[0.642]$ & $0.706[0.648]$ & $0.743[0.676]$ & $0.791[0.697]$ & $80.8 \%$ & $92.6 \%$ & $7.5 \%$ & $1.3 \%$ & $11.7 \%$ & $6.1 \%$ \\
\hline & 2010 & 0.632 [0.648] & $0.667[0.688]$ & $0.731[0.705]$ & $0.782[0.746]$ & $74.2 \%$ & $89.0 \%$ & $7.1 \%$ & $1.5 \%$ & $18.7 \%$ & $9.5 \%$ \\
\hline \multirow[t]{7}{*}{$21-25$} & 1960 & 0.571 & 0.575 & 0.578 & 0.619 & $90.4 \%$ & $96.3 \%$ & $3.0 \%$ & $1.0 \%$ & $6.6 \%$ & $2.7 \%$ \\
\hline & 1970 & 0.640 & 0.647 & 0.661 & 0.641 & $89.8 \%$ & $96.1 \%$ & $2.5 \%$ & $0.8 \%$ & $7.8 \%$ & $3.1 \%$ \\
\hline & 1980 & 0.651 [0.682] & $0.665[0.686]$ & $0.667[0.711]$ & $0.707[0.722]$ & $84.1 \%$ & $93.9 \%$ & $1.8 \%$ & $0.6 \%$ & $14.1 \%$ & $5.5 \%$ \\
\hline & 1990 & $0.641[0.636]$ & $0.645[0.642]$ & $0.677[0.667]$ & $0.750[0.705]$ & $80.1 \%$ & $92.6 \%$ & $3.8 \%$ & $0.8 \%$ & $16.2 \%$ & $6.6 \%$ \\
\hline & 2000 & $0.615[0.620]$ & $0.630[0.643]$ & $0.658[0.660]$ & 0.750 [0.693] & $75.4 \%$ & $90.8 \%$ & $7.5 \%$ & $1.4 \%$ & $17.2 \%$ & $7.8 \%$ \\
\hline & 2007 & $0.652[0.655]$ & $0.667[0.676]$ & $0.693[0.702]$ & $0.735[0.728]$ & $79.8 \%$ & $90.9 \%$ & $6.4 \%$ & $1.3 \%$ & $13.9 \%$ & $7.8 \%$ \\
\hline & 2010 & $0.622[0.590]$ & $0.653[0.626]$ & $0.673[0.670]$ & $0.760[0.722]$ & $71.8 \%$ & $87.5 \%$ & $7.0 \%$ & $1.3 \%$ & $21.2 \%$ & $11.2 \%$ \\
\hline
\end{tabular}

Data come from IPUMS. See note to Table 10 for information about the sample. Columns one through four of this table apply a different mixing rule than Table 10. For each column, we assume that institutionalized nonworkers all have potential wages below the median of their race*experience ${ }^{*}$ year cell, and we only apply the mixing rule specified at the top of the column to other nonworkers. 
Table 12. Ratio of Black and White Weekly Wages, Males Only

Mixing Over Only Non-Institutionalized Nonworkers

Years of

Potential

\begin{tabular}{|c|c|c|c|c|c|c|c|}
\hline \multirow{2}{*}{$\begin{array}{l}\text { Potential } \\
\text { Experience }\end{array}$} & \multirow[b]{2}{*}{ Year } & & \\
\hline & & $0 / 5$ & $0 / 0$ & $5 / 0$ & Raw & $0 / 0$ & Raw \\
\hline \multirow[t]{7}{*}{$6-10$} & 1960 & 0.669 & 0.669 & 0.669 & 0.675 & 0.684 & 0.696 \\
\hline & 1970 & 0.721 & 0.721 & 0.727 & 0.761 & 0.716 & 0.732 \\
\hline & 1980 & $0.715[0.745]$ & 0.715 [0.749] & 0.731 [0.769] & $0.795[0.780]$ & 0.796 [0.796] & $0.820[0.822]$ \\
\hline & 1990 & $0.683[0.645]$ & $0.691[0.657]$ & $0.707[0.684]$ & $0.764[0.733]$ & $0.721[0.700]$ & $0.773[0.726]$ \\
\hline & 2000 & $0.735[0.685]$ & $0.747[0.694]$ & $0.747[0.710]$ & $0.826[0.762]$ & $0.740[0.694]$ & $0.801[0.726]$ \\
\hline & 2007 & $0.722[0.701]$ & $0.722[0.708]$ & $0.729[0.716]$ & $0.800[0.750]$ & $0.722[0.714]$ & $0.800[0.819]$ \\
\hline & 2010 & $0.660[0.624]$ & $0.665[0.624]$ & $0.686[0.640]$ & $0.800[0.731]$ & $0.694[0.666]$ & $0.787[0.709]$ \\
\hline \multirow[t]{7}{*}{$11-15$} & 1960 & 0.645 & 0.645 & 0.645 & 0.669 & 0.654 & 0.657 \\
\hline & 1970 & 0.697 & 0.697 & 0.697 & 0.699 & 0.688 & 0.708 \\
\hline & 1980 & 0.742 [0.739] & $0.746[0.739]$ & $0.754[0.750]$ & 0.778 [0.778] & 0.767 [0.695] & $0.797[0.733]$ \\
\hline & 1990 & $0.680[0.650]$ & $0.687[0.656]$ & $0.687[0.662]$ & $0.742[0.714]$ & $0.720[0.643]$ & $0.751[0.680]$ \\
\hline & 2000 & $0.700[0.687]$ & $0.700[0.695]$ & $0.700[0.709]$ & $0.780[0.768]$ & $0.680[0.667]$ & $0.741[0.730]$ \\
\hline & 2007 & $0.684[0.667]$ & $0.684[0.667]$ & $0.700[0.667]$ & $0.741[0.748]$ & $0.670[0.662]$ & $0.700[0.693]$ \\
\hline & 2010 & $0.650[0.566]$ & $0.650[0.580]$ & $0.667[0.601]$ & 0.759 [0.693] & $0.652[0.617]$ & $0.714[0.673]$ \\
\hline \multirow[t]{7}{*}{$16-20$} & 1960 & 0.669 & 0.673 & 0.673 & 0.693 & 0.647 & 0.646 \\
\hline & 1970 & 0.668 & 0.668 & 0.668 & 0.668 & 0.626 & 0.657 \\
\hline & 1980 & $0.749[0.736]$ & 0.749 [0.739] & $0.760[0.748]$ & 0.784 [0.777] & $0.756[0.748]$ & $0.773[0.770]$ \\
\hline & 1990 & $0.703[0.667]$ & $0.711[0.667]$ & $0.730[0.667]$ & $0.762[0.710]$ & $0.707[0.698]$ & $0.740[0.721]$ \\
\hline & 2000 & $0.690[0.692]$ & $0.690[0.692]$ & $0.691[0.692]$ & $0.724[0.740]$ & $0.661[0.676]$ & $0.704[0.714]$ \\
\hline & 2007 & 0.707 [0.662] & $0.718[0.672]$ & $0.725[0.672]$ & $0.782[0.710]$ & $0.714[0.650]$ & $0.727[0.673]$ \\
\hline & 2010 & $0.671[0.653]$ & $0.671[0.666]$ & $0.687[0.680]$ & $0.743[0.722]$ & $0.698[0.660]$ & $0.745[0.685]$ \\
\hline \multirow[t]{7}{*}{$21-25$} & 1960 & 0.653 & 0.653 & 0.655 & 0.662 & 0.640 & 0.634 \\
\hline & 1970 & 0.668 & 0.668 & 0.668 & 0.669 & 0.604 & 0.620 \\
\hline & 1980 & $0.731[0.708]$ & $0.731[0.708]$ & $0.731[0.717]$ & $0.755[0.727]$ & $0.718[0.702]$ & $0.743[0.703]$ \\
\hline & 1990 & $0.698[0.673]$ & $0.701[0.681]$ & $0.714[0.705]$ & $0.763[0.750]$ & $0.706[0.682]$ & $0.723[0.714]$ \\
\hline & 2000 & $0.672[0.643]$ & $0.683[0.655]$ & $0.701[0.667]$ & $0.750[0.703]$ & $0.682[0.650]$ & $0.711[0.681]$ \\
\hline & 2007 & $0.687[0.643]$ & $0.694[0.648]$ & $0.694[0.657]$ & $0.733[0.694]$ & $0.661[0.663]$ & $0.667[0.703]$ \\
\hline & 2010 & $0.668[0.618]$ & $0.686[0.625]$ & $0.694[0.638]$ & $0.734[0.667]$ & $0.652[0.636]$ & $0.717[0.650]$ \\
\hline
\end{tabular}

Data come from IPUMS. Columns one through three contain the ratio of black potential wages at the 75th percentile to white potential wages at the 75th percentile. For each column, the heading indicates what percent of black and white other nonworkers are assumed to have potential wages above the corresponding 75 th percentile. For example, the $0 / 5$ column calculates the ratio assuming that $0 \%$ of black other nonworkers, and $5 \%$ of white other nonworkers, have potential wages above the 75th percentile of potential wages for their race*experience*year cells. Column four calculates the ratio ignoring nonworkers (equivalent to mixing 25/25). Columns five and six contain analogous results for the 90th percentile of potential wages. For the bracketed results, we exclude civilian workers from the IPUMS sample who also worked in the past week and were not institutionalized. We then replace these workers with matching respondents from the CPSMORG data, and we use the sampling weights from the two samples to re-weight these replacement observations. CPSMORG data are not available for 1960 and 1970. 